\title{
Towards a New Keynesian Theory of the Price Level*
}

\author{
John Barrdear ${ }^{\dagger}$ \\ Bank of England and the Centre for Macroeconomics
}

This version: 20th May 2015

\begin{abstract}
Modifying the standard New-Keynesian model to replace firms' full information and sticky prices with flexible prices and dispersed information, and imposing mild and plausible restrictions on the monetary authority's decision rule, produces the striking results that (i) there exists a unique and globally stable steady-state rate of inflation, despite the possibility of a lower bound on nominal interest rates; and (ii) in the vicinity of steady-state, the price level is determinate (and not just the rate of inflation), despite the central bank targeting inflation. The specification of firms' signal extraction problem under dispersed information removes the need to make use of Blanchard-Kahn conditions to solve the model, thereby removing the need to adhere to the Taylor principle and consequently circumventing the critique of Cochrane (2011). The model admits a determinate, stable solution with no role for sunspot shocks when the monetary authority responds by less than one-for-one to changes in expected inflation, including under an interest rate peg. An extension to include incomplete information on the part of the central bank permits the consideration of (rational) errors of judgement on the part of policymakers and provides a theoretical basis for inertial policymaking without interest rate smoothing, in support of Rudebusch (2002, 2006).
\end{abstract}

JEL classification: D82, D84, E31, E52

Key words: New-Keynesian, indeterminacy, dispersed information, FTPL, Blanchard-Kahn, Taylor rules, Taylor principle

\footnotetext{
${ }^{*}$ The views expressed in this paper are those of the author and not necessarily those of the Bank of England.

${ }^{\dagger}$ Email: john.barrdear@bankofengland.co.uk
} 


\section{Introduction}

This paper reexamines the topics of determinacy and the nominal anchor within New Keynesian models, demonstrating a model with dispersed information in which (i) the steady-state equilibrium is unique (as an arbitrary choice of the monetary authority) and globally stable, despite the potential for a lower bound on the nominal interest rate; and (ii) when out of steady-state the price level, and not just the rate of inflation, is determinate, despite the monetary authority being an inflation targetter. The overall price level of the economy is therefore determined, up to an initial value.

The model features price-setting firms having incomplete and heterogenous information regarding the state of the economy. The consequent need to specify and solve their signal extraction problem allows the model to be solved without the use of Blanchard and Kahn (1980), thereby circumventing the critique of Cochrane (2011) and removing the need for the monetary authority to adhere to the Taylor principle. The economy retains nominal stability despite the coefficient against (next-period) inflation in the monetary authority's decision rule taking values less than one, or even under an interest rate peg. Put another way, beyond the successful establishment and publication of the steady state rate of inflation, central banks do not need to act in order to stabilise the economy.

Of course, the primary competitor framework for thinking about the nominal stability of an economy is the Fiscal Theory of the Price Level (FTPL), developed by Leeper (1991), Sims (1994) and Woodford $(1994,1995)$, in which an 'active' fiscal authority may impose the price level on a 'passive' monetary authority in order to balance the present, discounted value of current and future budgets of the consolidated government. I do not comment on this literature here. Instead, this paper adopts the standard New Keynesian approach of supposing Ricardian equivalence and the use of lump sum taxes, so that fiscal policy remains passive and the provision of a nominal anchor remains entirely the responsibility of the monetary authority.

An extension of the main model to also incorporate incomplete information on the part of the central bank allows two further contributions. First, it represents a theoretical provision of inertial monetary policymaking following any shock to the economy, including transitory shocks, and not just persistent monetary shocks. It thereby adds weight to the argument of Rudebusch (2002, 2006), who contends that the inclusion of interest rate smoothing in estimates of of monetary policy decision rules carries little structural justification and that observed inertia is instead attributable to persistence in factors omitted from reduced-form estimates. Second, it allows the consideration of policymakers' errors of judgement by incorporating the possibility of (perfectly transitory) noise shocks to the central bank's signals.

\subsection{Structure of the paper}

To develop the paper, section 2 will first present a brief summary of the standard approach to solving rational, forward-looking models under Blanchard-Kahn conditions and the critique of their use under New Keynesian (indeed, all monetary) models by Cochrane (2011), which motivates this paper's use of dispersed information. Section 3 then presents the solution to a generalised model of dispersed information that nests the foundational model of Woodford (2003a), and the various works that have subsequently emerged, ${ }^{1}$ without a need to invoke Blanchard-Kahn (replacing it, instead, with a specification of agents' signal extraction problem).

\footnotetext{
${ }^{1}$ See, for example, Nimark (2008), Lorenzoni (2009), Angeletos and La'O (2009, 2010), Graham and Wright (2010), Graham (2011a,b) and Melosi (2014).
} 
Section 4 next presents the main model of the paper: a New Keynesian model in which the representative household and the monetary authority have full information, but firms have incomplete and heterogeneous information sets and the monetary authority is forward-looking. Section 5 then describes an extension to the baseline model by removing full information from the monetary authority (but leaving it with the representative household), while section 6 concludes.

\section{On the use of incomplete information as a solution technique and the need for incomplete information in monetary models}

\subsection{The setting: How do we typically solve rational, forward-looking models?}

Let $\boldsymbol{z}_{t}$ be the aggregate endogenous state of the economy in period $t$ and $\boldsymbol{x}_{t}$ be a vector of mean zero disturbances. Most macroeconomic models, once linearised, are presented in the following form:

$$
\boldsymbol{z}_{t}=A E_{t}\left[\boldsymbol{z}_{t+1}\right]+B \boldsymbol{x}_{t}
$$

where $A$ and $B$ are matricies of parameters and $E_{t}[\cdot] \equiv E\left[\cdot \mid \Omega_{t}\right]$ is the mathematical expectation conditional on all information available in period $t$. Such models are indeterminate (i.e. incomplete), however: we cannot use equation (1) to determine the exact values $\boldsymbol{z}_{t}$ will take for a given sequence of exogenous shocks $\left(\left\{\boldsymbol{x}_{t}\right\}\right)$ because the process by which expectations are formed has not been specified.

It is not sufficient to assume rational expectations in the sense of Muth (1961) - that agents (i) know the functional form and parameters of (1); and (ii) do not make systematic errors - as the model then only becomes

$$
\boldsymbol{z}_{t}=A \boldsymbol{z}_{t+1}+B \boldsymbol{x}_{t}-A \boldsymbol{\delta}_{z, t+1} \text { with } E\left[\boldsymbol{\delta}_{z, t+1}\right]=0
$$

where $\boldsymbol{\delta}_{z, t+1} \equiv \boldsymbol{z}_{t+1}-E_{t}\left[\boldsymbol{z}_{t+1}\right]$ is the one-step-ahead forecast error. Any mean-zero process for $\boldsymbol{\delta}_{z, t+1}$ will represent a rational expectations equilibrium and it remains necessary to select between them. Instead, the most common approach to closing such models is to impose saddle-path stability, a process dating to, and most famously associated with, Blanchard and Kahn (1980). This process involves the imposition of two key assumptions:

B-K assumption 1. A no-bubble constraint in expectation: $\lim _{s \rightarrow \infty} E_{t}\left[A^{s} \boldsymbol{z}_{t+s}\right]=0 \forall t$.

B-K assumption 2. Those eigenvalues of $A^{-1}$ that relate to forward-looking variables lie outside the unit circle, making the system explosive along those dimensions.

Under these final modelling choices, there remains only one solution: that $\boldsymbol{\delta}_{z, t+1}=0 \forall t$, conditional on $\boldsymbol{x}_{t}$. Agents are thus granted (conditionally) perfect foresight and, following a shock, those variables that are free to move will immediately jump to the system saddle path. Backward-looking variables (endogenous states) will adjust slowly and each period the forward-looking variables will "jump" to remain on the (equilibrium) saddle path until the steady-state is achieved. Other work has since developed and improved the methodology for finding the implied solution, and expanded the set of models to which this approach may be applied, ${ }^{2}$ but all of them retain the two defining assumptions of Blanchard and Kahn (1980).

\footnotetext{
${ }^{2}$ See, in particular, Uhlig (1997), King and Watson (1998), Klein (2000) and Sims (2002).
} 
Note that the Blanchard-Kahn approach does not formally lay out the expectation formation process; indeed it expressly declines to do so. Instead, it imposes conditions that any such process must meet, and makes those conditions sufficiently restrictive as to permit only one outcome. How agents actually arrive at that outcome technically remains unspecified (although the question at that point becomes moot).

\subsection{The problem: Blanchard-Kahn conditions do not make sense in monetary models}

The B-K approach has proven to be near ubiquitously popular in macroeconomics, to the extent that their assumptions are commonly taken to be axiomatically true. When macroeconomists write "the rational expectations equilibrium" (REE) they are, almost invariably, referring to the BlanchardKahn-derived rational expectations equilibrium. It therefore bears emphasising that while the B-K conditions will certainly pin down one solution, it is by no means the only solution and - more importantly - there is no guarantee that it represents an economically sensible solution.

The New Keynesian model solved under Blanchard-Kahn conditions, in particular, has been famously criticised by Cochrane $(2009,2011)$ as being implausible. Against B-K assumption 1, he observes that while a transversality condition on real variables is reasonable, assuming one for nominal variables is much less defensible - hyperinflations do happen! Against B-K assumption 2, he further notes that the Taylor principle that emerges (in order to deliver the necessary eigenvalue) amounts to an ex ante commitment to blow up the economy in the event of runaway inflation a commitment to produce even faster inflation - which cannot be credible, as policymakers would retain ex post options to arrest high inflation without ruling out break-out inflation in the first place. ${ }^{3}$

Cochrane's logic is impeccable, but it is worth emphasising that his critique applies more broadly as a criticism of the Blanchard-Kahn solution technique when applied to any monetary model (that is, one in which nominal variables enter $\boldsymbol{z}_{t}$ ). It is not a criticism of monetary models in themselves, ${ }^{4}$ but is instead an objection to the suggestion that a monetary authority following some version of a B-K-derived Taylor principle is sufficient to provide a nominal anchor to the economy.

\subsection{Other equilibrium-selection criteria}

A variety of authors have, both implicitly and explicitly, agreed with Cochrane's critique of the no-bubble condition (B-K assumption 1). For example, Bennett McCallum has noted in a number of papers ${ }^{5}$ that if one purpose of a model is to determine the conditions under which a system will be stable or unstable, then the solution technique for that model cannot logically feature an axiomatic requirement that there be no bubbles. Much of the literature on equilibrium selection has therefore sought to relax this assumption and still obtain the same REE, referring to it as the "fundamental solution." Key work in this field has included the Minimum State Variable approach

\footnotetext{
${ }^{3}$ Note that the eigenvalue condition is satisfied naturally under standard parameter choices for many real models, such as the Neoclassical growth model, that feature no role for a policymaker. The concern here is with models that do feature policymakers when the eigenvalue condition relies on a structural parameter that is a policy choice.

${ }^{4}$ Cochrane (2011) makes this point himself about the New Keynesian model in particular when he writes (p 570): 'This paper is not a criticism of new-Keynesian economics in general. In particular, I do not have anything to say here that criticizes its basic ingredients: an intertemporal, forward-looking "IS" curve or an intertemporally optimizing, forward-looking model of price setting subject to frictions, as captured in the "new-Keynesian Phillips curve."

${ }^{5}$ See, for example, McCallum (1999), pages 8-9.
} 
of McCallum (1983, 1999) and the E-Stability criterion of Evans and Honkapohja (2001). More recently, McCallum (2012a) has proposed a Continunity Refinement, in which he argues that a plausible solution must be continuous in the vicinity of the coefficients against forward-looking variables approaching zero. ${ }^{6}$

The plausibility of these approaches remains contested. ${ }^{7}$ But whatever their merits, all of these approaches continue to maintain B-K assumption 2: that the system be explosive among forwardlooking variables. While this assumption may be valid in some (real) models, for models that feature nominal aggregates, this amounts to an assumption about structural coefficients that are under the control of the monetary authority. In other words, the very possibility of explosive solutions to (2) - which the equilibrium-pruning literature seeks to rule out - is mathematically conditioned on an assumption that the monetary authority knowingly pre-commits to bring about hyperinflation (or hyperdeflation) if agents ever make a non-fundamental forecast error.

On the other hand, if B-K assumption 2 is not maintained (that is, if all eigenvalues of $A^{-1}$ are held to be inside the unit circle), then equation (2) becomes inherently stable, but in a full information setting the problem that Blanchard and Kahn set out to address remains: there are an infinite number of possible solutions, indexed by the set of possible (mean zero) processes that might determine forecast errors.

\section{On the benefits of incomplete information (about the state)}

An alternative approach is to embrace the idea of agents having only incomplete information regarding the state of the economy. By removing the assumption of full information, it becomes necessary to be explicit in specifying agents' signal extraction problems, through which they learn about the state that is hidden to them. ${ }^{8}$ The researcher therefore removes the problem of indeterminacy because the process for agents' expectation errors (including forecast errors) becomes expressly pinned down. There remain no multiple forecast errors for the researcher to "choose" between, so there remains no requirement to appeal to the Blanchard-Kahn conditions. A monetary model with incomplete information (or, more strictly, a fully-specified signal extraction process) is therefore able to be robust to this aspect of Cochrane's critique.

The specification of agents' signal extraction process (that is, the specification of the signals observed and the derivation of their optimal linear filter) also serves to eliminate any role for pure sunspot shocks in the economy. By "sunspot shock", I here mean any shock that is neither "fundamental" (appearing directly in agents' decision rules) nor aggregate "noise" (such as measurement error on the part of national statistical agencies), but nevertheless appears as a separate element in agents' signal vectors. Since sunspot shocks do not covary with other underlying shocks, the optimal linear filter puts zero weight on them when producing agents' first-order expectations. Since agents are rational, they realise that the zero weight is common to everyone and that, consequently, sun-

\footnotetext{
${ }^{6}$ The extension of the Forward Method to multivariate systems with predetermined variables by Cho and Moreno (2011) also bears mentioning as a recent development in the field of equilibrium selection, although they explicitly maintain the no-bubble condition.

${ }^{7}$ For example, Cochrane (2009) suggests that Least Squares Learnability requires that monetary shocks be perfectly observable and that the structural parameters of a New Keynesian Taylor Rule are not empirically identifiable as they do not feature in the implied equilibrium condition. McCallum (2012b) agrees that (at least in simple NK models) the structural Taylor Rule parameters drop out, but argues that (i) it is not the structural system, but the reduced-form one that agents estimate; and (ii) non-observability of the monetary shock does not inhibit learning, citing a result from Evans and Honkapohja (1998).

${ }^{8}$ I use the word "learn" in the signal-extraction/state-space sense, not the sense of Evans and Honkapohja (2001).
} 
spot shocks do not covary with first-order expectations either. As such, the optimal linear filter puts zero weight on them when producing second-order expectations too. The process then continues ad infinitum up the hierarchy.

\section{But what of the Taylor Principle?}

The Taylor Principle - which, loosely speaking, is satisfied when nominal interest rates respond by more than one-for-one to a change in inflation - does not have a clear point of genesis. As a concept, it was implicit in Taylor's (1993) related (but logically distinct) advocacy of a rules-based approach to monetary policy. But an argument that it is necessary in order to achieve nominal stability probably dates only to Taylor (1999). The actual phrase "Taylor principle" appears to date to Woodford (1999), who established its mathematical relationship to Blanchard and Kahn's solution criteria as a way of addressing the indeterminacy first explored by Sargent and Wallace (1975).

The language used to explain (and justify) the Taylor principle is quite simple. By raising the nominal interest rate by more than one-for-one in response to an increase in inflation, the monetary authority ensures that the real interest rate rises. This subdues economic activity among interestsensitive agents, which in turn dampens the rate of price inflation. Cochrane (2011) describes this logic as being "Old Keynesian" and emphasises that it is directly at odds with the mathematics of "New Keynesian" models that, via Blanchard-Kahn, rely on inducing explosive dynamics in order to achieve determinacy.

It is critical to appreciate that in New Keynesian models, the Taylor principle is used as a device to achieve determinacy, not to achieve stability. Under Blanchard-Kahn, it is the no-bubble condition that guarantees stability by ruling out the explosive behaviour introduced by the Taylor principle. When the Taylor principle is expressly violated, New Keynesian models become inherently stable, but with full information they are then indeterminate. A New Keynesian model that violates the Taylor principle and fully specifies the process for signal extraction (and thus, the forecast error) is therefore both stable and determinate.

Indeed, I show below that in a model with dispersed information and flexible prices, satisfying the Taylor principle produces a form of instability that cannot be addressed with a no-bubble constraint. This is because with dispersed information, stability in the current price level requires not only stability in expected future prices, but also stability in the current hierarchy of expectations (a requirement that is sidestepped under full information). As the coefficient against inflation in the monetary authority's decision rule rises towards one, the equilibrium strategic complementarity between firms increases, leading eventually to prices becoming explosive in higher-order beliefs.

Nevertheless, the language of a central bank systematically raising rates to dampen demand can remain intact here. The model developed below allows for specifications such that in the event of a positive "demand shock" (to the household discount factor), the monetary authority raises the nominal interest rate by more than inflation will rise (so that the ex ante real interest rate rises) without satisfying the Taylor principle (figure 1). ${ }^{9}$ The reason is simply that the authority responds systematically to both (expected future) inflation and output, and the demand shock causes both

\footnotetext{
${ }^{9}$ Of course, as shown in Woodford (2003b) and Galí (2008), under Blanchard-Kahn conditions a positive coefficient against output can allow the coefficient against inflation to be less than one and still obtain an eigenvalue greater than one. The model developed here explicitly seeks an eigenvalue less than one.
} 


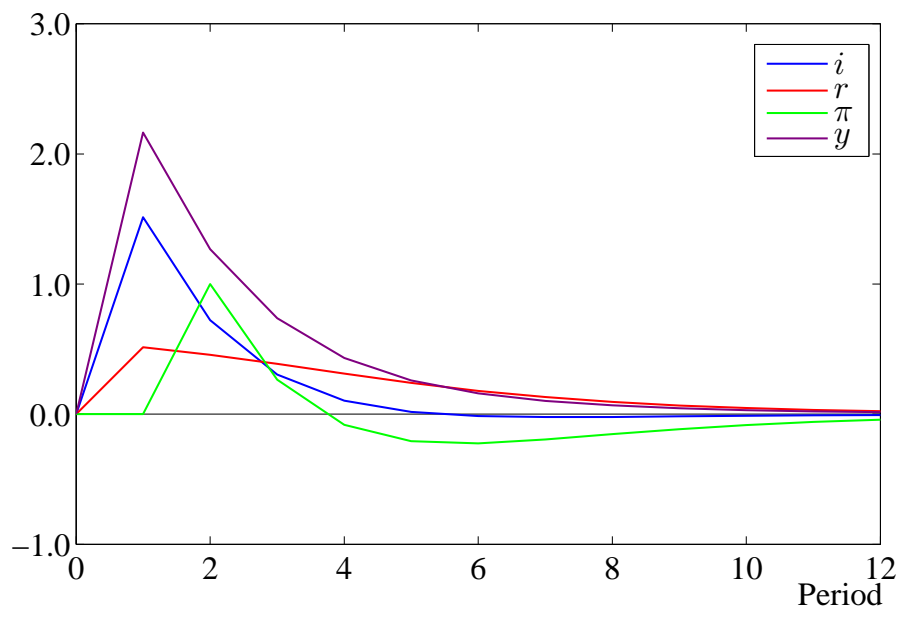

Note: The chart plots the impulse responses of log deviations from steady-state in the nominal interest rate $(i)$, the ex ante real interest rate $(r)$, inflation $(\pi)$ and output $(y)$ following a positive shock to the household discount factor. The Taylor-type rule is $i_{t}=\phi_{\pi} E_{t}\left[\pi_{t+1}\right]+\phi_{y} E_{t}\left[y_{t+1}\right]+x_{t}^{m}$ where $x_{t}^{m}$ is a monetary shock (held to zero) and I set $\phi_{\pi}=0.5$ and $\phi_{y}=0.8$. The largest eigenvalue of the solution is 0.82 . Inflation turns negative because the model features a determinate price level (so a period of above-trend inflation must be followed by a period of below-trend inflation). Other responses are also possible. For example, the real interest rate is negative on impact and positive thereafter if $\phi_{\pi}=\phi_{y}=0.5$ or, indeed, under an interest rate peg $\left(\phi_{\pi}=\phi_{y}=0\right)$.

Figure 1: Impulse responses following a positive demand shock

to rise. With sufficient cumulative weight across the two, the response of the nominal interest rate can exceed the response of inflation.

\section{Dispersed (that is, incomplete and heterogeneous) information}

As a necessary precursor to presenting the main model of this paper, I here present a generalised definition of an economy with incomplete and heterogeneous information and characterise its solution. The material of this section borrows heavily from existing literature on dispersed information, which started with Woodford (2003a). ${ }^{10}$ In particular, Woodford invoked the central insight of Townsend (1983) - that with heterogenous information and strategic interaction, rational agents become interested in an infinite regress of higher-order beliefs - and demonstrated that because of the sluggish response of higher-order expectations, aggregate rigidity broadly equivalent to that produced by Calvo (1983) pricing may be replicated in a model with fully flexible price-setting firms observing independent and unbiased signals of nominal GDP.

Significant work has followed Woodford (2003a), ${ }^{11}$ but the techniques deployed and the results presented here most substantially draw on the subsequent work of Nimark $(2008,2015)$, who extended Woodford's model to include the standard micro-founded household and monetary authority.

Definition 1. Let $\boldsymbol{z}_{t}$ be the vector of endogenous aggregate variables necessary to describe an economy's equilibrium conditions in a given period; ${ }^{12} \boldsymbol{x}_{t}$ be the $(n \times 1)$ vector of aggregate exogenous

\footnotetext{
${ }^{10}$ The field of dispersed information is one of three strands of research that seek to reintroduce the ideas of Lucas (1972) and Phelps (1984) - that information frictions are crucial to explaining the dynamics of aggregate variables following a shock. The other two strands are sticky information, which started with Mankiw and Reis (2002, 2006, 2007), and rational inattention, which dates to Sims (2003).

${ }^{11}$ In addition to Nimark's papers, see, for example, Lorenzoni (2009), Angeletos and La'O (2009, 2010), Graham and Wright (2010), Graham (2011a,b), Melosi (2014) and Kohlhas (2014).

${ }^{12}$ For example, for the standard three-equation New Keynesian model this will just be inflation.
} 
variables; $\boldsymbol{s}_{t}(i)$ be the vector of signals observed in period $t$ by agent $i \in[0,1]$; and $\boldsymbol{u}_{t}$ and $\boldsymbol{v}_{t}(i)$ be aggregate and idiosyncratic vectors of transitory, mean-zero and jointly-orthogonal innovations $\left(\right.$ so that $V \operatorname{Cov}\left(\boldsymbol{u}_{t}\right)=\Sigma_{\boldsymbol{u}}, V \operatorname{Cov}\left(\boldsymbol{v}_{t}(i)\right)=\Sigma_{\boldsymbol{v}} \forall i, \operatorname{Cov}\left(\boldsymbol{u}_{t}, \boldsymbol{v}_{t}(i)\right)=\mathbf{0} \forall i$ and $\operatorname{Cov}\left(\boldsymbol{v}_{t}(i), \boldsymbol{v}_{t}(j)\right)=$ $\mathbf{0} \forall i \neq j)$.

A linear economy with dispersed information is one that (i) evolves as

$$
\begin{aligned}
\boldsymbol{z}_{t} & =\sum_{q=0}^{\infty} A_{q} \bar{E}_{t}\left[\boldsymbol{z}_{t+q}\right]+B_{0} \bar{E}_{t}\left[\boldsymbol{x}_{t}\right]+C_{0} \boldsymbol{x}_{t} \\
\boldsymbol{x}_{t} & =P \boldsymbol{x}_{t-1}+\boldsymbol{u}_{t} \\
\bar{E}_{t}[\cdot] & =\int_{0}^{1} E\left[\cdot \mid \mathcal{I}_{t}(i)\right] d i \\
\mathcal{I}_{t}(i) & =\left\{\mathcal{I}_{t-1}(i), \boldsymbol{s}_{t}(i)\right\} \\
\boldsymbol{s}_{t}(i) & =M_{0} \boldsymbol{z}_{t}+M_{1} \boldsymbol{z}_{t-1}+N \boldsymbol{x}_{t}+\boldsymbol{v}_{t}(i)
\end{aligned}
$$

and (ii) is such that equation (3a) describes a competitive equilibrium, in that it is the result of aggregating agents' individually optimised decision rules.

The inclusion of endogenous aggregate variables beyond period $t+1$ in equation (3a) is done to allow for problem statements that may be non-recursive. Note that either (or both) of $\boldsymbol{x}_{t}$ and $\boldsymbol{v}_{t}(i)$ might include both 'fundamental' shocks (such as productivity shocks) and 'noise' shocks (such as measurement error).

Note, too, that the model nests the basic scenario of (1) by (i) setting $A_{q}=\mathbf{0} \forall q \geq 2$; (ii) taking the variance of $\boldsymbol{v}_{t}(i)$ to zero; and (iii) assuming that the signal equation (3e) is fully invertible. In that case, equation (3a) reduces to (1) with $A=A_{1}^{-1}\left(I-A_{0}\right)$ and $B=-A_{1}^{-1}\left(B_{0}+C_{0}\right)$.

Next, given the inclusion of heterogeneous information, so that the average expectation is distinct from agents' individual expectations, I also make use of the consequent hierarchy of higher-order expectations. The internally recursive definition listed here is used to ease with the solution below.

Definition 2. In a linear economy with dispersed information, the hierarchy of higher-order expectations regarding $\boldsymbol{x}_{t}$ is defined as

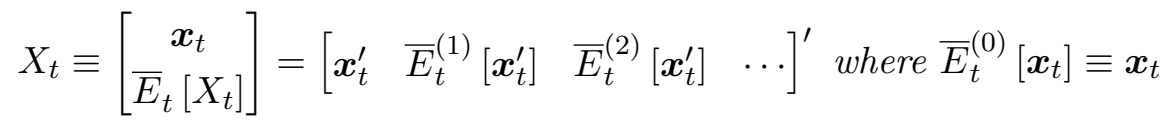

$$
\begin{aligned}
& \bar{E}_{t}^{(k)}\left[\boldsymbol{x}_{t}\right] \equiv \bar{E}_{t}\left[\bar{E}_{t}^{(k-1)}\left[\boldsymbol{x}_{t}\right]\right] \forall k>0
\end{aligned}
$$

Further, the matrices $S$ and $T$ are defined to select $\boldsymbol{x}_{t}$ and $\bar{E}_{t}\left[X_{t}\right]$ from $X_{t}$ respectively (that is, such that $S X_{t}=\boldsymbol{x}_{t}$ and $\left.T X_{t}=\bar{E}_{t}\left[X_{t}\right]\right)$.

Note that the matrix $T$ amounts to a shift operator. Post-multiplying a matrix $A$ with $T$ shifts the elements of $A$ to the right by $n$ places ( $n$ being the number of elements in $\boldsymbol{x}_{t}$ ). Finally, it remains only to define rationality in this context.

Definition 3. A rational economy with heterogeneous information is one in which

(i) all agents know the structure and parameters of the economy and this is common knowledge;

(ii) agents' expectations are unbiased; and 
(iii) agents' expectations are optimal in the sense that they minimise their mean square errors.

This is a more restrictive definition of rationality than normally imposed in macroeconomic models, which only formally impose (i) and (ii), even though (iii) is commonly imagined to hold implicitly. In a linearised setting, the optimal mechanism for signal extraction is a Kalman filter, ${ }^{13}$ in which agent $i$ 's period- $t$ expectation about an unknown vector $\left(X_{t}\right)$ is given by:

$$
E_{t}(i)\left[X_{t}\right]=E_{t-1}(i)\left[X_{t}\right]+K_{t}(i)\left\{\boldsymbol{s}_{t}(i)-E_{t-1}(i)\left[s_{t}(i)\right]\right\}
$$

where $K_{t}(i)$ is a projection matrix (the Kalman gain). When agents' signals are symmetric, as in (3e), the Kalman gain will be common to all agents. Provided that $X_{t}$ is stationary, a time-invariant Kalman gain will emerge so that $K_{t}(i)=K \forall i, t$.

With these definitions in place, I am in a position to state the following result (the proof is provided in Appendix A).

Proposition 1. A rational linear economy with dispersed information solves uniquely as

$$
\begin{aligned}
\boldsymbol{z}_{t} & =\Gamma X_{t} \\
X_{t} & =F X_{t-1}+G \boldsymbol{u}_{t}
\end{aligned}
$$

where the matrices $\Gamma, F$ and $G$ are implicitly given by

$$
\begin{aligned}
\Gamma & =\left(\sum_{q=0}^{\infty} A_{q} \Gamma F^{q}\right) T+B_{0} S T+C_{0} S \\
F & =I_{\infty} \otimes P+T^{\prime} \Omega \\
G & =\left[\begin{array}{c}
I_{n} \\
K \Theta
\end{array}\right]
\end{aligned}
$$

with

$$
\begin{aligned}
\Lambda & =M_{0} \Gamma F+M_{1} \Gamma+N P S \\
\Theta & =\left(M_{0} \Gamma+N S\right) G \\
\Omega & =T^{\prime} \Omega T+K \Lambda(I-T) \\
K & =\left(F V \Lambda^{\prime}+G \Sigma_{\boldsymbol{u}} \Theta^{\prime}\right)\left(\Lambda V \Lambda^{\prime}+\Theta \Sigma_{\boldsymbol{u}} \Theta^{\prime}+\Sigma_{\boldsymbol{v}}\right)^{-1} \\
V & =F V F^{\prime}+G \Sigma_{\boldsymbol{u}} G^{\prime}-K\left(\Lambda V F^{\prime}+\Theta \Sigma_{\boldsymbol{u}} G^{\prime}\right)
\end{aligned}
$$

The matrix $V$ is the time-invariant variance-covariance of agents' contemporaneous expectation error $\left(V_{t \mid t}=V \operatorname{Cov}\left(X_{t}-E_{t}(i)\left[X_{t}\right]\right)\right)$. Note that the identification of $\Gamma$ in equation (6c) represents an application of the method of undetermined coefficients conditional on the rest of the solution.

Critically, in this economy all aggregate variables - and the complete hierarchy of expectations about the state of the economy - have explicit, moving-average representations as weighted sums of past exogenous shocks. Since all expectations (including those of future variables) are based on current and past signals, the overall economy has an entirely backward-looking structure, despite all individual agents being fully optimising, rational and forward-looking.

Although proposition 1 establishes a unique equilibrium, it does not provide for the stability of that equilibrium. Instead, stability requires the following condition.

\footnotetext{
${ }^{13}$ Optimal in the sense of minimising mean square error. In a linear model with Gaussian shocks, the Kalman filter represents the full Bayesian estimator.
} 
Proposition 2. Define $Q \equiv \sum_{q=0}^{\infty} A_{q} \Gamma F^{q}$. The equilibrium identified in proposition 1 will be stable if, and only if, all eigenvalues of the matrix $Q Q^{\prime}$ lie within the unit circle.

\subsection{A simple example}

As a simple example, suppose that $\boldsymbol{x}_{t}$ is univariate with $P=\rho \in(0,1)$, and that agents each observe a single unbiased signal such that $M_{0}=M_{1}=0$ and $N=1$ :

$$
\begin{gathered}
x_{t}=\rho x_{t-1}+u_{t} \text { where } u_{t} \sim N\left(0, \sigma_{u}^{2}\right) \\
s_{t}(i)=x_{t}+v_{t}(i) \text { where } v_{t}(i) \sim N\left(0, \sigma_{v}^{2}\right)
\end{gathered}
$$

Each agent chooses an action, $z_{t}(i)$. Agents face quadratic losses when their choice deviates from either the hidden state or the average choice of others: ${ }^{14}$

$$
u_{i}\left(\boldsymbol{z}_{t}, x_{t}\right)=-(1-\beta)\left(z_{t}(i)-x_{t}\right)^{2}-\beta\left(z_{t}(i)-z_{t}\right)^{2} \quad \beta \in(0,1)
$$

where $z_{t}=\int_{0}^{1} z_{t}(i) d i$. With agents maximising their expected payoff without explicitly knowing either the state or the average action, their optimal choice is given by

$$
z_{t}(i)=\beta E_{t}(i)\left[z_{t}\right]+(1-\beta) E_{t}(i)\left[x_{t}\right]
$$

or, in aggregate,

$$
z_{t}=\beta \bar{E}_{t}\left[z_{t}\right]+(1-\beta) \bar{E}_{t}\left[x_{t}\right]
$$

In this example, equation (7c) corresponds to the competitive equilibrium conditions (3a) in the general case described above.

A similar setting to this one was explored by Woodford (2003a), who supposed $x_{t}$ to be the growth rate of nominal GDP and the agents conducting signal extraction to be price-setting firms. In this case, the matrix $\Gamma$ is easily obtained by substituting (7c) back into itself to obtain

$$
\begin{aligned}
z_{t} & =\Gamma X_{t} \\
\Gamma & =(1-\beta)\left[\begin{array}{lllll}
1 & \beta & \beta^{2} & \beta^{3} & \ldots
\end{array}\right]
\end{aligned}
$$

Further, the $F$ matrix is lower triangular and both $F$ and $G$ matrices are fully specified, conditional on the Kalman gain (note that with only one signal, the Kalman gain will be a vector $\left(\boldsymbol{k}=\left[\begin{array}{lll}k_{1} & k_{2} & k_{3} \cdots\end{array}\right]^{\prime}\right)$.

$$
F=\rho\left[\begin{array}{ccccc}
1 & 0 & 0 & 0 & \cdots \\
k_{1} & \left(1-k_{1}\right) & 0 & 0 & \cdots \\
k_{2} & \left(k_{1}-k_{2}\right) & \left(1-k_{1}\right) & 0 & \cdots \\
k_{3} & \left(k_{2}-k_{3}\right) & \left(k_{1}-k_{2}\right) & \left(1-k_{1}\right) & \\
\vdots & \vdots & \vdots & & \ddots
\end{array}\right] \quad G=\left[\begin{array}{c}
1 \\
k_{1} \\
k_{2} \\
k_{3} \\
\vdots
\end{array}\right]
$$

The eigenvalues of $F$ are then just $\rho$ and $\rho\left(1-k_{1}\right)$, with the latter repeated ad infinitum. So long as $k_{1} \in(0,1)$, which requires only that $\rho, \sigma_{u}^{2}$ and $\sigma_{v}^{2}$ be positive (see below), the hierarchy of beliefs will be stable. Note that the evolution and stability of agents' expectations are independent of the degree of strategic complementarity $(\beta)$ here.

\footnotetext{
${ }^{14}$ An alternative utility function described by Morris and Shin (2002) presents the strategic complementarity as being a zero-sum game, but produces the same optimal decision rule for individual agents.
} 
To appreciate how this comes about, consider equations (6d) and (6h), which here reduce to

$$
\begin{aligned}
F & =I_{\infty} \otimes \rho+T^{\prime} \Omega \\
\Omega & =\{\boldsymbol{k} \Lambda(I-T)\}+T^{\prime}\{\boldsymbol{k} \Lambda(I-T)\} T+\left(T^{\prime}\right)^{2}\{\boldsymbol{k} \Lambda(I-T)\} T^{2}+\cdots \\
\Lambda & =\left[\begin{array}{lllll}
\rho & 0 & 0 & 0 & \cdots
\end{array}\right]
\end{aligned}
$$

Since the matrix $T$ is a shift operator, where post-multiplying a matrix $A$ with $T$ shifts the elements of $A$ to the right by $n$ places ( $n$ being the number of elements in $\boldsymbol{x}_{t} ; n=1$ in this example), then pre-multiplying $A$ by $T^{\prime}$ shifts the elements of $A$ down by $n$ places. I therefore have here that

$$
\begin{aligned}
\{\boldsymbol{k} \Lambda(I-T)\} & =\left[\begin{array}{llllll}
\rho \boldsymbol{k} & -\rho \boldsymbol{k} & \mathbf{0} & \mathbf{0} & \ldots
\end{array}\right] \\
T^{\prime}\{\boldsymbol{k} \Lambda(I-T)\} T & =\left[\begin{array}{ccccccc}
0 & 0 & 0 & 0 & 0 & \ldots \\
\mathbf{0} & \rho \boldsymbol{k} & -\rho \boldsymbol{k} & \mathbf{0} & \mathbf{0} & \ldots
\end{array}\right] \\
\left(T^{\prime}\right)^{2}\{\boldsymbol{k} \Lambda(I-T)\} T^{2} & =\left[\begin{array}{ccccccc}
0 & 0 & 0 & 0 & 0 & 0 & \ldots \\
0 & 0 & 0 & 0 & 0 & 0 & \ldots \\
\mathbf{0} & \mathbf{0} & \rho \boldsymbol{k} & -\rho \boldsymbol{k} & \mathbf{0} & \mathbf{0} & \ldots
\end{array}\right]
\end{aligned}
$$

from which the emergence of $F$ should be clear.

Coupled with this, the time-invariant Kalman gain satisfies

$$
\begin{aligned}
& \boldsymbol{k}=\left(F V\left[\begin{array}{l}
\rho \\
\mathbf{0}
\end{array}\right]+\sigma_{u}^{2}\left[\begin{array}{l}
1 \\
\boldsymbol{k}
\end{array}\right]\right) \times\left(\left[\begin{array}{ll}
\rho & \mathbf{0}^{\prime}
\end{array}\right] V\left[\begin{array}{l}
\rho \\
\mathbf{0}
\end{array}\right]+\sigma_{u}^{2}+\sigma_{v}^{2}\right)^{-1} \\
& V=F V F^{\prime}+\sigma_{u}^{2}\left[\begin{array}{cc}
1 & \boldsymbol{k}^{\prime} \\
\boldsymbol{k} & \boldsymbol{k} \boldsymbol{k}^{\prime}
\end{array}\right]-\boldsymbol{k}\left(F V\left[\begin{array}{l}
\rho \\
\mathbf{0}
\end{array}\right]+\sigma_{u}^{2}\left[\begin{array}{l}
1 \\
\boldsymbol{k}
\end{array}\right]\right)^{\prime}
\end{aligned}
$$

Denoting $v_{11}$ as the upper left element of $V$ and $\boldsymbol{v}_{1}$ as its left-most column, this simplifies to

$$
\begin{aligned}
& \boldsymbol{k}=\left(\rho F \boldsymbol{v}_{1}+\sigma_{u}^{2}\left[\begin{array}{l}
1 \\
\boldsymbol{k}
\end{array}\right]\right) \times \frac{1}{v_{11}+\sigma_{u}^{2}+\sigma_{v}^{2}} \\
& V=F V F^{\prime}-\rho \boldsymbol{k} \boldsymbol{v}_{1}^{\prime} F^{\prime}+\sigma_{u}^{2}\left[\begin{array}{cc}
1-k_{1} & \left(1-k_{1}\right) \boldsymbol{k}^{\prime} \\
(I-T) \boldsymbol{k} & (I-T) \boldsymbol{k} \boldsymbol{k}^{\prime}
\end{array}\right]
\end{aligned}
$$

Reading off the top element in $\boldsymbol{k}$ and the top-left element in $V$ gives two equations in two unknowns

$$
\begin{aligned}
k_{1} & =\frac{\rho v_{11}+\sigma_{u}^{2}}{v_{11}+\sigma_{u}^{2}+\sigma_{v}^{2}} \\
v_{11} & =\rho^{2}\left(1-k_{1}\right) v_{11}+\left(1-k_{1}\right) \sigma_{u}^{2}
\end{aligned}
$$

Note that $k_{1}$ must fall within the range $(0,1)$ for any strictly positive values of $\rho, \sigma_{u}^{2}$ and $\sigma_{v}^{2}$. Solving these and substituting the answers back in, the whole of $\boldsymbol{k}$ and $V$ may be solved recursively. For example, we can read out that

$$
\begin{aligned}
& k_{2}=\frac{\rho\left(k_{1} v_{11}+\left(1-k_{1}\right) v_{21}\right)+\sigma_{u}^{2} k_{1}}{v_{11}+\sigma_{u}^{2}+\sigma_{v}^{2}} \\
& k_{3}=\frac{\rho\left(k_{2} v_{11}+\left(k_{1}-k_{2}\right) v_{21}+\left(1-k_{1}\right) v_{31}\right)+\sigma_{u}^{2} k_{2}}{v_{11}+\sigma_{u}^{2}+\sigma_{v}^{2}}
\end{aligned}
$$




\section{A New Keynesian Theory of the Price Level}

I now move on to describe a variation of the New Keynesian model for which: in steady-state the rate of inflation is uniquely determined as a choice of the monetary authority, while out of steady-state (and conditional on no change in steady-state) not just the rate of inflation but also the deviation of the price level is determinate, despite the monetary authority being an inflation-targeter. As such, the overall price level is determined, up to an initial value.

The model features Ricardian equivalence and lump sum taxes to eliminate any influence of fiscal policy. The key differences between the model presented here and the textbook three equation model of Woodford (2003b) or Galí (2008) are:

1. Instead of granting firms access to full information but preventing them from fully using it by imposing that prices are somehow "sticky," I assume that prices are perfectly flexible but subject firms to incomplete and heterogeneous information.

2. Instead of having the monetary authority respond to current output and inflation, I assume that it responds to expected next-period output and inflation.

3. I impose an upper bound for the responsiveness of the monetary authority to deviations of inflation from target - that is, I disregard the Taylor principle - when in steady-state (although not necessarily when out of steady-state).

The first of these changes seems well justified by (i) microeconomic evidence suggesting that, in the United States, at least, the median duration of prices in CPI data appears to be less than four months (Klenow and Kryvtsov, 2008; Klenow and Malin, 2010) and (ii) the fact that state-based pricing must at least partially offset any monetary non-neutrality derived from time-based pricing.

The second alteration is a fairly standard extension and in any event quite clearly represents a more accurate characterisation of modern central banking practice. For example, the official remit for the Monetary Policy Committee (MPC) of the Bank of England declares that "[t]he inflation target is forward-looking to ensure inflation expectations are firmly anchored in the medium term." (HM Treasury, 2013) Together with flexible prices, this change also delivers the determinacy of the aggregate price level rather than just the inflation rate (see below).

The final change ensures the stability and uniqueness of the steady-state rate of inflation. Although this may strike readers as odd, it bears emphasising the difficulty that empirical studies have in obtaining estimates for central banks' coefficients against inflation that exceed unity. For example, Coibion and Gorodnichenko (2012) document that in the United States, if the econometrician uses Federal Reserve Green Book forecasts to capture central bank expectations and interest rate smoothing is not included in the empirical specification, the Taylor principle was not satisfied during the Greenspan era. ${ }^{15}$ Creel and Hubert (2015) investigate the transition to inflation targeting in Canada, Sweden and the UK, using a structural break test, estimates of time-varying parameters and a Markov-Switching VAR. They find that coefficients against inflation in estimated policy decision rules did not materially change with the transition and, more importantly, remained solidly below one. As will be described below, this requirement is also only a condition of the decision rule when in steady state. Non-linear specifications that give greater weight to inflation when out of steady state remain admissible.

\footnotetext{
${ }^{15}$ Coibion and Gorodnichenko (2012) interpret this fact as speaking in favour of including interest rate smoothing, taking a need for the Taylor principle to be satisfied as axiomatically true.
} 
The unique determination of the price level is achieved in two parts. First, note that in the standard New Keynesian model, references to the previous-period price level appear in two locations: (i) the Phillips curve when individual prices are sticky so that not all firms can update each period; and (ii) the Taylor rule when the central bank responds to current inflation (since $\pi_{t}=p_{t}-p_{t-1}$ ). By assuming both flexible prices and that the monetary authority focuses on future inflation, any reference to the previous-period price level is removed from the equilibrium conditions, leaving only the current and future price levels to consider.

Second, the introduction of incomplete information transforms all expectations about unknown variables - including all future variables - into functions of current and past observables. Together, these changes are sufficient to render the current price level itself into a function of firms' expectations. Since the hierarchy of firms' expectations follows an autoregressive process, the price level therefore has a moving average representation as a function of the path of exogenous shocks and is therefore fully determined without any need to appeal to the Blanchard-Kahn conditions.

The base model presented in this section only features incomplete information on the part of firms. Strictly, this is all that is necessary to avoid the need to invoke Blanchard-Kahn, as the equilibrium condition of the economy may be written exclusively in terms of the (firm-determined) price level. An extension to also impose incomplete information on the monetary authority similarly to Kohlhas (2014) - is presented in section 5 below.

\subsection{Timing}

In contrast to the canonical New Keynesian model, in which all agents have full information and the nominal interest rate, inflation and demand/output are all jointly determined by a Walrasian auctioneer, I instead suppose that each period proceeds in two stages:

1. In stage one ("overnight"), firms observe their signals and adjust their prices accordingly, thereby determining inflation.

2. In stage two ("the working day"), the representative household and monetary authority, both of whom have full information, jointly determine the market-clearing nominal interest rate and average nominal wage. The household reveals the quantity demanded from each firm at the given prices, firms discover their current-period marginal costs and produce the goods. The household consumes the goods entirely.

\subsection{The household}

Each period, a representative household with full information maximises

$$
\begin{aligned}
E_{t}^{\Omega}\left[\sum_{s=0}^{\infty} \beta^{s} e^{x_{t+s}^{c}}\left\{\mathcal{U}\left(C_{t+s}\right)-\mathcal{V}\left(H_{t+s}\right)\right\}\right] \text { where } \mathcal{U}\left(C_{t}\right) & =\frac{C_{t}^{1-\frac{1}{\sigma}}-1}{1-\frac{1}{\sigma}} \\
\text { and } \mathcal{V}\left(H_{t}\right) & =\frac{H_{t}^{1+\frac{1}{\psi}}}{1+\frac{1}{\psi}}
\end{aligned}
$$

subject to a standard budget constraint and where $E_{t}^{\Omega}[\cdot] \equiv E\left[\cdot \mid \Omega_{t}\right]$ is the mathematical expectation conditional on all information available in period $t ; C_{t}$ is aggregate consumption; $H_{t}$ is the aggregate labour supply; $\sigma$ is the elasticity of intertemporal substitution; $\psi$ is the Frisch elasticity 
of labour supply; and $x_{t}^{c}$ is a persistent, mean zero "preference" shock (specified below). Aggregate consumption is given by the Dixit-Stiglitz aggregator over individual consumption goods:

$$
C_{t}=\left(\int\left(e^{-v_{t}^{y}(j)} C_{t}(j)\right)^{\frac{\varepsilon-1}{\varepsilon}} d j\right)^{\frac{\varepsilon}{\varepsilon-1}}
$$

where $\varepsilon$ is the elasticity of substitution and $v_{t}^{y}(j)$ is a transitory, mean zero, idiosyncratic shock to the household's demand for good $j$ (defined below). The household's subsequent first-order conditions are:

$$
\begin{aligned}
& \frac{W_{t}}{P_{t}} \mathcal{U}^{\prime}\left(C_{t}\right)=\mathcal{V}^{\prime}\left(H_{t}\right) \\
& e^{x_{t}^{c}} \mathcal{U}^{\prime}\left(C_{t}\right)=\beta\left(1+i_{t}\right) E_{t}^{\Omega}\left[e^{x_{t+1}^{c}} \mathcal{U}^{\prime}\left(C_{t+1}\right) \frac{1}{\Pi_{t+1}}\right]
\end{aligned}
$$

where $W_{t} / P_{t}$ is the real wage; $i_{t}$ is the net nominal interest rate; and $\Pi_{t} \equiv P_{t} / P_{t-1}$ is the gross rate of inflation. It can also be shown that household demand for good $j$ is given by:

$$
C_{t}(j)=\left(\frac{P_{t}(j)}{P_{t}}\right)^{-\varepsilon} C_{t} e^{v_{t}^{y}(j)}
$$

and the aggregate price level by:

$$
P_{t}=\left(\int P_{t}(j)^{1-\varepsilon} d j\right)^{\frac{1}{1-\varepsilon}}
$$

\subsection{Firms}

\section{Production}

Each good is produced by a single firm according to a common production function that deploys labour with decreasing marginal productivity:

$$
\begin{aligned}
Y_{t}(j) & =A_{t} L_{t}(j)^{1-\alpha} \\
A_{t} & =G^{t}
\end{aligned}
$$

where $L_{t}(j)$ is the hours worked by employees of firm $j$ in period $t$ and $A_{t}$ is total factor productivity, broadly defined, which simply grows determinately. Firm $j$ 's real marginal cost is then:

$$
M C_{t}(j)=(1+\eta) \frac{W_{t}(j)}{P_{t}} \frac{1}{A_{t}^{\eta+1}} Y_{t}(j)^{\eta}
$$

where $\eta \equiv \frac{\alpha}{1-\alpha}$ is the elasticity of marginal cost w.r.t. output and $W_{t}(j)$ is the nominal wage paid by the firm, defined as:

$$
W_{t}(j) \equiv W_{t} e^{v_{t}^{w}(j)}
$$

where $v_{t}^{w}(j)$ is a transitory, mean zero shock to the firm's wage bargaining.

\section{Price setting}

Firms have complete flexibility to reset their prices in every period, subject to their incomplete information. Their optimal price is a simple mark-up over their expected nominal marginal cost:

$$
P_{t}(i)=\left(\frac{\varepsilon}{\varepsilon-1}\right) E_{t}(i)\left[P_{t} M C_{t}(i)\right]
$$




\section{Information}

Firms have only incomplete and heterogeneous access to information about the state of the economy. They each observe a set of signals about the aggregate economy (defined below) and use these to update their beliefs. Note that equation (26) implies that there is strategic complementarity in firms' decision-making, so that each of them will care about not only the real marginal cost they will face but also the decisions of all other firms.

\subsection{Market clearing and aggregation}

All markets clear in every period, so that

$$
\begin{aligned}
Y_{t}(j) & =C_{t}(j) \forall j, t \\
\int_{0}^{1} L_{t}(j) d j & =H_{t} \forall t
\end{aligned}
$$

This implies that aggregate output is given by:

$$
Y_{t}=\Delta_{t} A_{t} H_{t}^{1-\alpha}
$$

where $\Delta_{t}$, represents distortions from relative prices and transitory shocks to relative demand:

$$
\Delta_{t} \equiv\left(\int\left\{e^{v_{t}^{y}(j)}\left(\frac{P_{t}(j)}{P_{t}}\right)^{\varepsilon}\right\}^{-(1+\eta)} d j\right)^{-\frac{1}{1+\eta}}
$$

\subsection{The monetary authority}

The monetary authority targets inflation and, like the household, enjoys full information. It sets the nominal gross interest rate according to a potentially non-linear function of (i) the difference between expected next-period inflation and a publicly-known target; (ii) the difference between expected next-period output and it's steady-state level (see below); and (iii) a persistent, mean zero monetary policy shock $\left(x_{t}^{m}\right)$ :

$$
1+i_{t}=E_{t}^{\Omega}\left[f\left(\frac{\Pi_{t+1}}{\Pi^{*}}, \frac{Y_{t+1}}{Y_{t+1}^{s s}}, x_{t}^{m} ; \Phi\right)\right]
$$

where $\Pi_{t+1} \equiv P_{t+1} / P_{t}$ is next-period gross inflation and $\Pi^{*}$ is the gross inflation target. I leave the function $f(\cdot)$ unspecified except to assume that when in steady-state (that is, when $x_{t}^{m}=0$, $E_{t}^{\Omega}\left[Y_{t+1}\right]=Y_{t+1}=Y_{t+1}^{s s}$ and $\left.E_{t}^{\Omega}\left[\Pi_{t+1}\right]=\Pi_{t+1}=\Pi^{s s}\right)$ :

$$
\begin{aligned}
f_{1}\left(\frac{\Pi^{s s}}{\Pi^{*}}, 1,0 ; \Phi\right) & \geq 0 \\
f_{11}\left(\frac{\Pi^{s s}}{\Pi^{*}}, 1,0 ; \Phi\right) & \geq 0 \\
\frac{1}{\Pi^{*}} f_{1}\left(\frac{\Pi^{s s}}{\Pi^{*}}, 1,0 ; \Phi\right) & <R^{s s}
\end{aligned}
$$

where $R^{s s}$ is the gross real interest rate in steady state. The first two of these simply assume uncontroversially, one assumes - that the nominal interest rate is weakly increasing and weakly convex with respect to inflation when in steady-state. The third imposes an upper bound on the steady-state responsiveness of the nominal interest rate to inflation. Supposing an annual real rate of $4 \%$, in a quarterly model this upper limit will be roughly 1.01 . 
This requirement in (31c) may strike readers as odd given that many calibrated DSGE models suppose that the monetary authority responds by considerably more than one-for-one to changes in inflation (the Taylor principle). However:

- The model does not require the use of Blanchard-Kahn conditions in finding a solution and so does not need to observe the Taylor principle.

- The requirement specified here only needs to apply in steady-state. It remains perfectly permissible for the response to be higher when away from steady state.

For example, suppose that when away from the lower bound, the monetary authority's decision rule has the following second-order approximation: ${ }^{16}$

$$
i_{t}=i^{s s}+\phi_{y} E_{t}^{\Omega}\left[y_{t+1}\right]+\left(\phi_{\pi}+\left(x_{t}^{c}\right)^{2}\right) E_{t}^{\Omega}\left[\pi_{t+1}\right]+x_{t}^{m}
$$

so that the authority responds by more to deviations of inflation from target when faced with a "demand shock". In this case, the partial derivative of the nominal interest rate to expected deviations of inflation from target is:

$$
\frac{\partial i_{t}}{\partial E_{t}^{\Omega}\left[\pi_{t+1}\right]}=\phi_{\pi}+\left(x_{t}^{c}\right)^{2}
$$

Supposing that the variance of shocks to the household discount factor equals one, the monetary authority's marginal response to inflation deviations will then be $\phi_{\pi}+1$ on average, ${ }^{17}$ but will vary around this and will fall to $\phi_{\pi}$ when the shock is zero. Such a framework - in which the monetary authority's responsiveness differentiates between shocks - is another plausible and arguably more realistic deviation from the more common Taylor-type rules. For example, the Bank of England's remit expressly permits such a differential treatment, allowing the MPC to "look through" deviations of inflation from target in certain circumstances (HM Treasury, 2013).

\subsection{Steady state}

I define steady state to be the solution to the model under the assumption that (i) $\boldsymbol{x}_{t+q}=\mathbf{0} \forall q \geq 0$ and (ii) this is known to the household and the monetary authority.

From the perspective of the household and the monetary authority, the economy is therefore deterministic. From the perspective of firms, however, the economy remains stochastic. That is, if $V_{t \mid t}=V \operatorname{Cov}\left(E_{t}(i)\left[X_{t}\right]-X_{t}\right)$ is the (common) variance of firms' expectation errors, then although $V_{t \mid t} \rightarrow V$ under a convergent Kalman filter, $V \neq \mathbf{0}$, even in steady-state.

Conditional on a steady-state solution for inflation, the steady-state values for real variables may readily be found in the usual way, imposing a transversality condition on the real debt of the household. To determine the value of steady-state inflation, consider the household Euler equation:

$$
e^{x_{t}^{c}} \mathcal{U}^{\prime}\left(C_{t}\right)=\beta\left(1+i_{t}\right) E_{t}^{\Omega}\left[e^{x_{t+1}^{c}} \mathcal{U}^{\prime}\left(C_{t+1}\right) \frac{1}{\Pi_{t+1}}\right]
$$

In steady state, with no shocks and the household exhibiting perfect foresight, this becomes

$$
\mathcal{U}^{\prime}\left(C_{t}^{s s}\right)=\beta\left(1+i_{t}^{s s}\right)\left(\mathcal{U}^{\prime}\left(C_{t+1}^{s s}\right) \frac{1}{\Pi_{t+1}^{s s}}\right)
$$

\footnotetext{
${ }^{16}$ Note that equation (32) implicitly assumes that $\Pi^{s s}=\Pi^{*}$ (so that, when expressed in log deviations from steadystate, $\pi^{*}=0$ ). This need not necessarily be the case, but since conditional on the Fisher relation both $\Pi^{s s}$ and $\Pi^{*}$ are chosen by the monetary authority, it seems most plausible to assume that they are equal.

${ }^{17}$ The unconditional average response will of course be different to $\phi_{\pi}+1$ due to covariance terms.
} 
Since the labour supply is constant, consumption will grow with TFP and this further reduces to the famous Fisher relation

$$
1+i_{t}^{s s}=R^{s s} \Pi_{t+1}^{s s}
$$

where the steady-state gross real rate of interest is $R^{s s}=G^{\frac{1}{\sigma}} / \beta$. For the monetary authority, the corresponding steady-state equation is

$$
1+i_{t}^{s s}=f\left(\frac{\Pi_{t+1}^{s s}}{\Pi^{*}}, 1,0 ; \Phi\right)
$$

from which it follows that the steady-state rate of inflation is implicitly defined by

$$
\Pi^{s s}=\left(R^{s s}\right)^{-1} f\left(\frac{\Pi^{s s}}{\Pi^{*}}, 1,0 ; \Phi\right)
$$

where the time subscript has been removed.

Figure 2 plots equation (36) and two illustrative examples of equation (37). The slope of the steady-state household line corresponds to the gross real interest rate and so is faintly steeper than the $45^{\circ}$-line (not shown). Of the two monetary authority lines, option 1 shows what might be thought of as a 'standard' policy rule: satisfying the Taylor principle where possible, while still being subject to a lower bound. Option 2 shows a rule that instead satisfies assumption (31c).

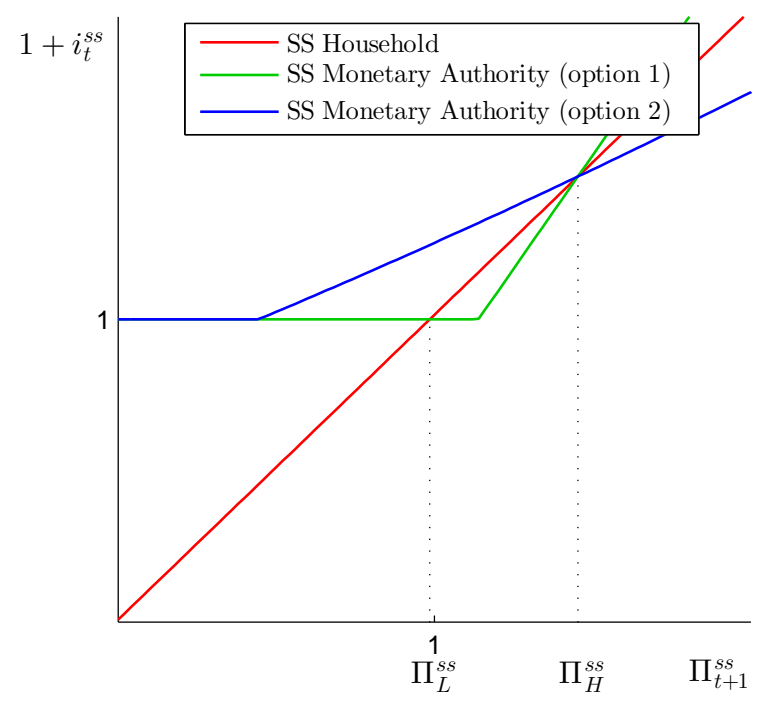

Figure 2: Steady-state inflation in the New Keynesian model.

Under option 1, as illustrated and explored by Benhabib, Schmitt-Grohe, and Uribe (2001), two steady-state equilibria emerge. Of these, $\Pi_{L}^{s s}$ is stable and $\Pi_{H}^{s s}$ is unstable. It is the higher, unstable steady-state that the Blanchard-Kahn conditions are designed to select. By choosing a response to inflation that exceeds the real gross interest rate, the monetary authority produces an unstable, explosive steady state. By further imposing a transversality condition on inflation, deviations from that explosive steady state are expressly ruled out by assumption. Subject to acceptance of the Blanchard-Kahn conditions to solve them, standard New Keynesian models are therefore locally saddle-path stable following 'fundamental' shocks, but maintain an assumption that beliefs about steady state remain perfectly anchored.

Under option 2, however, the slope of the steady-state monetary authority line at the point of intersection is less than $R^{s s}$ (indeed, it is than one). As such, the model features a unique and 
globally stable steady-state equilibrium at a rate of inflation chosen by the monetary authority. The imposition of a lower bound is not a problem under option 2. Indeed, the model features a unique steady state (and a determinate price level around that steady-state) even in the presence of an interest rate peg. The only requirement is that the Taylor principle not be imposed in steady state.

In typical full-information models where expectation-formation remains unspecified, option 2 produces an indeterminacy: although the steady state is stable, the path of inflation back to that steady state following a shock cannot be described, as the path for agents' beliefs is not identified. But by explicitly modelling the signal extraction process of price-setting firms, the model becomes determinate: a well-specified path for expectations delivers a well-specified path for endogenous aggregate variables (like inflation).

Here, with a unique steady-state equilibrium in the rate of inflation, I suppose that (i) the initial aggregate price level $\left(P_{0}\right)$ and (ii) details of the steady-state are common knowledge, so that all agents, including all firms, know that the steady-state price level is given by

$$
P_{t}^{s s}=\left(\Pi^{s s}\right)^{t} P_{0}
$$

As with standard New Keynesian models, this is an assumption of the perfect anchoring of expectations regarding the steady-state rate of inflation.

\subsection{Deviations from steady-state}

I log-linearise the model around steady-state and use lower-case letters to denote log deviations from steady-state (e.g. $y_{t}=\ln \left(Y_{t}\right)-\ln \left(Y_{t}^{s s}\right)$ ). The three summary equations of the model are given by:

$$
\begin{aligned}
y_{t} & =E_{t}^{\Omega}\left[y_{t+1}\right]-\sigma\left(i_{t}-E_{t}^{\Omega}\left[\pi_{t+1}\right]\right)+\sigma\left(x_{t}^{c}-E_{t}^{\Omega}\left[x_{t+1}^{c}\right]\right) \\
i_{t} & =\phi_{y} E_{t}^{\Omega}\left[y_{t+1}\right]+\phi_{\pi} E_{t}^{\Omega}\left[\pi_{t+1}\right]+x_{t}^{m} \\
p_{t}(i) & =E_{t}(i)\left[p_{t}\right]+\kappa E_{t}(i)\left[y_{t}\right]
\end{aligned}
$$

where $\pi_{t}=p_{t}-p_{t-1}$ and $p_{t}=\int p_{t}(i) d i$. The full expression for $\kappa$ is given in the appendix. These represent the same three equations as the standard New Keynesian model, with two key differences: (i) the monetary authority's interest rate rule is forward-looking; and (ii) the Phillips curve has no forward- or backward-looking elements as prices are fully flexible. Recall that $E_{t}^{\Omega}[\cdot]=E\left[\cdot \mid \Omega_{t}\right]$ is the expectation conditional on all period- $t$ information, while $E_{t}(i)[\cdot]=E\left[\cdot \mid \mathcal{I}_{t}(i)\right]$ is the expectation conditional on firm $i$ 's period- $t$ information set, where $\mathcal{I}_{t}(i) \subset \Omega_{t}$.

Substituting equations (40a) and (40b) into equation (40c) and taking the average then produces the (competitive) equilibrium condition of the model:

$$
\begin{aligned}
p_{t} & =(1-\xi) \bar{E}_{t}\left[p_{t}\right]+\xi(1-\delta) \sum_{q=0}^{\infty} \delta^{q} \bar{E}_{t}\left[p_{t+q+1}\right]+\boldsymbol{b}_{p}^{\prime} \bar{E}_{t}\left[\boldsymbol{x}_{t}\right] \\
\delta & =1-\sigma \phi_{y} \\
\xi & =\kappa \sigma\left(1-\phi_{\pi}\right)
\end{aligned}
$$

The full expression for $\boldsymbol{b}_{p}$ is given in the appendix. Equation (41a) shows that the period- $t$ equilibrium aggregate price level is a weighted average of firms' average beliefs about current and future 
values of the same. Correspondingly, anything that raises firms' expectations about the future price level will cause the current price level to increase. Note, in particular, that with fully flexible prices, so that firms' price setting is a sequence of static (that is, period-by-period) optimisation problems, the household discount factor $(\beta)$ does not enter the the determination of the price level. Instead, the discount factor for price determination $(\delta)$ is a function of the monetary authority's responsiveness to (future) output and the household's responsiveness to the interest rate.

The equilibrium condition (41a) corresponds to equation (3a) in the definition of an economy with dispersed information. So long as firms' signals (specified below) are in the form of equation (3e), the solution will therefore be of the form

$$
\begin{aligned}
p_{t} & =\gamma_{p}^{\prime} X_{t} \\
X_{t} & =F X_{t-1}+G \boldsymbol{u}_{t}
\end{aligned}
$$

\subsection{Stability conditions}

In particular, the expression for $\gamma_{p}$ is given by

$$
\begin{aligned}
\gamma_{p}^{\prime} & =\boldsymbol{b}_{p}^{\prime} S T(I-H)^{-1} \\
H & =\left((1-\xi) I+\xi(1-\delta)(I-\delta F)^{-1} F\right) T
\end{aligned}
$$

Defining $\rho\{\star\}$ to be the spectral radius (that is, the largest absolute eigenvalue) of the matrix $\star$, the stability of $(42)$ then requires that

$$
\begin{aligned}
\rho\{F\} & <1 \text { to ensure the stability of } X_{t} \\
\rho\{\delta F\} & <1 \text { to ensure the invertibility of }(I-\delta F) \\
\rho\{H\} & <1 \text { to ensure the invertibility of }(I-H)
\end{aligned}
$$

The latter two of these conditions can be best understood by reconsidering the equilibrium condition of the economy (41a). Condition (44b) relates to stability in expectations of future prices:

$$
(1-\delta) \sum_{q=0}^{\infty} \delta^{q} \bar{E}_{t}\left[p_{t+q+1}\right]=(1-\delta) \gamma_{p}^{\prime} \sum_{q=0}^{\infty} \delta^{q} F^{q} \bar{E}_{t}\left[X_{t}\right]
$$

This object will be finite only if any expected increase in future price $p_{t+q}$ is able to be offset by the discount factor $\delta^{q}$. Plugging in the solution, this amounts to a requirement that $\lim _{q \rightarrow \infty}(\delta F)^{q}=0$, which is true i.f.f. $\rho\{\delta F\}<1$.

Condition (44c) relates to stability in the hierarchy of expectations. This is perhaps best appreciated by considering the setting where $\delta=0$, in which case $H=I-(1-\xi) T$ (so that condition $(44 \mathrm{c})$ becomes $\rho\{(1-\xi) I\}<1)$ and the equilibrium price level would be given by

$$
p_{t}=(1-\xi) \bar{E}_{t}\left[p_{t}\right]+\boldsymbol{b}_{p}^{\prime} \bar{E}_{t}\left[\boldsymbol{x}_{t}\right]=\boldsymbol{b}_{p}^{\prime} \sum_{k=0}^{\infty}(1-\xi)^{k} \bar{E}_{t}^{(k)}\left[\boldsymbol{x}_{t}\right]
$$

where the second equality is obtained by plugging the first back into itself ad infinitum. This object will be finite only if $(1-\xi) \in(-1,1)$.

In the full model, when (44c) is satisfied, firms will place decreasing weight on higher-order expectations. In that case, an arbitrarily accurate approximation of the full solution may be found 
by defining a cut-off, $k^{*}$, and simulating orders of expectation up to that limit. When (44c) is not satisfied, firms will place increasing weight on higher-order expectations and so, for any non-zero shock, the price level will be explosive.

Finally, note that given the solution for $\gamma_{p}$, it is straightforward to obtain a corresponding expression for $\gamma_{y}$ such that $y_{t}=\gamma_{y}^{\prime} X_{t}$ :

$$
\gamma_{y}^{\prime}=\sigma\left(1-\phi_{\pi}\right) \gamma_{p}^{\prime}\left((1-\delta)(I-\delta F)^{-1} F-I\right)+\boldsymbol{\mu}_{y}^{\prime}(I-\delta P)^{-1} S
$$

\subsection{Firms' signals}

To close the model, it remains only to specify what signals are observed by the firms. Unlike models of full information, where the matter is trivial - everybody observes everything - this question is of crucial importance when considering any model of incomplete information.

One distinction to be made is between what information a firm is exposed to in principle, and what information is actually used to inform their decision making. The exogenous imposition of an information processing constraint in the style of Sims (2003), or the imposition of a finite flow cost to be paid for each signal incorporated (analogous to an informational menu cost), for example, might explain why firms with potential exposure to truly enormous torrents of information might instead form their beliefs - and so base their decision making - on the conditionally rational combination of only a small number of signals. In the simulations shown below, I assume that each firm observes:

- A noisy signal regarding the previous period aggregate level of output.

- A noisy signal regarding the previous period aggregate price level.

That is,

$$
\boldsymbol{s}_{t}(i)=\left[\begin{array}{l}
y_{t-1}+x_{t}^{n_{y}}+v_{t}^{n_{y}}(i) \\
p_{t-1}+x_{t}^{n_{p}}+v_{t}^{n_{p}}(i)
\end{array}\right]
$$

where $x_{t}^{n_{y}}$ and $x_{t}^{n_{p}}$ are public noise shocks to firms' signals regarding the level of output and the price level respectively, in order to capture the effect of imperfect measurement by national statistical agencies. The idiosyncratic noise may be interpreted as firms' failure to directly observe the public signal (perhaps instead getting an impression from newspaper coverage), an error of judgement, or as the imperfect applicability of national public signals to the aggregation level most relevant to each firm (e.g. at an industry or sector level). Note that if the variance of idiosyncratic shocks in (46) were to be zero, agents' information sets would be common but still incomplete, as (i) signals would be received with a lag and (ii) they would still include public noise.

When making comparisons to full information models, I will therefore also grant access to signals of the underlying demand shocks themselves:

$$
\boldsymbol{s}_{t}(i)=\left[\begin{array}{c}
y_{t-1}+x_{t}^{n_{y}}+v_{t}^{n_{y}}(i) \\
p_{t-1}+x_{t}^{n_{p}}+v_{t}^{n_{p}}(i) \\
x_{t}^{c}+v_{t}^{c}(i) \\
x_{t}^{m}+v_{t}^{m}(i)
\end{array}\right]
$$

The use of general signals about the previous-period output and price levels may strike some readers as unrealistic. However, the results presented below remain qualitatively robust to adding any of the following further signals to firms' information sets: 
- Their own previous period quantity sold.

- Their own previous period nominal wage paid.

- A noisy signal of the previous period interest rate.

\subsection{Stochastic processes}

The economy therefore features four aggregate shocks: two "fundamental" shocks (a household preference shock and a monetary shock) and two "noise" shocks. Gathered together, I refer to these as the underlying state of the economy and suppose that they follow an AR(1) process:

$$
\begin{aligned}
\boldsymbol{x}_{t} & \equiv\left[\begin{array}{llll}
x_{t}^{c} & x_{t}^{m} & x_{t}^{n_{y}} & x_{t}^{n_{p}}
\end{array}\right]^{\prime} \\
& =P \boldsymbol{x}_{t-1}+Q \boldsymbol{u}_{t}
\end{aligned}
$$

where $\boldsymbol{u}_{t}$ is a vector of period- $t$ innovations identically and independently distributed as $N\left(\mathbf{0}, \sigma_{u}^{2} I\right)$ and $P$ is a matrix of fixed and commonly known parameters.

The set of idiosyncratic shocks for each firm $\left(\boldsymbol{v}_{t}(i)\right)$ is assumed to be entirely transitory, fully independent and jointly distributed as $N\left(\mathbf{0}, \sigma_{v}^{2} I\right)$, with $\operatorname{Cov}\left(\boldsymbol{x}_{t}, \boldsymbol{v}_{t}(i)\right)=\mathbf{0} \forall i, t$.

\subsection{Simulation results}

Table 1 lists benchmark parameters for the simulations presented below. Each aggregate shock (i.e. each element of $\boldsymbol{x}_{t}$ ) is assumed to follow an independent AR(1) process with innovations exhibiting unit variance. Idiosyncratic shocks are also assumed to be fully independent, although with higher variance than for aggregate shocks. Note that with flexible prices, there is no role for the household discount factor in equilibrium, despite the household being forward looking and possessing full information.

\begin{tabular}{|c|c|l|}
\hline Parameter & Value & Description \\
\hline$\sigma$ & 1.0 & Elasticity of intertemporal substitution (log utility) \\
$\varepsilon$ & 4.0 & Elasticity of demand \\
$\psi$ & 1.0 & Frisch elasticity of labour supply \\
$\eta$ & 0.5 & Elasticity of marginal cost \\
$\phi_{\pi}$ & 0.5 & CB coefficient against next-period inflation \\
$\phi_{y}$ & 0.5 & CB coefficient against next-period output \\
$\rho$ & 0.7 & The AR(1) coefficient for each underlying shock \\
$\sigma_{u}^{2}$ & 1.0 & The variance of aggregate innovations \\
$\sigma_{v}^{2}$ & 5.0 & The variance of idiosyncratic shocks \\
\hline
\end{tabular}

Table 1: Benchmark parameterisation

Under the benchmark parameters listed here, $\kappa=1$ (the slope of the Phillips curve), $(1-\xi)=$ 0.5 (contemporaneous coefficient in the equilibrium condition) and $\delta=0.5$ (discount factor in the equilibrium condition). The corresponding spectral radius of $H$ is 0.769 .

All models have been solved with $k^{*}=150$. That is, the first 150 orders of higher-order expectations are included in the estimated solutions. With four variables in the underlying state $\left(\boldsymbol{x}_{t}\right)$, this implies a total of 604 variables in the estimated full state $\left(X_{t}\right)$. Given the benchmark parameter choices (note that $\rho\{H\}^{150} \approx 8 \times 10^{-18}$ ), the results presented here are not appreciably sensitive to increasing the $k^{*}$ threshold. 
The discussion below focusses on the dynamics of the economy following two shocks: a monetary shock (that is, to $x_{t}^{m}$ ) and a common noise shock to firms' signals of the price level (that is, to $x_{t}^{n_{p}}$ ). Charts showing impulse responses following shocks to household preferences $\left(x_{t}^{c}\right)$ and to common noise in firms' signals of the output level $\left(x_{t}^{n_{y}}\right)$ are provided in the appendix.

\section{A monetary shock under the baseline parameterisation}

Figure 3 plots the impulse responses of the level of output and the price level (together with firms' average forecasts of the same); firms' average forecast errors; and hierarchies of firms' average expectations about the four underlying shocks following a monetary shock under the baseline parameterisation (in particular, with $\phi_{\pi}=0.5$ and $\phi_{y}=0.5$ ). Following the shock, firms rationally attribute some of the signals they observe to (common) measurement error and some to idiosyncratic noise. They are also unable to perfectly attribute the remainder between the two fundamental shocks, causing their beliefs about household preferences to deviate from zero. This leads firms to consistently underestimate the size of the shock, so that their forecast errors exhibit a persistent, but ultimately temporary bias.

The response of the aggregate price level is more hump-shaped and more persistent than that of the level of output because of the strategic complementarity in firms' price-setting decisions. Since firms' demand is a function of their relative prices, individual firms do not wish to set their own price too far from what they believe the aggregate price will be. As all firms have the same incentive, the average price level therefore moves more sluggishly. The level of output returns monotonically to its steady-state value following the shock, but note that this persistence is despite the complete flexibility of firms' prices: monetary non-neutrality emerges entirely through firms' information frictions here.

It is interesting to note that firms' average forecast errors exhibit substantial serial correlation - usually a sure sign of non-rationality - despite the firms' fully rational use of the information available to them. This emerges because of firms' incomplete information sets when the researcher (and the reader) are able to observe the firms' behaviour with the benefit of full information. Note, too, that convergence between forecast-error vintages and convergence of forecast errors (to zero) are distinct. Forecast errors regarding the level of output do not change overly much across vintages, instead simply converging back to zero over time as the shock subsides. Forecast errors regarding the price level, however, exhibit substantial step improvements from period to period in addition to converging eventually back to zero.

\section{A monetary shock under an interest rate peg}

As mentioned above, this model is able to accommodate settings in which the monetary authority does not respond to the state of the economy at all. To illustrate this, figure 4 replicates figure 3 , but under an interest rate peg (that is, when $\phi_{\pi}=0$ and $\phi_{y}=0$ ). Without any monetary authority response, the depth of the contraction is considerably larger (a little over twice as deep). Firms' beliefs about the true (monetary) shock are more accurate, although their beliefs about the household preference shock deviate further from zero. Both sets of beliefs exhibit a much less humpshaped response. Firms' average forecasts are both more accurate and exhibit a faster decaying bias. Consequently, despite the greater depth of the recession, the duration of the downturn is reduced. 


\section{Various monetary regimes}

Figure 5 next illustrates the trade-off between monetary regimes mentioned above more explicitly, plotting impulse responses for the (true) levels of output and prices under various monetary policy regimes. For higher values of $\phi_{\pi}$ or $\phi_{y}$, the level of output falls less on impact, but remains below trend for longer thereafter. This trade-off emerges because, by responding to the state of the economy, the monetary authority 'muddies the waters' of firms' signals, making the informational environment less favourable. When the shock occurs in period 1, so that firms first learn about it and respond in period 2 , then from period 3 onwards although firms receive a string of signals suggesting that the economy is improving, they can never be absolutely certain whether this improvement is because of the policy intervention or because of a sequence of lucky, offsetting shocks.

The effect of different regimes on the price level following a monetary shock is quite striking. Greater stability - that is, smaller deviations from trend - is achieved with higher values of $\phi_{y}$ (as might be expected) and with lower values of $\phi_{\pi}$. This latter result comes, mathematically, from the expression for $\xi$. As $\phi_{\pi}$ approaches unity from below, $\xi$ falls to zero, the eigenvalues of $H$ (in equation (43a)) approach unity and, consequently, the expression for $p_{t}$ becomes ever larger. For values of $\phi_{\pi}$ equal to or greater than one, the system becomes explosive.

\section{A monetary shock under common and full information}

As this model is one of incomplete and heterogeneous information, it is natural to ask how the model varies as firms have access to common information sets or even full information. Figure 6 illustrates these scenarios. When firms observe the benchmark signals (of lagged aggregate output and price levels), lowering the variance of idiosyncratic shocks towards zero moves firms towards sharing common information sets that nevertheless remain incomplete (as the signals are observed with a lag and still retain common noise shocks). Even in extremis, with $\sigma_{v}^{2}=0$, monetary policy shocks retain both an on-impact effect on output and some degree of persistence on the same.

When firms also have access to signals of the current-period underlying state, lowering the variance of idiosyncratic shocks towards zero moves firms towards full (and, hence, common) information. Since prices are flexible, in the limit as firms become able to observe all fundamental shocks as they occur, the level of output becomes perfectly unresponsive to monetary shocks and prices bear the full brunt of the shock.

\section{A shock to price expectations}

Figure 7 presents impulse responses following a common noise shock to firms' signals about the aggregate price level. Since it is a noise shock (which only affects the economy through agents' beliefs), rather than a fundamental shock (which enters agents' decision rules directly), this may be thought of as a short-hand way of capturing the effect of a shock to firms' expectations.

Under the interpretation of being an expectation shock, figure 7 shows that it largely represents a self-fulfilling prophecy. Unlike with a fundamental shock, the path of the actual price level closely matches that of firms' average expectation for the same. Although firms initially believe that output will rise (because they attribute some of the movement in their signals to the fundamental household preference and monetary shocks), output actually falls because the price rise was fundamentally unjustified. 
The price level and firms' average forecasts

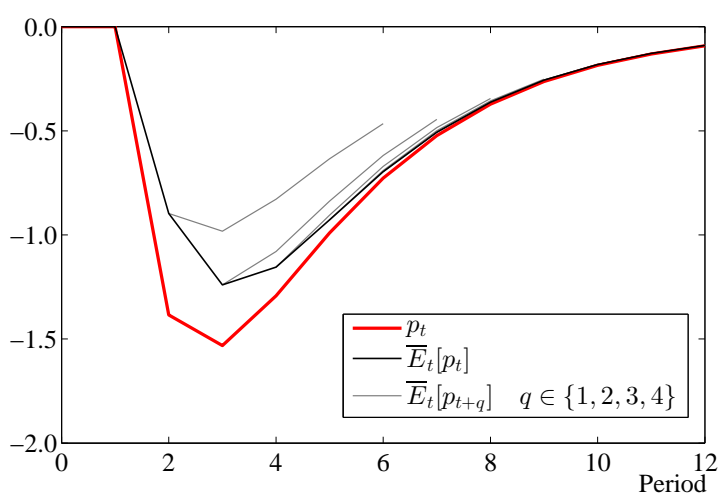

Average forecast errors about the price level

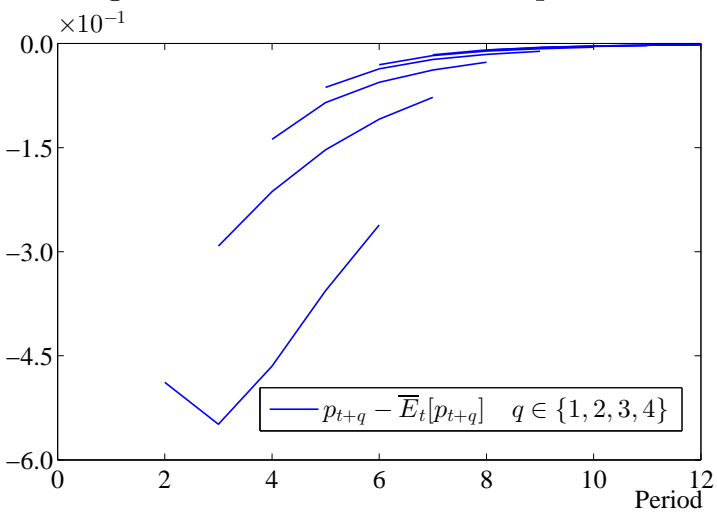

Hierarchy of firms' expectations about $x_{t}^{c}$

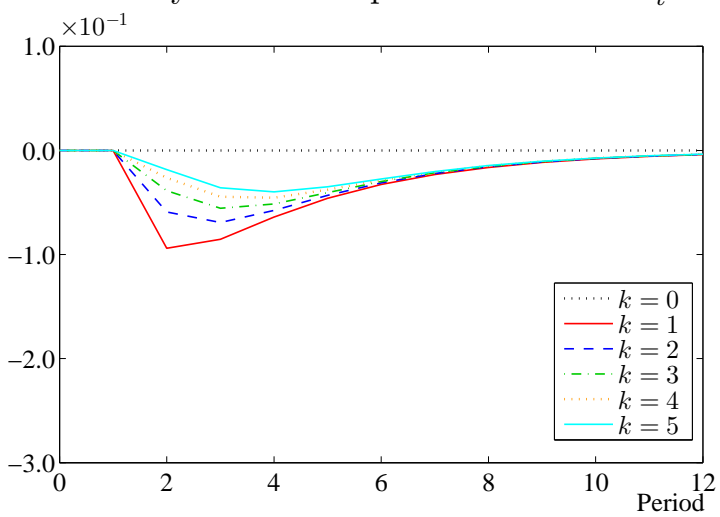

Hierarchy of firms' expectations about $x_{t}^{n_{y}}$

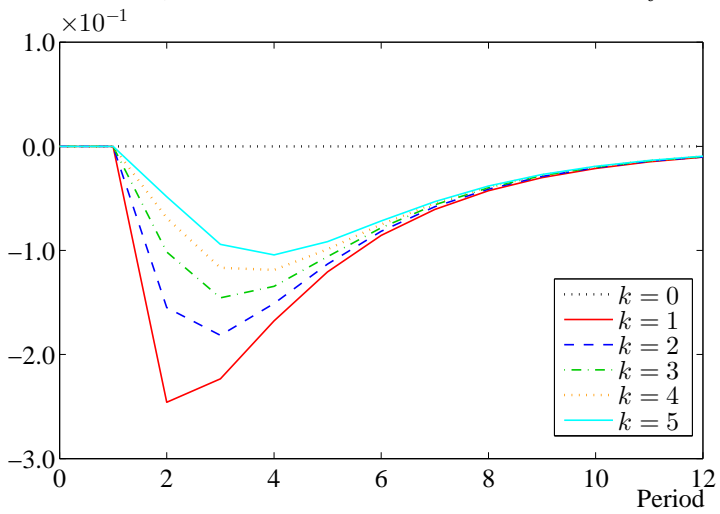

The output level and firms' average forecasts

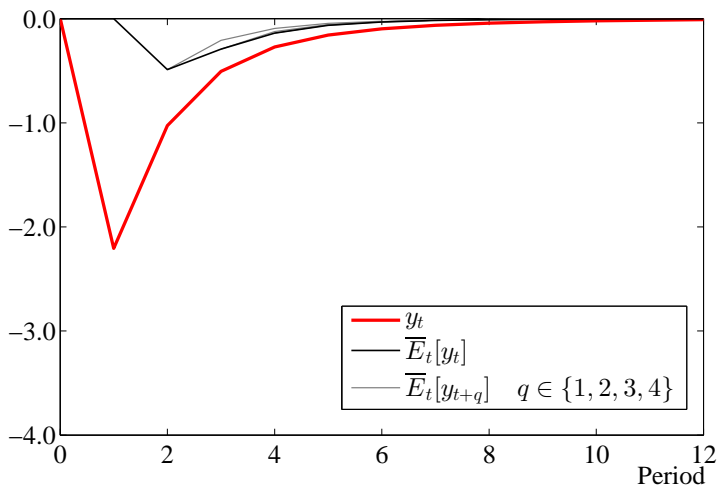

Average forecast errors about the output level

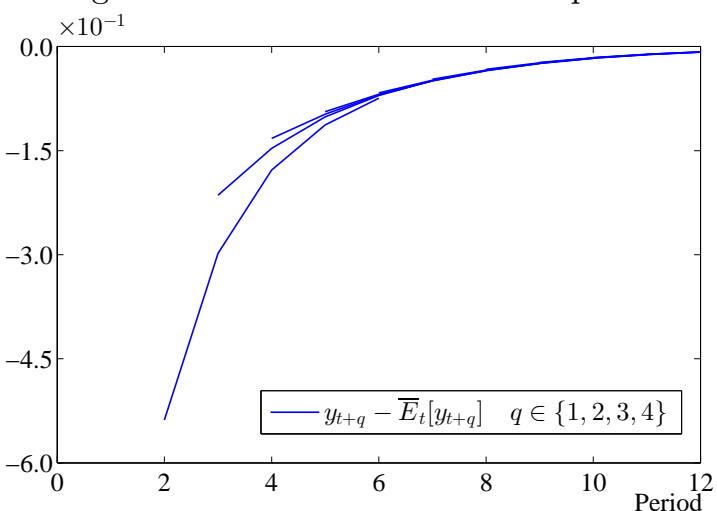

Hierarchy of firms' expectations about $x_{t}^{m}$

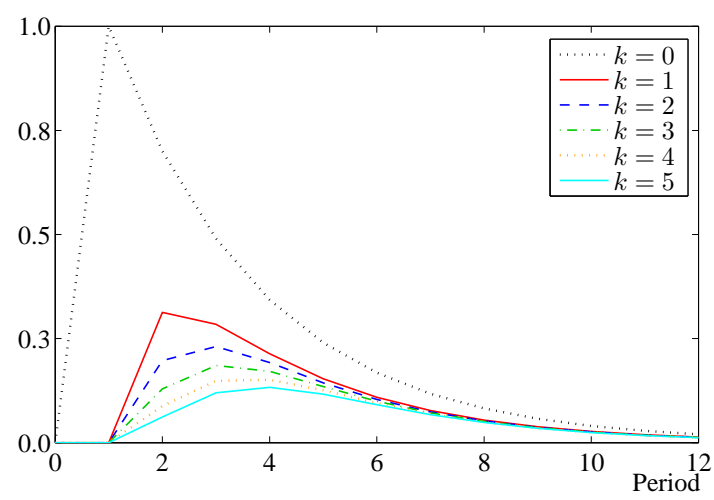

Hierarchy of firms' expectations about $x_{t}^{n_{p}}$

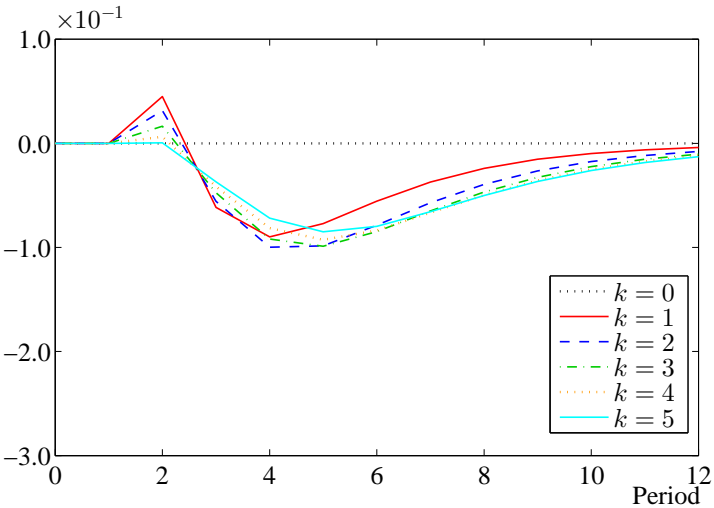

Note: The top two panels show the actual path, the path of firms' average contemporaneous belief and the sequence of firms' average 4-period-ahead forecasts for each of the level of output and the price level. The next two panels show the sequence of firms' average forecast errors for the same. The bottom four panels show the hierarchies of firms' average beliefs about each of the underlying shocks, with $\bar{E}_{t}^{(0)}\left[\boldsymbol{x}_{t}\right]=\boldsymbol{x}_{t}$ and $\bar{E}_{t}^{(k)}\left[\boldsymbol{x}_{t}\right]=\bar{E}_{t}\left[\bar{E}_{t}^{(k-1)}\left[\boldsymbol{x}_{t}\right]\right]$ for $k \geq 1$.

Figure 3: Impulse responses following a monetary shock $\left(\phi_{\pi}=0.5\right.$ and $\left.\phi_{y}=0.5\right)$ 
The price level and firms' average forecasts

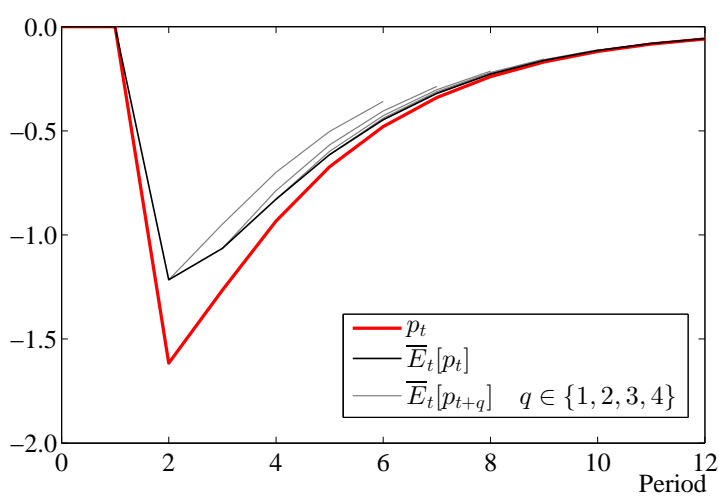

Average forecast errors about the price level

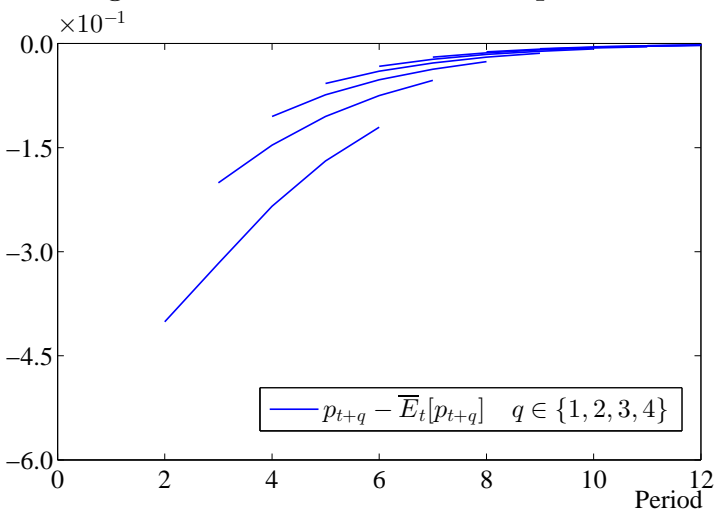

Hierarchy of firms' expectations about $x_{t}^{c}$

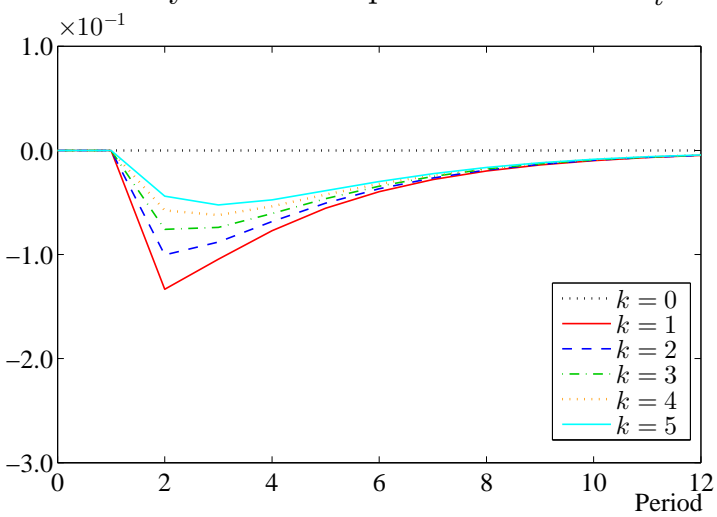

Hierarchy of firms' expectations about $x_{t}^{n_{y}}$

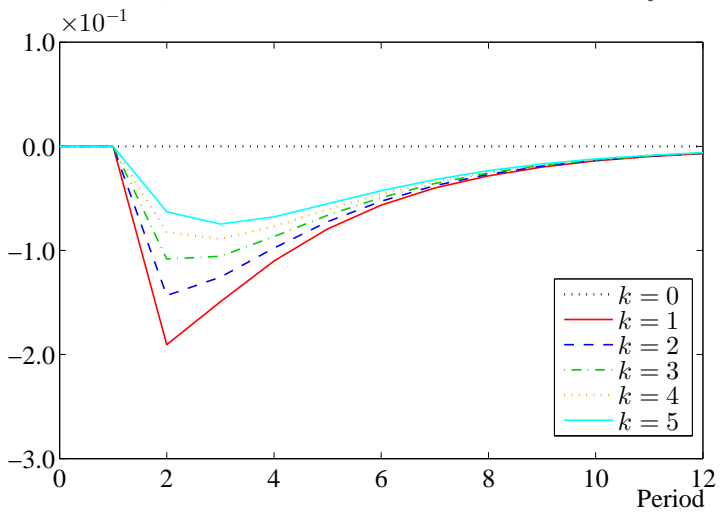

The output level and firms' average forecasts

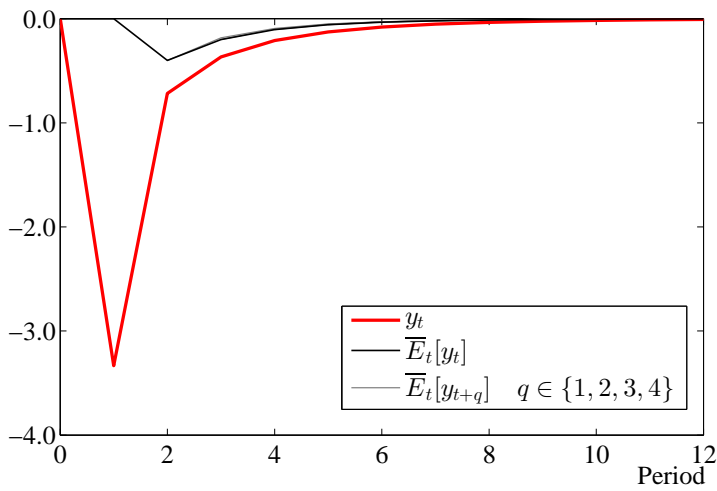

Average forecast errors about the output level

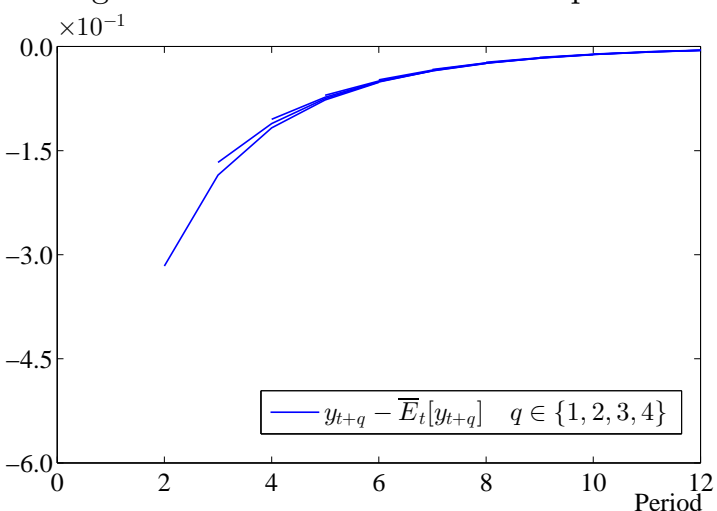

Hierarchy of firms' expectations about $x_{t}^{m}$

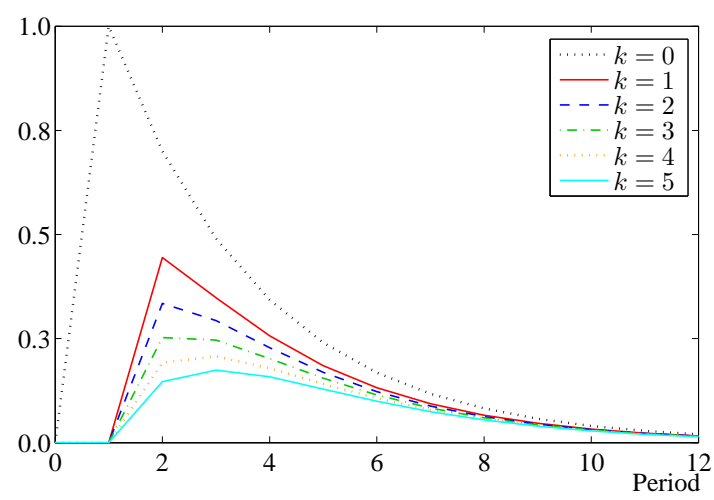

Hierarchy of firms' expectations about $x_{t}^{n_{p}}$

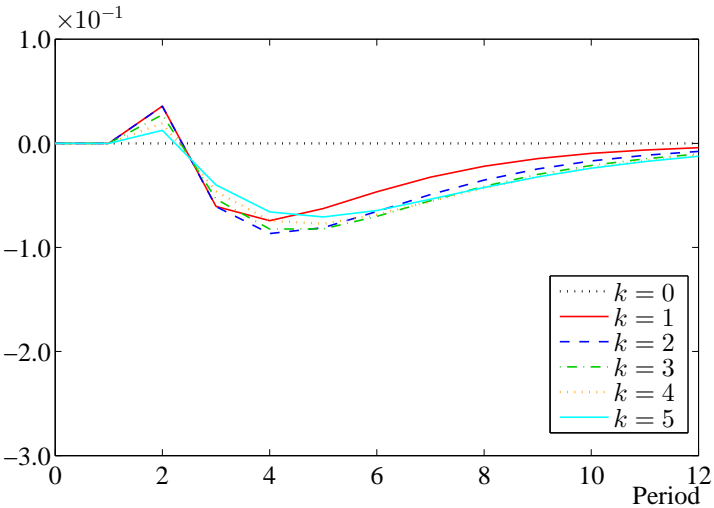

Note: The top two panels show the actual path, the path of firms' average contemporaneous belief and the sequence of firms' average 4-period-ahead forecasts for each of the level of output and the price level. The next two panels show the sequence of firms' average forecast errors for the same. The bottom four panels show the hierarchies of firms' average beliefs about each of the underlying shocks, with $\bar{E}_{t}^{(0)}\left[\boldsymbol{x}_{t}\right]=\boldsymbol{x}_{t}$ and $\bar{E}_{t}^{(k)}\left[\boldsymbol{x}_{t}\right]=\bar{E}_{t}\left[\bar{E}_{t}^{(k-1)}\left[\boldsymbol{x}_{t}\right]\right]$ for $k \geq 1$.

Figure 4: Impulse responses following a monetary shock under an interest rate peg $\left(\phi_{\pi}=\phi_{y}=\right.$ $0)$ 
Output level

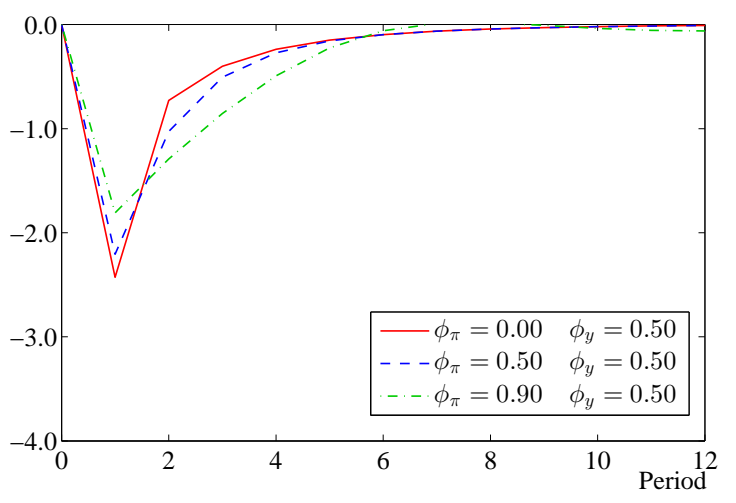

Price level

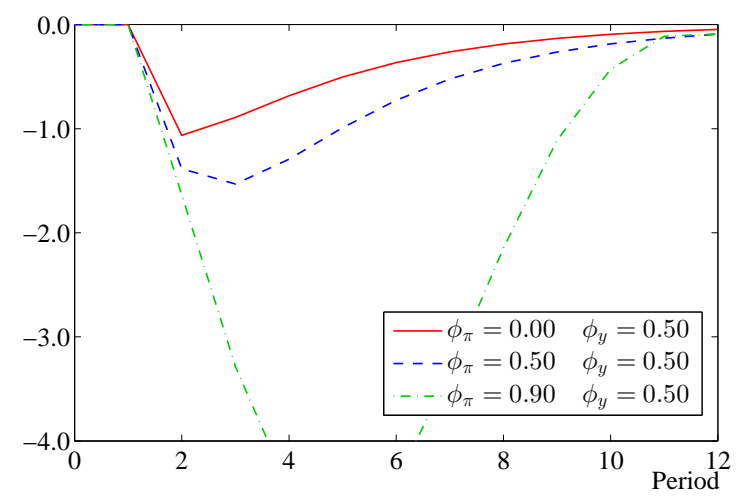

(a) Varying $\phi_{\pi}$

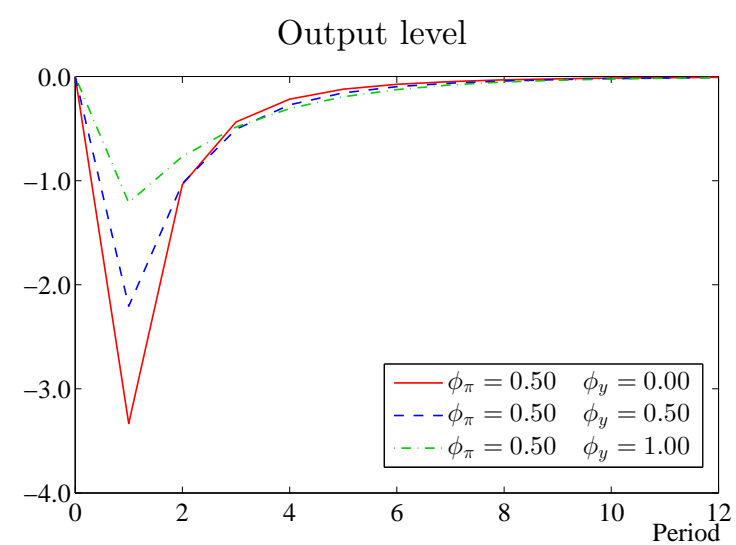

Price level

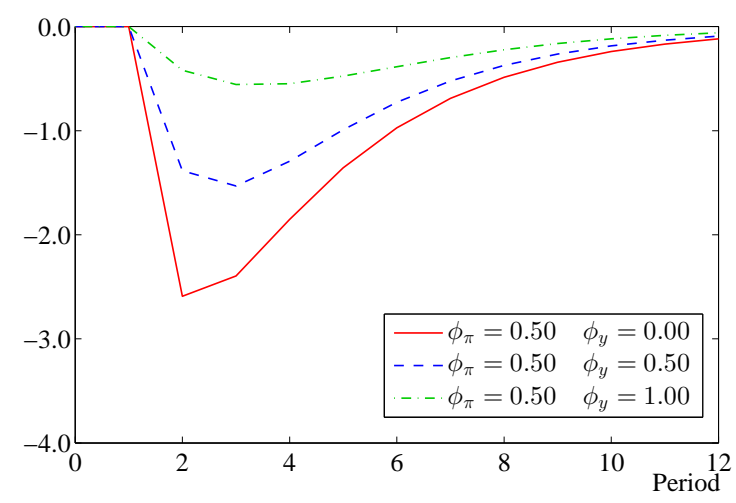

(b) Varying $\phi_{y}$

Note: The left-hand panels plot impulse responses for the level of output and the price level following a monetary shock for different values of $\phi_{\pi}$ while holding $\phi_{y}$ fixed. The right-hand panels plot the same while holding $\phi_{\pi}$ fixed and varying $\phi_{y}$. Note that for values of $\phi_{\pi} \geq 1$, the price level is explosive.

Figure 5: Impulse responses following a monetary shock under various monetary policy regimes 
Output level

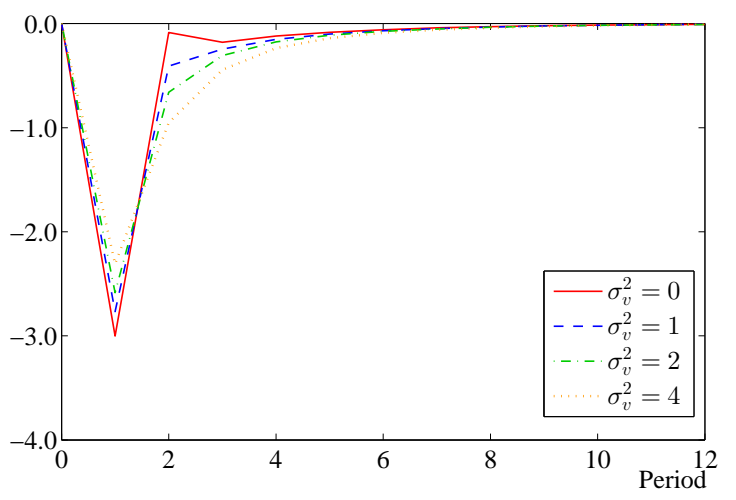

Price level

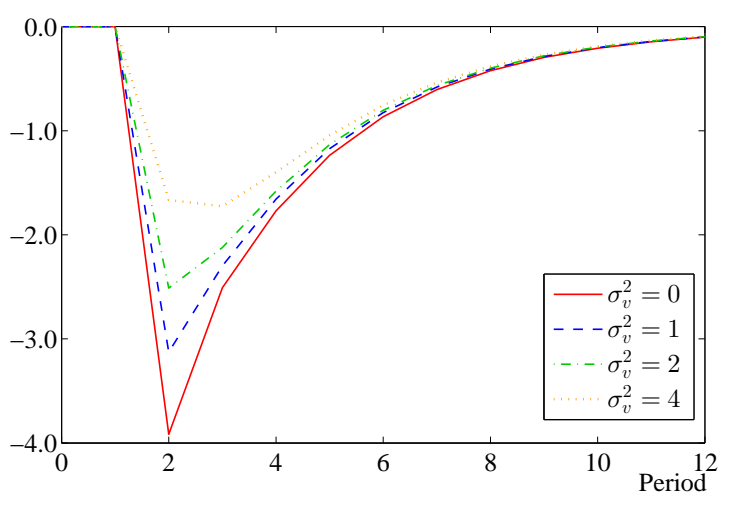

$\boldsymbol{s}_{t}(i)=\left[\begin{array}{l}y_{t-1}+x_{t}^{n_{y}}+v_{t}^{n_{y}}(i) \\ p_{t-1}+x_{t}^{n_{p}}+v_{t}^{n_{p}}(i)\end{array}\right]$

(a) Benchmark signals
Output level

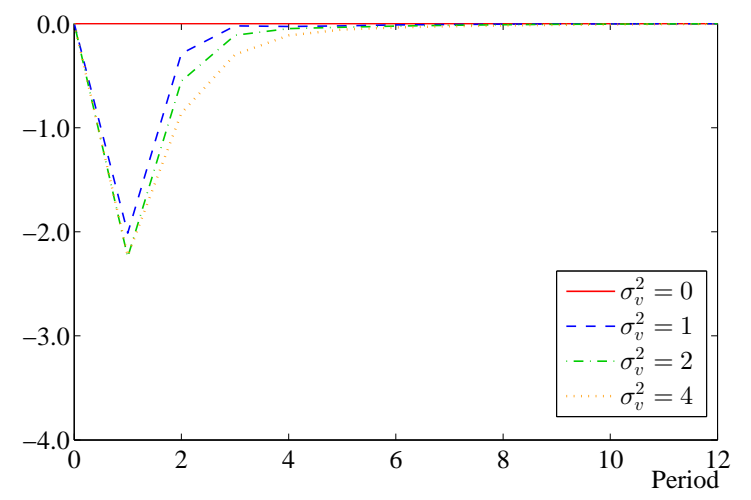

Price level

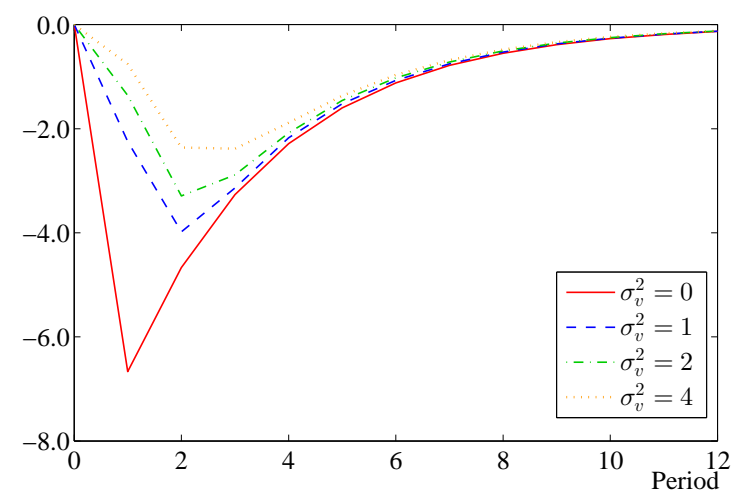

$$
\boldsymbol{s}_{t}(i)=\left[\begin{array}{c}
y_{t-1}+x_{t}^{n_{y}}+v_{t}^{n_{y}}(i) \\
p_{t-1}+x_{t}^{n_{p}}+v_{t}^{n_{p}}(i) \\
x_{t}^{c}+v_{t}^{c}(i) \\
x_{t}^{m}+v_{t}^{m}(i)
\end{array}\right]
$$

(b) Expanded signals

Note: The charts vary the variance of idiosyncratic shocks under two signal regimes (the monetary policy regime remains at $\phi_{\pi}=\phi_{y}=0.5$ for both). The left-hand panels consider the benchmark scenario with firms observing signals of the previous-period levels of output and prices. As the variance of idiosyncratic shocks falls to zero, firms' information sets become common, but remain incomplete. The right-hand panels further add direct signals about the fundamental shocks, so that as the variance of idiosyncratic shocks falls to zero, firms' information sets become complete.

Figure 6: Impulse responses following a monetary shock under varying degrees of information quality 
The price level and firms' average forecasts

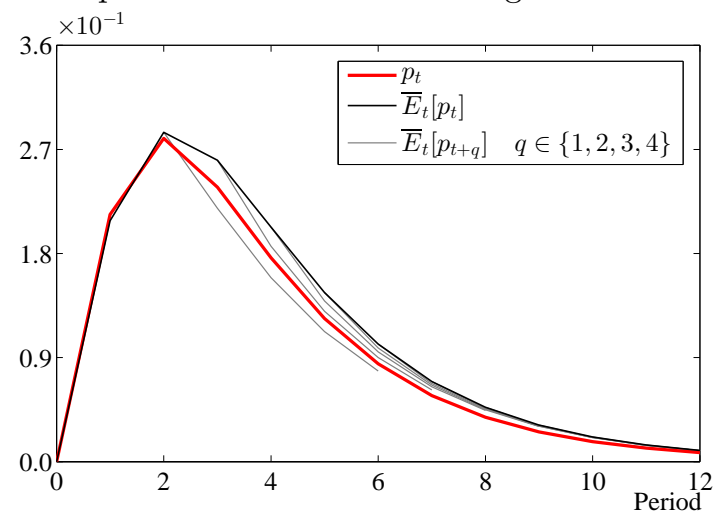

Average forecast errors about the price level

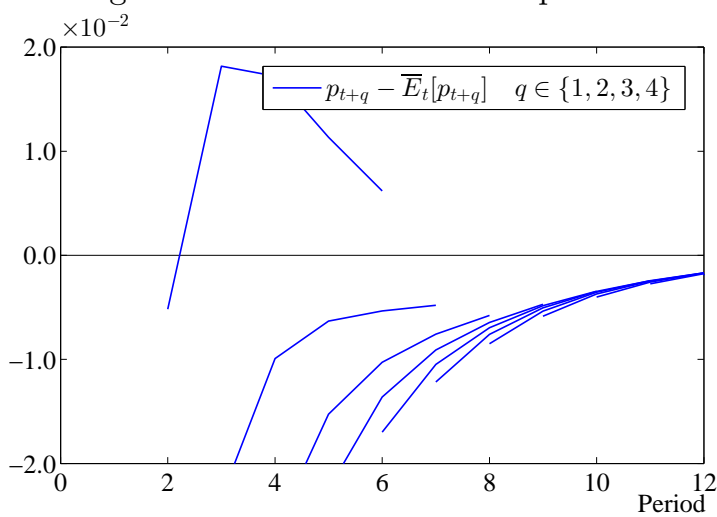

Hierarchy of firms' expectations about $x_{t}^{c}$

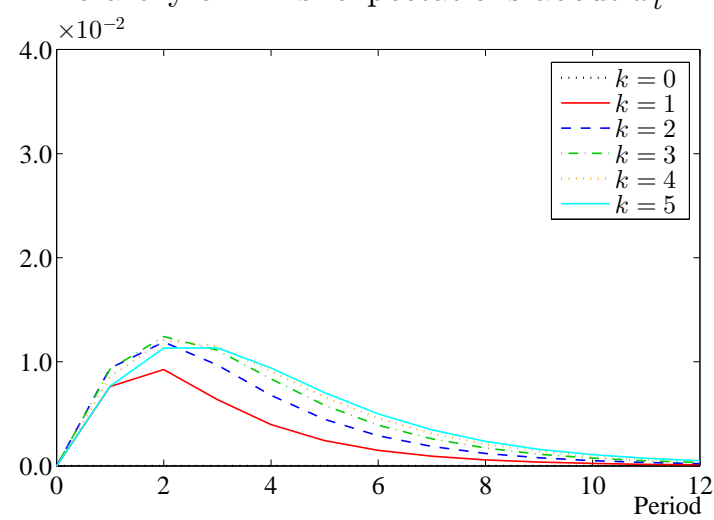

Hierarchy of firms' expectations about $x_{t}^{n_{y}}$

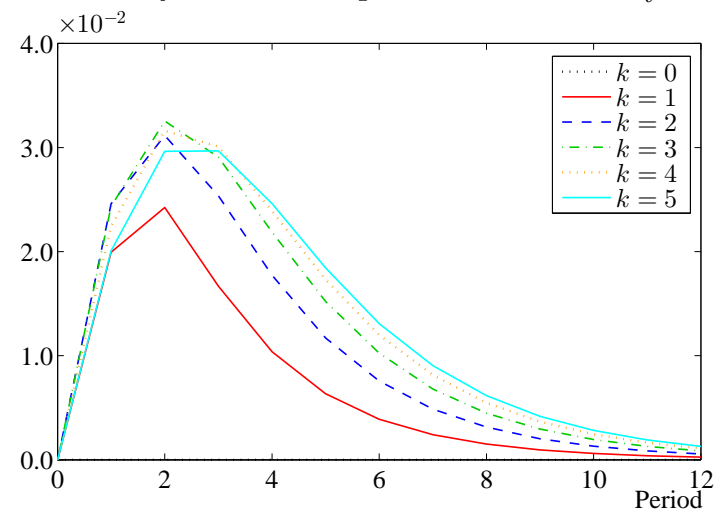

The output level and firms' average forecasts

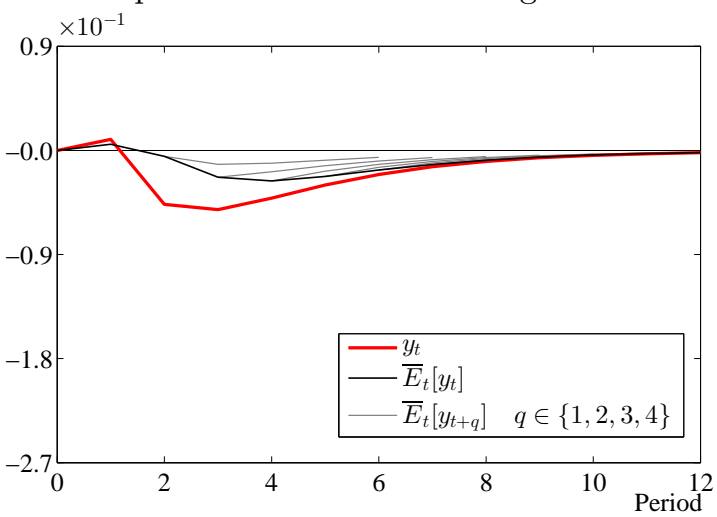

Average forecast errors about the output level

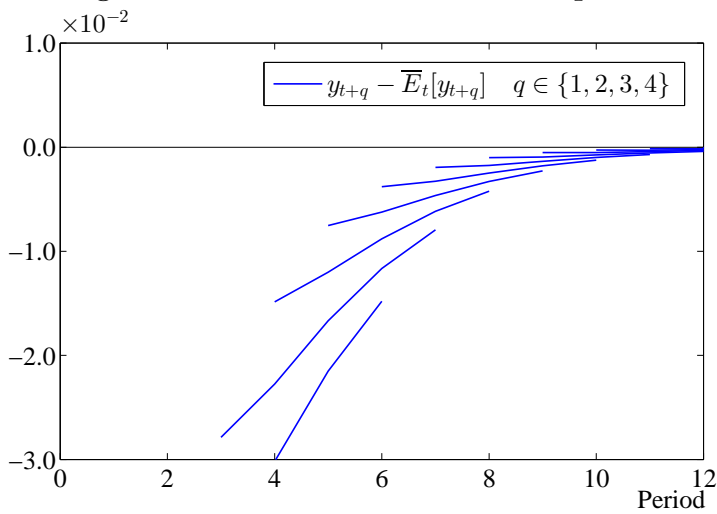

Hierarchy of firms' expectations about $x_{t}^{m}$

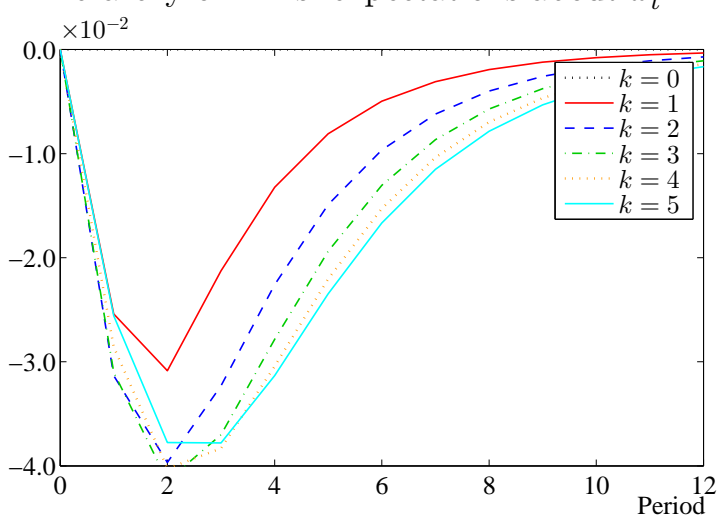

Hierarchy of firms' expectations about $x_{t}^{n_{p}}$

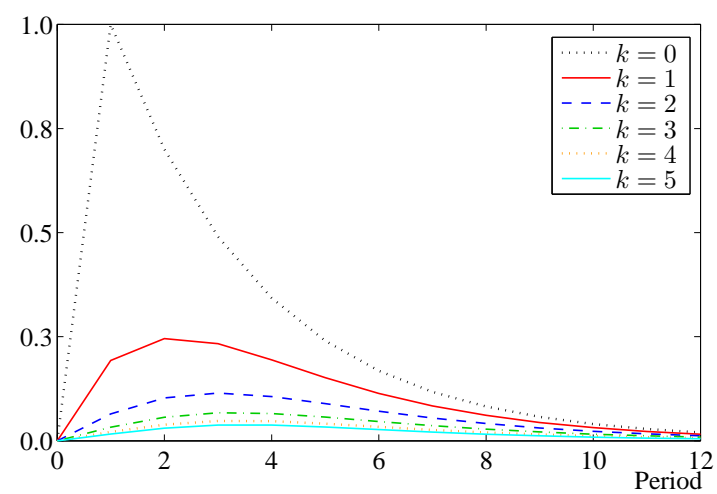

Note: The top two panels show the actual path, the path of firms' average contemporaneous belief and the sequence of firms' average 4-period-ahead forecasts for each of the level of output and the price level. The next two panels show the sequence of firms' average forecast errors for the same. The bottom four panels show the hierarchies of firms' expectations about each of the four aggregate shocks.

Figure 7: Impulse responses following a common noise shock to signals about the price level 


\subsection{Adding a pure sunspot shock $^{18}$}

The addition of a pure sunspot shock - that is, an exogenous shock in agents' signals that is neither "fundamental" as a structural shock in the agents' decision rules, nor measurement error "noise" in signals based on those structural shocks - does not affect this economy at all. This is because they are, by definition, uncorrelated with the fundamental and noise shocks. They therefore carry no additional information and the optimal Kalman filter gives them zero weight. To illustrate this point, I expand the "underlying state" to include a pure sunspot:

$$
\boldsymbol{x}_{t}=\left[\begin{array}{lllll}
x_{t}^{c} & x_{t}^{m} & x_{t}^{n_{y}} & x_{t}^{n_{p}} & x_{t}^{S S}
\end{array}\right]^{\prime}
$$

and similarly expand the baseline set of signals to include the sunspot:

$$
\boldsymbol{s}_{t}(i)=\left[\begin{array}{cc}
s 1: & y_{t-1}+x_{t}^{n_{y}}+v_{t}^{y}(i) \\
s 2: & p_{t-1}+x_{t}^{n_{p}}+v_{t}^{p}(i) \\
s 3: & x_{t}^{S S}
\end{array}\right]
$$

Recall that the optimal Kalman gain is $K_{t}(i)=\operatorname{Cov}\left(X_{t}, \boldsymbol{s}_{t \mid t-1}^{\mathrm{err}}(i)\right)\left[\operatorname{Var}\left(\boldsymbol{s}_{t \mid t-1}^{\mathrm{err}}(i)\right)\right]^{-1}$ where $\boldsymbol{s}_{t \mid t-1}^{\mathrm{err}}(i)=\boldsymbol{s}_{t}(i)-E_{t-1}(i)\left[\boldsymbol{s}_{t}(i)\right]$ is the signal innovation (new information made available in agent $i$ 's period- $t$ signal vector). Since $X_{t}$ is stationary and agents' signal extraction problems are symmetric, this is common to all agents and converges to a constant $K_{t}(i) \rightarrow K$.

The following tables list these two components of the Kalman gain under the baseline parameterisation. Table 2a gives the covariance of the hierarchy of expectations with the innovation in each of the signals, while $2 \mathrm{~b}$ gives the variance-covariance matrix of the signal innovations. The sunspot shock, as a signal, covaries neither with other shocks nor with firms' average expectations about those other shocks. It therefore provides no information and the weight attached to it is zero.

(a) $\operatorname{Cov}\left(X_{t}^{0: 2}, \boldsymbol{s}_{t \mid t-1}^{\mathrm{err}}(i)\right)$

\begin{tabular}{|c|c|c|c|}
\hline & $\mathrm{s} 1$ & $\mathrm{~s} 2$ & $\mathrm{~s} 3$ \\
\hline$x_{t}^{c}$ & 0.525 & 0.107 & 0 \\
$x_{t}^{m}$ & -1.750 & -0.357 & 0 \\
$x_{t}^{n_{y}}$ & 1.374 & 0.280 & 0 \\
$x_{t}^{n_{p}}$ & -0.058 & 1.635 & 0 \\
$x_{t}^{S s}$ & 0 & 0 & 1.592 \\
\hline $\bar{E}_{t}^{(1)}\left[x_{t}^{c}\right]$ & 0.335 & 0.107 & 0 \\
$\bar{E}_{t}^{(1)}\left[x_{t}^{m}\right]$ & -1.117 & -0.356 & 0 \\
$\bar{E}_{t}^{(1)}\left[x_{t}^{n_{y}}\right]$ & 0.878 & 0.278 & 0 \\
$\bar{E}_{t}^{(1)}\left[x_{t}^{n_{p}}\right]$ & -0.110 & 0.539 & 0 \\
$\bar{E}_{t}^{(1)}\left[x_{t}^{S s}\right]$ & 0 & 0 & 0.535 \\
\hline $\bar{E}_{t}^{(2)}\left[x_{t}^{c}\right]$ & 0.223 & 0.097 & 0 \\
$\bar{E}_{t}^{(2)}\left[x_{t}^{m}\right]$ & -0.742 & -0.323 & 0 \\
$\bar{E}_{t}^{(2)}\left[x_{t}^{n_{y}}\right]$ & 0.583 & 0.254 & 0 \\
$\bar{E}_{t}^{(2)}\left[x_{t}^{n_{p}}\right]$ & -0.058 & 0.273 & 0 \\
$\bar{E}_{t}^{(2)}\left[x_{t}^{S s}\right]$ & 0 & 0 & 0.224 \\
\hline
\end{tabular}

(b) $\operatorname{Var}\left(\boldsymbol{s}_{t \mid t-1}^{\mathrm{err}}(i)\right)$

\begin{tabular}{|c|c|c|c|}
\hline & s1 & s2 & s3 \\
\hline s1 & 12.150 & & \\
\hline s2 & 0.981 & 8.570 & \\
\hline s3 & 0 & 0 & 6.592 \\
\hline
\end{tabular}

Table 2: Components of firms' Kalman gain in the presence of a sunspot shock

\footnotetext{
${ }^{18}$ I thank Wouter den Haan for a fruitful conversation that emphasised this point.
} 


\section{Extending the model to incomplete Central Bank information}

In this section, I extend the basic model of the previous section to (i) add stochastic TFP; and (ii) remove full information from the monetary authority, but leave it with the representative household. In particular, the monetary authority will be uncertain about the aggregate level of TFP, output and the price level, and will receive signals about these that are subject to noise, both in common with firms and specific to the central bank.

\subsection{The representative household}

The representative household is unchanged from the baseline model above.

\section{$5.2 \quad$ Firms}

\section{Production}

Each good remains produced by a single firm according to a common production function with decreasing marginal productivity for labour, but now with stochastic TFP:

$$
Y_{t}(i)=e^{x_{t}^{a}+v_{t}^{a}(i)} L_{t}(i)^{1-\alpha}
$$

where the shocks $x_{t}^{a}$ and $v_{t}^{a}(i)$ are independent and mean zero (see below for more detail). Firm $i$ 's real marginal cost is then:

$$
M C_{t}(i)=(1+\eta) \frac{W_{t} e^{v_{t}^{w}(i)}}{P_{t}} e^{-(1+\eta)\left(x_{t}^{a}+v_{t}^{a}(i)\right)} Y_{t}(i)^{\eta}
$$

where $\eta \equiv \frac{\alpha}{1-\alpha}$ is the elasticity of marginal cost w.r.t. output.

\section{Price setting}

Firms' price-setting remains unchanged from the baseline model above (see below for more detail on firms' information).

\subsection{The monetary authority}

The monetary authority sets the nominal interest rate according to the same general rule and subject to the same conditions (31), but now subject to incomplete information (see below for more detail):

$$
1+i_{t}=E_{t}^{C B}\left[f\left(\frac{\Pi_{t+1}}{\Pi^{*}}, \frac{Y_{t+1}}{Y_{t+1}^{s s}}, x_{t}^{m} ; \Phi\right)\right]
$$

\subsection{Market clearing and aggregation}

Market clearing now implies that aggregate output is given by:

$$
Y_{t}=\Delta_{t} e^{x_{t}^{a}} H_{t}^{1-\alpha}
$$

where $\Delta_{t}$ represents distortions from relative prices and transitory shocks to productivity and relative demand:

$$
\Delta_{t} \equiv\left(\int\left\{e^{v_{t}^{a}(j)+v_{t}^{y}(j)}\left(\frac{P_{t}(j)}{P_{t}}\right)^{\varepsilon}\right\}^{-(1+\eta)} d j\right)^{-\frac{1}{1+\eta}}
$$




\subsection{Stochastic processes}

The underlying state of the economy therefore features five variables: $\boldsymbol{x}_{t}=\left[\begin{array}{lllll}x_{t}^{a} & x_{t}^{c} & x_{t}^{m} & x_{t}^{n_{y}} & x_{t}^{n_{y}}\end{array}\right]^{\prime}$. I suppose that these follow the same $\operatorname{AR}(1)$ process as the baseline model with $P \rho I$ and $Q=I$.

Individual firm idiosyncratic shocks $\left(\boldsymbol{v}_{t}(i)\right)$ and shocks specific to the central bank $\left(\boldsymbol{v}_{t}^{C B}\right)$ are all perfectly transitory, independent and normally distributed with mean zero and unit variance.

\subsection{Information}

\section{Firms}

I expand firms' signals slightly from the previous section to allow for stochastic TFP:

$$
\boldsymbol{s}_{t}(i)=\left[\begin{array}{c}
y_{t-1}+x_{t}^{n_{y}}+v_{t}^{y}(i) \\
p_{t-1}+x_{t}^{n_{p}}+v_{t}^{p}(i) \\
x_{t-1}^{a}+v_{t-1}^{a}(i)
\end{array}\right]
$$

That is, in addition to observing noisy signals about the previous period's aggregate levels of output and prices (unchanged from the baseline model), firms also observe their own TFP from the previous period.

\section{The monetary authority}

The monetary authority observes the following signals each period:

$$
\boldsymbol{s}_{t}^{(C B)}=\left[\begin{array}{c}
y_{t-1}+x_{t}^{n_{y}}+v_{t}^{C B: y} \\
p_{t-1}+x_{t}^{n_{p}}+v_{t}^{C B: p} \\
a_{t-1}+v_{t}^{C B: a} \\
x_{t}^{m}
\end{array}\right]
$$

That is, it observes the same underlying signals about the previous-period output and price levels as individual firms, subject to its own "idiosyncratic" error of interpretation. It also observes a noisy signal regarding the previous-period aggregate TFP and perfectly observes the current-period monetary shock.

Since the $\boldsymbol{v}_{t}^{C B}$ shocks are specific to the monetary authority and represent only noise (they do not directly enter the decision rules of the household or firms), they are represent a pure way of capturing a policymaker's error of judgement. Unlike the corresponding shocks to firms, which are atomistic, errors of judgement on the part of the monetary authority have the potential to affect the wider economy.

Since $\boldsymbol{v}_{t}^{C B}$ shocks are perfectly transitory, the reader may well posit that their effect, if significant, will be short-lived. However, as I illustrate below, the recursive nature of the Kalman filter, together with the persistence of fundamental shocks, will cause the effects of any such error to be long-lived. 


\subsection{Linear model and solution}

Using the notation that lower-case letters represent log-deviations from the deterministic steady state, I show in the appendix that the linearised model is now given by:

$$
\begin{aligned}
y_{t} & =E_{t}^{\Omega}\left[y_{t+1}\right]-\sigma\left(i_{t}-E_{t}^{\Omega}\left[p_{t+1}\right]+p_{t}\right)+\sigma\left(x_{t}^{c}-E_{t}^{\Omega}\left[x_{t+1}^{c}\right]\right) \\
i_{t} & =\phi_{\pi} E_{t}^{C B}\left[p_{t+1}-p_{t}\right]+\phi_{y} E_{t}^{C B}\left[y_{t+1}\right]+x_{t}^{m} \\
p_{t} & =\bar{E}_{t}\left[p_{t}\right]+\kappa \bar{E}_{t}\left[y_{t}\right]-\lambda \bar{E}_{t}\left[x_{t}^{a}\right]
\end{aligned}
$$

where $\pi_{t}=p_{t}-p_{t-1}$ and $p_{t}=\int p_{t}(i) d i$. The appendix also derives the following solution to the model: ${ }^{19}$

$$
\begin{aligned}
X_{t} & \equiv\left[\begin{array}{c}
\boldsymbol{x}_{t} \\
E_{t}\left[X_{t}\right] \\
E_{t}^{C B}\left[X_{t}\right]
\end{array}\right] \\
X_{t} & =F X_{t-1}+G \boldsymbol{u}_{t}+H \boldsymbol{v}_{t}^{C B} \\
p_{t} & =\gamma_{p}^{\prime} X_{t}
\end{aligned}
$$

The term in $\boldsymbol{v}_{t}^{C B}$ remains because, unlike individual firms, the monetary authority is not atomistic, so its errors of judgement do not "wash out" with the law of large numbers.

\subsection{Simulations}

Figure 8 plots impulse responses for the economy following a private noise shock to the monetary authority's signal of aggregate TFP. The central bank, erroneously thinking that the productivity of the economy has improved, correspondingly believes that output will rise and prices will fall on impact but then rise gradually back to steady-state. This combination of a (believed) sustained positive output gap and positive future inflation causes the central bank to raise the interest rate on impact. Firms do not observe anything in period 1, so prices do not change, but the increase in the interest rate causes household demand to fall. In the second period, firms observe that period-1 output fell and so lower their prices. This substantially, but not entirely, acts to offset the negative effect on output from the central bank's error.

The error-induced recession then peters out over time. Interestingly, the authority subsequently believes - incorrectly, but rationally conditional on their earlier noise shock - that a common noise shock (measurement error on the part of the national statistical agency) is present in both signals of output and the price level. Relative to their peak deviation, these induced errors of belief are more persistent than the central bank's belief about TFP (about which they experienced the error in the first place).

\subsection{Endogenous policy inertia}

A key topic of debate in the understanding of central banks' reaction functions is the structural source of the observed inertia in policymaking. As mentioned above, when estimating reduced-form Taylor rules for interest rate decision making, the data are best able to be fit with functional forms that include an autoregressive coefficient on the interest rate. This has led many commentators to conclude that monetary authorities proactively engage in interest rate smoothing.

\footnotetext{
${ }^{19}$ Note that the central bank's beliefs, coming from a single information set, are subject to the law of iterated expectations.
} 
The price level

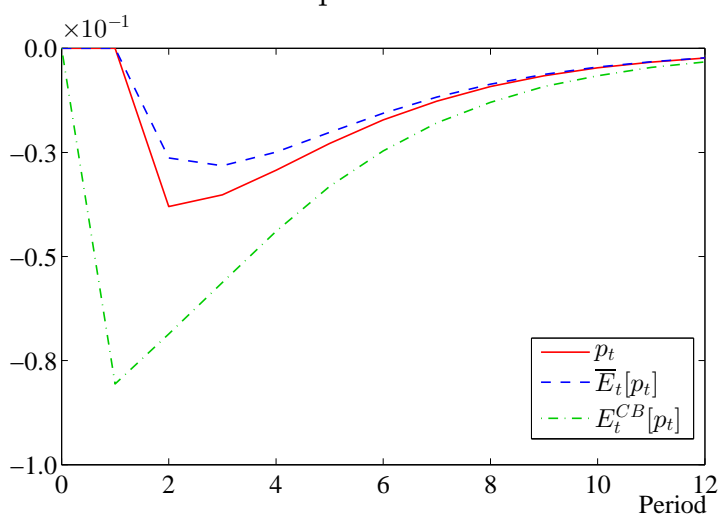

Expectations about $x_{t}^{a}$

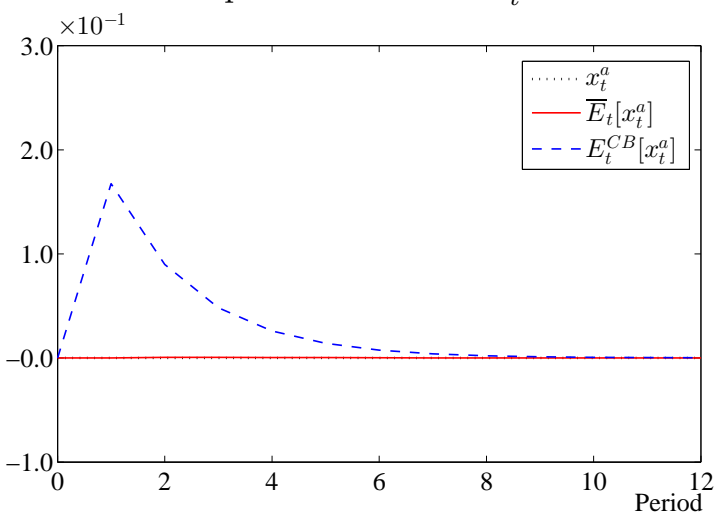

Expectations about $x_{t}^{n_{y}}$

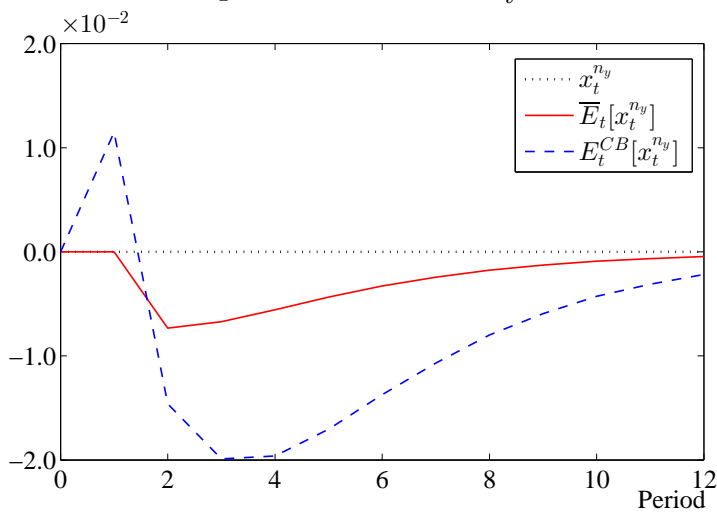

The output level

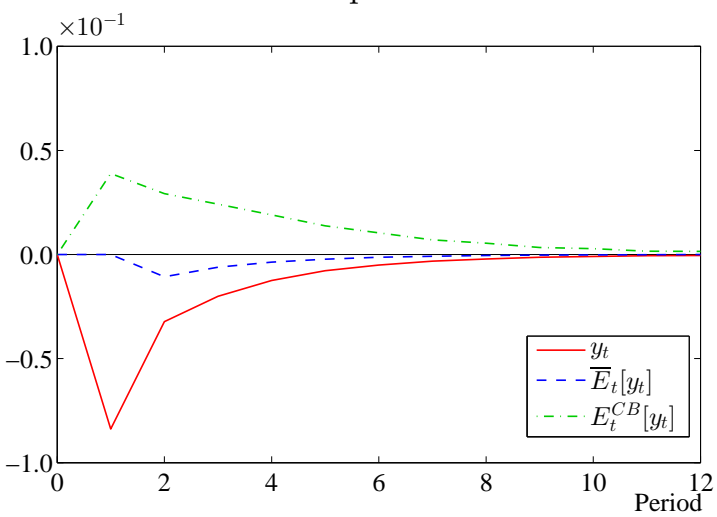

Expectations about $x_{t}^{c}$

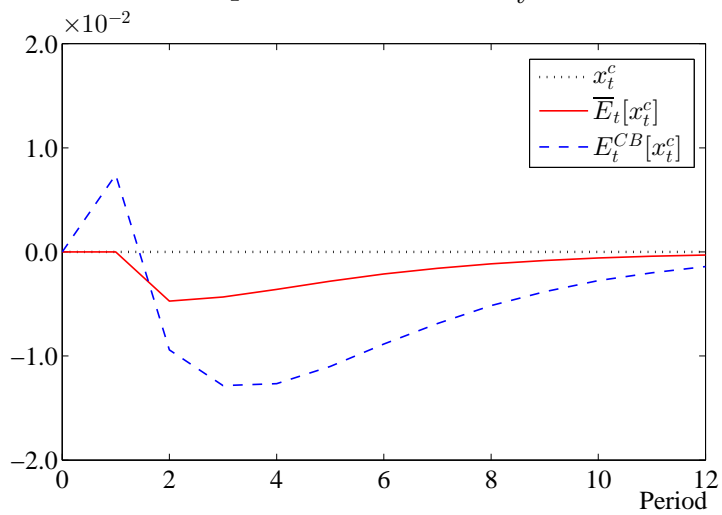

Expectations about $x_{t}^{n_{p}}$

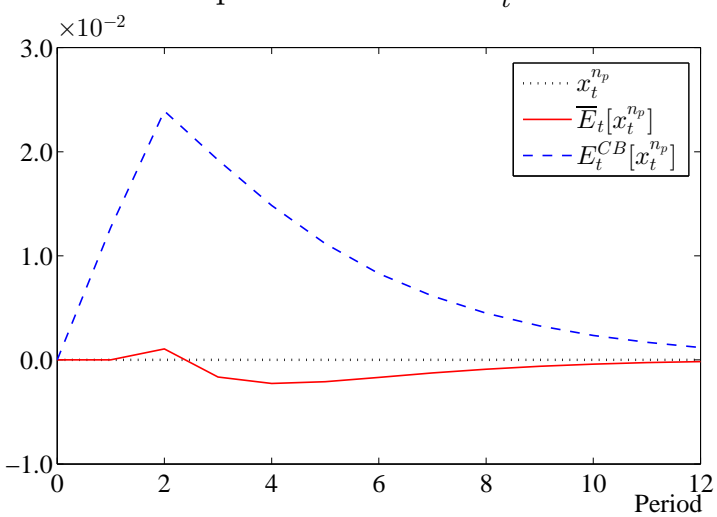

Note: The top two panels show the actual path of the price level and the level of output, together with the average of firms' expectations and the central bank expectation of the same. The bottom four panels show the path of firms' average expectation and the central bank's expectation about the level of aggregate TFP $\left(x_{t}^{a}\right)$, the household preference shock $\left(x_{t}^{c}\right)$ and the public measurement errors in signals about output $\left(x_{t}^{n_{y}}\right)$ and the price level $\left(x_{t}^{n_{p}}\right)$. The equivalent chart for the monetary shock $\left(x_{t}^{m}\right)$ is not shown, but shows that the central bank observes it with certainty, while the average firm believes it to be positive throughout (largely in mirror to firms' average belief about $x_{t}^{c}$ ).

Figure 8: Impulse responses following a transitory noise shock to the central bank's signal regarding aggregate TFP

A 'gradualist' approach to changing monetary policy has unquestionably been present on some occasions. The most notable recent example, of course, occurred in the second half of 2014 and early 2015 when, contemplating an exit from holding their policy rates at, or near, their effective lower bounds, communications from both the US Federal Reserve and the Bank of England explicitly 
emphasised that rate increases, when they began, would occur at a gradual and measured pace. But although gradualism clearly describes central banks' decision rules under some circumstances, whether such an approach represents a defining attribute of monetary policymaking under all states of the world remains a contentious issue.

Rudebusch (2002, 2006), in particular, argues that the appearance of inertial policymaking suggested by estimated reduced-form rules is an illusion that, instead, reflects the fact that the true drivers of policy choices (omitted variables in basic estimates of the policymaker's decision rule) are themselves persistent. Rudebusch argues that these "true drivers" may be proxied by assuming persistence in the monetary shock process. Consequently, Hamilton, Pruitt, and Borger (2011) and Coibion and Gorodnichenko (2012) have argued that if the 'interest rate smoothing' interpretation is correct, inertial policy responses should be observable following any shock, while if central banks do not actively engage in interest rate smoothing, policy inertia should only be observable following a persistent monetary shock. Coibion and Gorodnichenko (2012) test this hypothesis, and find considerable policy inertia following a wide sequence of identified non-monetary shocks. They also document that the Taylor principle would have been satisfied in the Greenspan era of US monetary policy under an assumption of interest rate smoothing, but not under the Rudebuschstyle assumption of persistent shocks. They subsequently conclude the data are strongly supportive of the interest rate smoothing interpretation.

However, the model developed in this paper represents a source of policy inertia that emerges regardless of the source of the underlying shock, despite the use of a simple Taylor-type rule that responds only to expectations of next-period inflation and output, and which does not require the Taylor principle to achieve nominal stability. Since the aggregate price and output levels are themselves functions of the complete hierarchy of firms' average beliefs about all underlying shocks (and not just monetary shocks), the central bank's decision must, in effect, be based on its own views regarding that entire hierarchy of beliefs. Since both firms' expectations and those of the monetary authority are (optimally) recursive, they are necessarily slow to adjust given the noise present in signals about the economy. Inertial policy therefore emerges endogenously, even following perfectly transitory noise shocks that play no fundamental role in the economy.

\section{Conclusion}

This paper has developed a New Keynesian model that features a unique, globally-stable steadystate equilibrium in inflation and, around that steady-state, a determinate price level, despite the monetary authority targeting inflation. The central bank's coefficient against inflation may violate the Taylor principle without endangering the nominal stability of the economy (indeed, the model admits the possibility of an interest rate peg). These results are striking, but emerge from an entirely standard model with only three adjustments, all of which plausibly represent accurate descriptions of reality:

- Instead of granting firms access to full information but preventing them from fully using it by imposing that prices are sticky, I assume that prices are perfectly flexible but subject firms to incomplete and heterogeneous information.

- Instead of having the monetary authority respond to current output and current inflation, I assume that it responds to current output and expected next-period inflation. 
- I impose an upper bound for the responsiveness of the monetary authority to deviations of inflation from target when in steady-state (although not necessarily when out of steady-state).

Within steady-state, the final assumption grants that the steady-state rate of inflation is uniquely pinned down as a choice of the monetary authority. Out of steady-state (that is, when the model is subject to shocks), the combination of flexible prices and a central bank that responds only to expected future inflation removes all mention of previous-period prices when producing current-period decisions. Together with incomplete information, under which all expectations (including of future variables) become combinations of current and past observables, the current-period price level becomes a function of only firms' expectations regarding the hidden state of the economy, and their beliefs about the beliefs of other firms. The price level of the economy is therefore determined, up to an initial value.

The solution proceeds by specifying and solving the signal extraction problem of price-setting firms. This uniquely pins down the process for expectation errors (including forecast errors) and so removes the need to call on the assumptions of Blanchard and Kahn (1980). This, in turn, allows the model to circumvent the critique of New Keynesian models by Cochrane (2011). Furthermore, with the firms' signal extraction problems fully specified, there remains no role for pure sunspot shocks - shocks that are neither fundamental (not appearing directly in agents' decision rules) nor noise in the measurement error sense. Even if such shocks appear in all agents' signals, the optimal weight attributed to them in the Kalman filter is zero (as they carry no informational value).

Extending the model to incorporate incomplete information on the part of the central bank allows it to further justify the absence of the Taylor principle by producing policy inertia in interest rates, thereby providing a theoretical match to the arguments of Rudebusch (2002, 2006). The extension also allows the model to confront the possibility of policymakers' (rational) errors of judgment that occur following a noise shock specific to the central bank.

\section{References}

Angeletos, G., and J. LA'O (2009): "Incomplete Information, Higher-Order Beliefs and Price Inertia," NBER Working Papers, No. 15003.

(2010): "Noisy Business Cycles," in NBER Macroeconomics Annual 2009, ed. by D. Acemoglu, K. Rogoff, and M. Woodford, vol. 24, chap. 5, pp. 319-378. University of Chicago Press, Chicago.

Benhabib, J., S. Schmitt-Grohe, and M. Uribe (2001): "The Perils of Taylor Rules," Journal of Economic Theory, 96(1-2), 40-69.

Blanchard, O., And C. Kahn (1980): "The Solution of Linear Difference Models under Rational Expectations," Econometrica, 48(5), 1305-1311.

Calvo, G. (1983): "Staggered Prices in a Utility-Maximizing Framework," Journal of Monetary Economics, 12(3), 383-398.

Cho, S., And A. Moreno (2011): "The forward method as a solution refinement in rational expectations models," Journal of Economic Dynamics and Control, 35(3), 257-272. 
Cochrane, J. H. (2009): "Can learnability save new-Keynesian models?," Journal of Monetary Economics, 56(8), 1109-1113.

(2011): "Determinacy and Identification with Taylor Rules," Journal of Political Economy, $119(3), 565-615$.

Coibion, O., and Y. Gorodnichenko (2012): "Why Are Target Interest Rate Changes So Persistent?," American Economic Journal: Macroeconomics, 4(4), 126-62.

Creel, J., and P. Hubert (2015): "Has Inflation Targeting Changed The Conduct Of Monetary Policy?," Macroeconomic Dynamics, 19(01), 1-21.

Evans, G., and S. Honkapohja (1998): "Economic Dynamics with Learning: New Stability Results," Review of Economic Studies, 65(1), 23-44.

(2001): Learning and Expectations in Macroeconomics. Princeton University Press, Princeton.

Galí, J. (2008): Monetary Policy, Inflation, and the Business Cycle: An Introduction to the New Keynesian Framework. Princeton University Press, Princeton.

Graham, L. (2011a): "Individual rationality, model-consistent expectations and learning," CDMA Working Paper Series 201112, Centre for Dynamic Macroeconomic Analysis.

(2011b): "Learning, information and heterogeneity," CDMA Working Paper Series 201113, Centre for Dynamic Macroeconomic Analysis.

Graham, L., And S. Wright (2010): "Information, hetereogeneity and market incompleteness," Journal of Monetary Economics, 57(2), 164-174.

Grewel, M. S., And A. P. Andrews (2008): Kalman Filtering: Theory and Practice Using MATLAB. John Wiley \& Sons, Inc., Hoboken, New Jersey, 3 edn.

Hamilton, J. D., S. Pruitt, and S. Borger (2011): "Estimating the Market-Perceived Monetary Policy Rule," American Economic Journal: Macroeconomics, 3(3), 1-28.

HM Treasury (2013): Review of the monetary policy framework. The Stationery Office, London.

King, R., And M. Watson (1998): "The Solution of Singular Linear Difference Systems under Rational Expectations," International Economic Review, 39(4), 1015-26.

KLEIn, P. (2000): "Using the generalized Schur form to solve a multivariate linear rational expectations model," Journal of Economic Dynamics and Control, 24(10), 1405-1423.

Klenow, P., and O. Kryvtsov (2008): "State-Depenent or Time-Dependent Pricing: Does It Matter For Recent U.S. Inflation?," Quarterly Journal of Economics, 123(3), 863-904.

Klenow, P., and B. Malin (2010): "Microeconomic Evidence on Price-Setting," in Handbook of Monetary Economics, ed. by B. Friedman, and M. Woodford, vol. 3, chap. 6, pp. 231-284. Elsevier.

Kohlhas, A. (2014): "Learning-by-Sharing: Monetary Policy and the Information Content of Public Signals," Job market paper, Stockholm University. 
Leeper, E. M. (1991): “Equilibria under 'active' and 'passive' monetary and fiscal policies," Journal of Monetary Economics, 27(1), 129-147.

Lorenzoni, G. (2009): “A Theory of Demand Shocks," American Economic Review, 99(5), 20552084 .

LuCAS, R. (1972): "Expectations and the Neutrality of Money," Journal of Economic Theory, 4(2), $103-124$.

Mankiw, G., And R. Reis (2002): "Sticky information versus sticky prices: A proposal to replace the New Keynsian Phillips curve," The Quarterly Journal of Economics, 117(4), 1295-1328.

(2006): "Pervasive Stickiness," American Economic Review, 96(2), 164-169.

(2007): "Sticky Information in General Equilibrium," Journal of the European Economic Association, 5(2-3), 603-613.

McCallum, B. (1983): "On non-uniqueness in rational expectations models : An attempt at perspective," Journal of Monetary Economics, 11(2), 139-168.

(1999): "Role of the Minimal State Variable Criterion in Rational Expectations Models," International Tax and Public Finance, 6(4), 621-639.

(2012a): "A Continuity Refinement for Rational Expectations Solutions," NBER Working Papers 18323, National Bureau of Economic Research, Inc.

(2012b): "Determinacy, Learnability, Plausibility, and the Role of Money in New Keynesian Models," NBER Working Papers 18215, National Bureau of Economic Research, Inc.

Melosi, L. (2014): "Estimating Models with Dispersed Information," American Economic Journal: Macroeconomics, 6, 1-31.

Morris, S., And H. S. Shin (2002): "Social Value of Public Information," American Economic Review, 92(5), 1521-1534.

Muth, J. (1961): "Rational Expectations and the Theory of Price Movements," Econometrica, $29(3), 315-335$.

Nimark, K. (2008): "Dynamic pricing and imperfect common knowledge," Journal of Monetary Economics, 55(2), 365-382.

(2015): "A low dimensional Kalman filter for systems with lagged states in the measurement equation," Economics Letters, 127, 10-13.

Phelps, E. (1984): "The trouble with 'rational expectations' and the problem of inflation stabilization," in Individual Forecasting and Aggregate Outcomes: 'Rational Expectations' Examined, ed. by R. Frydman, and E. Phelps, chap. 2, pp. 31-46. Cambridge University Press.

Rudebusch, G. (2002): "Term structure evidence on interest rate smoothing and monetary policy inertia," Journal of Monetary Economics, 49(6), 1161-1187.

(2006): "Monetary Policy Inertia: Fact or Fiction?," International Journal of Central Banking, 2(4). 
Sargent, T., And N. Wallace (1975): "Rational" Expectations, the Optimal Monetary Instrument, and the Optimal Money Supply Rule," Journal of Political Economy, 83(2), 241-54.

Sims, C. (1994): "A Simple Model for Study of the Determination of the Price Level and the Interaction of Monetary and Fiscal Policy," Economic Theory, 4(3), 381-99.

(2002): "Solving Linear Rational Expectations Models," Computational Economics, 20(12), 1-20.

(2003): "Implications of Rational Inattention," Journal of Monetary Economics, 50(3), 665-690.

TAYlor, J. (1993): "Discretion versus policy rules in practice," Carnegie-Rochester Conference Series on Public Policy, 39(1), 195-214.

(1999): "The robustness and efficiency of monetary policy rules as guidelines for interest rate setting by the European central bank," Journal of Monetary Economics, 43(3), 655-679.

Townsend, R. M. (1983): "Forecasting the Forecasts of Others," Journal of Political Economy, $91(4), 546-587$.

Uhlig, H. (1997): "A Toolkit for Analysing Nonlinear Dynamic Stochastic Models Easily," in Computational Methods for the Study of Dynamic Economies, ed. by R. Marimon, and A. Scott, Handbook of Macroeconomics, chap. 3, pp. 30-61. Oxford University Press.

Woodford, M. (1994): "Monetary Policy and Price Level Determinacy in a Cash-in-Advance Economy," Economic Theory, 4(3), 345-80.

_ (1995): "Price-level determinacy without control of a monetary aggregate," CarnegieRochester Conference Series on Public Policy, 43(1), 1-46.

_ (1999): "Optimal Monetary Policy Inertia," Manchester School, 67(0), 1-35.

- (2003a): "Imperfect Common Knowledge and the Effects of Monetary Policy," in Knowledge, Information, and Expectations in Modern Macroeconomics: In Honor of Edmund S. Phelps, ed. by P. Aghion, R. Frydman, J. Stiglitz, and M. Woodford. Princeton University Press.

(2003b): Interest and Prices: Foundations of a Theory of Monetary Policy. Princeton University Press. 


\section{APPENDICES}

\section{A SOLVING INCOMPLETE INFORMATION MODELS}

This appendix presents a proof of propositions 1 and 1, together with a brief discussion of implementing the model numerically (e.g. in Matlab). Recall that the system may be summarised as:

$$
\begin{aligned}
\boldsymbol{z}_{t} & =A_{0} \bar{E}_{t}\left[\boldsymbol{z}_{t}\right]+A_{1} \bar{E}_{t}\left[\boldsymbol{z}_{t+1}\right]+B_{0} \bar{E}_{t}\left[\boldsymbol{x}_{t}\right]+C_{0} \boldsymbol{x}_{t} \\
\boldsymbol{s}_{t}(i) & =M_{0} \boldsymbol{z}_{t}+M_{1} \boldsymbol{z}_{t-1}+N \boldsymbol{x}_{t}+\boldsymbol{v}_{t}(i) \\
\boldsymbol{x}_{t} & =P \boldsymbol{x}_{t-1}+\boldsymbol{u}_{t}
\end{aligned}
$$

and that, defining $X_{t} \equiv\left[\begin{array}{c}\boldsymbol{x}_{t} \\ \bar{E}_{t}\left[X_{t}\right]\end{array}\right]$, the following solution is proposed:

$$
\begin{aligned}
\boldsymbol{z}_{t} & =\Gamma X_{t} \\
X_{t} & =F X_{t-1}+G \boldsymbol{u}_{t}
\end{aligned}
$$

The proof proceeds in three parts. First, I describe the agents' optimal linear estimator of $X_{t}$ when observing signals that may be obtained with a lag (a modified Kalman filter described and solved by Nimark, 2015). Second, given the agents' Kalman filter, confirm the conjectured law of motion for the hierarchy of agents' average expectations. My presentation of this differs to past examples such as Nimark (2008) or Melosi (2014) in that, conditional on period- $t$ signals being based only on the underlying state and not on $\boldsymbol{z}_{t}$, an explicit closed-form expression for $F$ is derived, while earlier work derived only implicit solutions that required iteration to obtain a fixed-point solution. Finally, given the law of motion for the agents' hierarchy of expectations, I note that $\Gamma$ may then be obtained through application of the method of undetermined coefficients. A discussion of numerical implementation follows.

\section{A.1 Agents' optimal linear estimator}

With the proposed solution of $z_{t}=\Gamma X_{t}$, the signal equation may be rewritten as

$$
\boldsymbol{s}_{t}(i)=\left(M_{0} \Gamma+N S\right) X_{t}+M_{1} \Gamma X_{t-1}+\boldsymbol{v}_{t}(i)
$$

The model presented here is not yet in standard state space form, however, because of the presence of the lagged state in agents' signal vector. The standard approach to such a scenario is typically to define $\widetilde{X}_{t} \equiv\left[\begin{array}{ll}X_{t}^{\prime} & X_{t-1}^{\prime}\end{array}\right]^{\prime}$ and then re-express everything in terms of $\widetilde{X}_{t}$. Such an approach is mathematically correct, but doubles the size of the state vector, which may be troublesome when simulating the result with finite computing resources.

Nimark (2015) derived a modified Kalman filter that permits the use of just $X_{t}$ as the state vector when agents observe signals that partially derive from $X_{t-1}$. I provide a sketch of Nimark's derivation here. To begin, I define the general notation that $\theta_{t \mid q}^{\text {err }}(i)$ represents the error in agent $i$ 's period- $q$ expectation regarding $\theta_{t}$. In particular, the following will be used:

$$
\begin{aligned}
s_{t \mid t-1}^{\mathrm{err}}(i) & \equiv \boldsymbol{s}_{t}(i)-E_{t-1}(i)\left[\boldsymbol{s}_{t}(i)\right] & & : \text { signal innovation } \\
X_{t \mid t-1}^{\mathrm{err}}(i) & \equiv X_{t}-E_{t-1}(i)\left[X_{t}\right] & & : \text { prior expectation error } \\
X_{t \mid t}^{\mathrm{err}}(i) & \equiv X_{t}-E_{t}(i)\left[X_{t}\right] & & : \text { contemporaneous expectation error }
\end{aligned}
$$


I also define the variance-covariance of agents' expectation errors as:

$$
V_{t \mid t-1} \equiv \operatorname{Var}\left(X_{t \mid t-1}^{\mathrm{err}}(i)\right) \quad V_{t \mid t} \equiv \operatorname{Var}\left(X_{t \mid t}^{\mathrm{err}}(i)\right)
$$

noting that $V_{t \mid t-1}$ and $V_{t \mid t}$ are common to all agents as their problems are identical. The filter updates in the standard way:

$$
E_{t}(i)\left[X_{t}\right]=E_{t-1}(i)\left[X_{t}\right]+K_{t} s_{t \mid t-1}^{\mathrm{err}}(i)
$$

and as with a standard Kalman filter, the optimal Kalman gain is calculated as:

$$
K_{t}=\operatorname{Cov}\left(X_{t}, \boldsymbol{s}_{t \mid t-1}^{\mathrm{err}}(i)\right)\left[\operatorname{Var}\left(\boldsymbol{s}_{t \mid t-1}^{\mathrm{err}}(i)\right)\right]^{-1}
$$

Since idiosyncratic shocks are transitory and mean zero, the signal innovation is given by

$$
\boldsymbol{s}_{t \mid t-1}^{\mathrm{err}}(i)=\underbrace{\left(M_{0} \Gamma F+M_{1} \Gamma+N P S\right)}_{\Lambda} X_{t-1 \mid t-1}^{\mathrm{err}}(i)+\underbrace{\left(M_{0} \Gamma+N S\right) G}_{\Theta} \boldsymbol{u}_{t}+\boldsymbol{v}_{t}(i)
$$

and the variance-covariance of signal innovations will be:

$$
\operatorname{Var}\left(s_{t \mid t-1}^{\mathrm{err}}(i)\right)=\Lambda V_{t-1 \mid t-1} \Lambda^{\prime}+\sigma_{u}^{2} \Theta \Theta^{\prime}+\sigma_{v}^{2} I
$$

The covariance between the full state and the signal innovation is given by:

$$
\begin{aligned}
\operatorname{Cov}\left(X_{t}, \boldsymbol{s}_{t \mid t-1}^{\mathrm{err}}(i)\right) & =\operatorname{Cov}\left(F X_{t-1}+G \boldsymbol{u}_{t}, \Lambda X_{t-1 \mid t-1}^{\mathrm{err}}(i)+\Theta \boldsymbol{u}_{t}+\boldsymbol{v}_{t}(i)\right) \\
& =F \operatorname{Cov}\left(X_{t-1}, X_{t-1 \mid t-1}^{\mathrm{err}}(i)\right) \Lambda^{\prime}+\sigma_{u}^{2} G \Theta^{\prime} \\
& =F \operatorname{Cov}\left(X_{t-1 \mid t-1}^{\mathrm{err}}(i)+E_{t-1}(i)\left[X_{t-1}\right], X_{t-1 \mid t-1}^{\mathrm{err}}(i)\right) \Lambda^{\prime}+\sigma_{u}^{2} G \Theta^{\prime} \\
& =F \operatorname{Cov}\left(X_{t-1 \mid t-1}^{\mathrm{err}}(i), X_{t-1 \mid t-1}^{\mathrm{err}}(i)\right) \Lambda^{\prime}+\sigma_{u}^{2} G \Theta^{\prime} \\
& =F V_{t-1 \mid t-1} \Lambda^{\prime}+\sigma_{u}^{2} G \Theta^{\prime}
\end{aligned}
$$

where the second equality uses the independence of idiosyncratic shocks, the third line uses the definition of the expectation error and the fourth line is because $X_{t-1 \mid t-1}^{\text {err }}(i)$ and $E_{t-1}(i)\left[X_{t-1}\right]$ will be orthogonal to each other by the optimality of the filter.

Expanding the contemporaneous expectation error gives

$$
X_{t \mid t}^{\mathrm{err}}(i)=X_{t \mid t-1}^{\mathrm{err}}(i)-K_{t} \boldsymbol{s}_{t \mid t-1}^{\mathrm{err}}(i)
$$

or, rearranging slightly,

$$
X_{t \mid t}^{\mathrm{err}}(i)+K_{t} \boldsymbol{s}_{t \mid t-1}^{\mathrm{err}}(i)=X_{t \mid t-1}^{\mathrm{err}}(i)
$$

Taking the variance-covariance of both sides, and noting that $s_{t \mid t-1}^{\mathrm{err}}(i)$ and $X_{t \mid t}^{\mathrm{err}}(i)$ must be orthogonal by the optimality of the filter, we have

$$
V_{t \mid t}+K_{t} \operatorname{Var}\left(s_{t \mid t-1}^{\mathrm{err}}(i)\right) K_{t}^{\prime}=V_{t \mid t-1}
$$

Plugging in the expression for $K_{t}$ and rearranging then gives

$$
V_{t \mid t}=V_{t \mid t-1}-\operatorname{Cov}\left(X_{t}, s_{t \mid t-1}^{\mathrm{err}}(i)\right)\left[\operatorname{Var}\left(\boldsymbol{s}_{t \mid t-1}^{\mathrm{err}}(i)\right)\right]^{-1} \operatorname{Cov}\left(X_{t}, \boldsymbol{s}_{t \mid t-1}^{\mathrm{err}}(i)\right)^{\prime}
$$

Expanding the prior expectation error

$$
X_{t \mid t-1}^{\mathrm{err}}(i)=F\left(X_{t-1}-E_{t-1}(i)\left[X_{t-1}\right]\right)+G \boldsymbol{u}_{t}
$$


it immediately follows that the prior variance-covariance must be given by

$$
V_{t \mid t-1}=F V_{t-1 \mid t-1} F^{\prime}+\sigma_{u}^{2} G G^{\prime}
$$

Gathering everything together, the filter updates as:

$$
\begin{aligned}
K_{t} & =\left(F V_{t-1 \mid t-1} \Lambda^{\prime}+\sigma_{u}^{2} G \Theta^{\prime}\right)\left(\Lambda V_{t-1 \mid t-1} \Lambda^{\prime}+\sigma_{u}^{2} \Theta \Theta^{\prime}+\sigma_{v}^{2} I\right)^{-1} \\
V_{t \mid t} & =F V_{t-1 \mid t-1} F^{\prime}+\sigma_{u}^{2} G G^{\prime}-K_{t}\left(F V_{t-1 \mid t-1} \Lambda^{\prime}+\sigma_{u}^{2} G \Theta^{\prime}\right)^{\prime}
\end{aligned}
$$

Provided that the largest eigenvalue of $F$ lies within the unit circle, this will converge to a timeinvariant system:

$$
\begin{aligned}
& K=\left(F V \Lambda^{\prime}+\sigma_{u}^{2} G \Theta^{\prime}\right)\left(\Lambda V \Lambda^{\prime}+\sigma_{u}^{2} \Theta \Theta^{\prime}+\sigma_{v}^{2} I\right)^{-1} \\
& V=F V F^{\prime}+\sigma_{u}^{2} G G^{\prime}-K\left(\Lambda V F^{\prime}+\sigma_{u}^{2} \Theta G^{\prime}\right)
\end{aligned}
$$

\section{A.2 Deriving the law of motion for the full hierarchy}

Define the matrices $S$ and $T$ to select $\boldsymbol{x}_{t}$ and $\bar{E}_{t}\left[X_{t}\right]$ from $X_{t}$ respectively (that is, such that $S X_{t}=\boldsymbol{x}_{t}$ and $\left.T X_{t}=\bar{E}_{t}\left[X_{t}\right]\right)$ :

$$
\begin{aligned}
S & =\left[\begin{array}{lllll}
I_{n} & \mathbf{0}_{n} & \mathbf{0}_{n} & \mathbf{0}_{n} & \cdots
\end{array}\right] \\
T & =\left[\begin{array}{lllll}
\mathbf{0}_{n} & I_{n} & \mathbf{0}_{n} & \mathbf{0}_{n} & \cdots \\
\mathbf{0}_{n} & \mathbf{0}_{n} & I_{n} & \mathbf{0}_{n} & \\
\mathbf{0}_{n} & \mathbf{0}_{n} & \mathbf{0}_{n} & I_{n} & \\
\mathbf{0}_{n} & \mathbf{0}_{n} & \mathbf{0}_{n} & \mathbf{0}_{n} & \ddots \\
\vdots & & & & \ddots
\end{array}\right]
\end{aligned}
$$

Under a Kalman filter, firm $j$ 's expectation regarding $X_{t}$ updates as

$$
E_{t}(j)\left[X_{t}\right]=E_{t-1}(j)\left[X_{t}\right]+K\left\{\boldsymbol{s}_{t}(j)-E_{t-1}(j)\left[\boldsymbol{s}_{t}(j)\right]\right\}
$$

where $K$ is a time-invariant projection matrix (the Kalman gain), common to all firms because their

problems are symmetric. Substituting in the firm's signal equation and the law of motion for the full hierarchy, we obtain

$$
\begin{aligned}
E_{t}(j)\left[X_{t}\right]=F E_{t-1}(j)\left[X_{t-1}\right] & +K \Lambda\left(X_{t-1}-E_{t-1}(j)\left[X_{t-1}\right]\right) \\
& +K\left(\Theta \boldsymbol{u}_{t}+\boldsymbol{v}_{t}(j)\right)
\end{aligned}
$$

where $\Lambda=M_{0} \Gamma F+M_{1} \Gamma+N P S$ and $\Theta=\left(M_{0} \Gamma+N S\right) G$. Taking the average of this expression gives

$$
\begin{aligned}
\bar{E}_{t}\left[X_{t}\right] & =F \bar{E}_{t-1}\left[X_{t-1}\right]+K \Lambda\left(X_{t-1}-\bar{E}_{t-1}\left[X_{t-1}\right]\right)+K M \boldsymbol{u}_{t} \\
& =F T X_{t-1}+K \Lambda(I-T) X_{t-1}+K \Theta \boldsymbol{u}_{t}
\end{aligned}
$$

The law of motion is thus demonstrated, with the matricies $F$ and $G$ satisfying

$$
F=\left[\begin{array}{c}
{\left[\begin{array}{ll}
P & 0_{n \times \infty}
\end{array}\right]} \\
F T+K \Lambda(I-T)
\end{array}\right] \quad G=\left[\begin{array}{c}
I \\
K \Theta
\end{array}\right]
$$


Equation (A.22) only implicitly defines $F$, however, as it is internally recursive. To find an explicit solution (conditional on $K$ ), I next expand the $\Lambda$ and $K$ matrices:

$$
\begin{aligned}
\Lambda & =\left[\begin{array}{llll}
\Lambda_{0} & \Lambda_{1} & \Lambda_{2} & \cdots
\end{array}\right] \\
K & =\left[\begin{array}{c}
K_{0} \\
K_{1} \\
K_{2} \\
\vdots
\end{array}\right]
\end{aligned}
$$

and partition $F$ to be of the form

$$
F=\left[\begin{array}{ccccc}
P & \mathbf{0} & \mathbf{0} & \mathbf{0} & \cdots \\
F_{21} & F_{22} & F_{23} & F_{24} & \cdots \\
F_{31} & F_{32} & F_{33} & F_{34} & \cdots \\
F_{41} & F_{42} & F_{43} & F_{44} & \cdots \\
\vdots & \vdots & \vdots & \vdots & \ddots
\end{array}\right]
$$

Next note that

$$
F T=\left[\begin{array}{ccccc}
\mathbf{0} & P & \mathbf{0} & \mathbf{0} & \cdots \\
\mathbf{0} & F_{21} & F_{22} & F_{23} & \cdots \\
\mathbf{0} & F_{31} & F_{32} & F_{33} & \cdots \\
\mathbf{0} & F_{41} & F_{42} & F_{43} & \cdots \\
\vdots & \vdots & \vdots & \vdots & \ddots
\end{array}\right]
$$

and

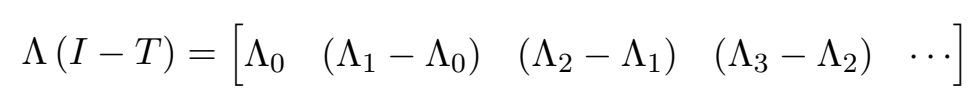

so that the bottom portion of $F$ is given by

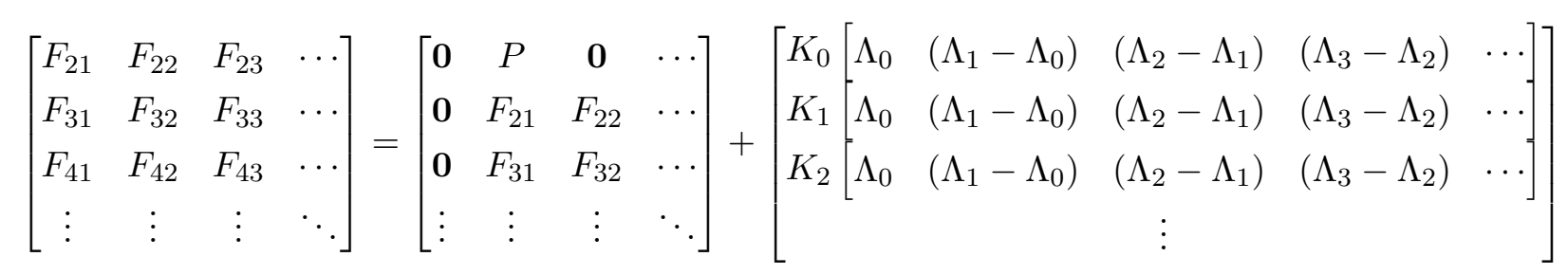

Note that the $F_{2 *}$ row is now fully determined. Given this, I can fill in the $F_{3 *}$ row as

$$
\begin{aligned}
& {\left[\begin{array}{cccc}
F_{21} & F_{22} & F_{23} & \cdots \\
F_{31} & F_{32} & F_{33} & \cdots \\
F_{41} & F_{42} & F_{43} & \cdots \\
\vdots & \vdots & \vdots & \ddots
\end{array}\right]=\left[\begin{array}{cccc}
\mathbf{0} & P & \mathbf{0} & \cdots \\
\mathbf{0} & K_{0} \Lambda_{0} & P+K_{0}\left(\Lambda_{1}-\Lambda_{0}\right) & \cdots \\
\mathbf{0} & F_{31} & F_{32} & \cdots \\
\vdots & \vdots & \vdots & \ddots
\end{array}\right]}
\end{aligned}
$$

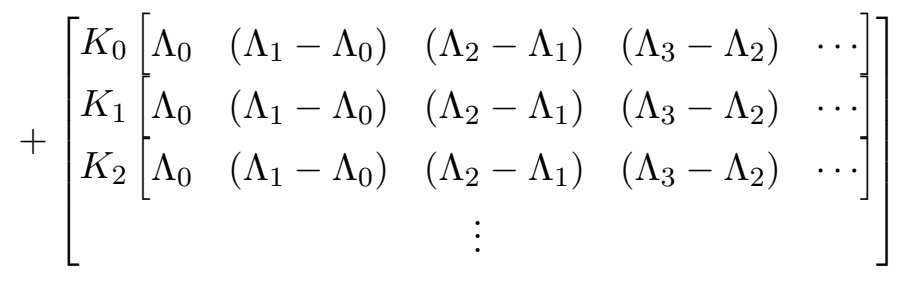


Filling in the $F_{4 *}$ row then gives

$$
\begin{aligned}
& {\left[\begin{array}{cccc}
F_{21} & F_{22} & F_{23} & \cdots \\
F_{31} & F_{32} & F_{33} & \cdots \\
F_{41} & F_{42} & F_{43} & \cdots \\
\vdots & \vdots & \vdots & \ddots
\end{array}\right]=\left[\begin{array}{cccc}
\mathbf{0} & P & \mathbf{0} & \cdots \\
\mathbf{0} & K_{0} \Lambda_{0} & P+K_{0}\left(\Lambda_{1}-\Lambda_{0}\right) & \cdots \\
\mathbf{0} & K_{1} \Lambda_{0} & K_{0} \Lambda_{0}+K_{1}\left(\Lambda_{1}-\Lambda_{0}\right) & \cdots \\
\vdots & \vdots & \vdots & \ddots
\end{array}\right]}
\end{aligned}
$$

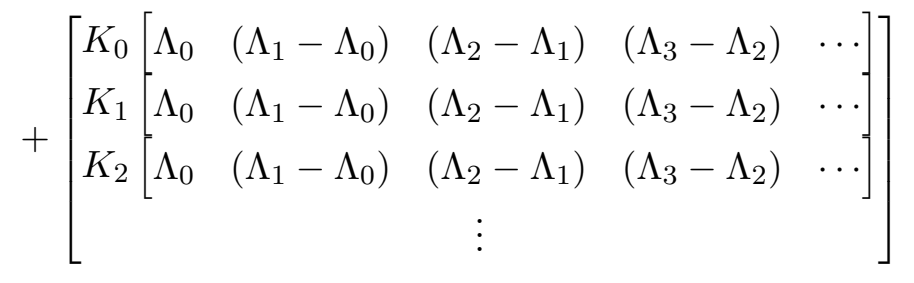

Recall that this is just the lower section of $F$ and that the top "row" is already known. Continuing this substitution and returning to the full $F$ matrix, we obtain

$$
\begin{aligned}
F=\left[\begin{array}{lllll}
P & \mathbf{0} & \mathbf{0} & \mathbf{0} & \cdots \\
\mathbf{0} & P & \mathbf{0} & \mathbf{0} & \cdots \\
\mathbf{0} & \mathbf{0} & P & \mathbf{0} & \cdots \\
\mathbf{0} & \mathbf{0} & \mathbf{0} & P & \\
\vdots & \vdots & \vdots & & \ddots
\end{array}\right]+ & {\left[\begin{array}{ccccc}
\mathbf{0} & \mathbf{0} & \mathbf{0} & \mathbf{0} & \cdots \\
K_{0} \Lambda_{0} & K_{0}\left(\Lambda_{1}-\Lambda_{0}\right) & K_{0}\left(\Lambda_{2}-\Lambda_{1}\right) & K_{0}\left(\Lambda_{3}-\Lambda_{2}\right) & \cdots \\
\mathbf{0} & K_{0} \Lambda_{0} & K_{0}\left(\Lambda_{1}-\Lambda_{0}\right) & K_{0}\left(\Lambda_{2}-\Lambda_{1}\right) & \cdots \\
\mathbf{0} & \mathbf{0} & K_{0} \Lambda_{0} & K_{0}\left(\Lambda_{1}-\Lambda_{0}\right) & \cdots \\
\vdots & \vdots & \vdots & \vdots & \ddots
\end{array}\right] } \\
+ & {\left[\begin{array}{ccccc}
\mathbf{0} & \mathbf{0} & \mathbf{0} & \mathbf{0} & \cdots \\
\mathbf{0} & \mathbf{0} & \mathbf{0} & \mathbf{0} & \cdots \\
K_{1} \Lambda_{0} & K_{1}\left(\Lambda_{1}-\Lambda_{0}\right) & K_{1}\left(\Lambda_{2}-\Lambda_{1}\right) & K_{1}\left(\Lambda_{3}-\Lambda_{2}\right) & \cdots \\
\mathbf{0} & K_{1} \Lambda_{0} & K_{1}\left(\Lambda_{1}-\Lambda_{0}\right) & K_{1}\left(\Lambda_{2}-\Lambda_{1}\right) & \cdots \\
\vdots & \vdots & \vdots & \vdots & \ddots
\end{array}\right] } \\
+ & {\left[\begin{array}{ccccc}
\mathbf{0} & \mathbf{0} & \mathbf{0} & \mathbf{0} & \cdots \\
\mathbf{0} & \mathbf{0} & \mathbf{0} & \mathbf{0} & \cdots \\
\mathbf{0} & \mathbf{0} & \mathbf{0} & \mathbf{0} & \cdots \\
K_{2} \Lambda_{0} & K_{2}\left(\Lambda_{1}-\Lambda_{0}\right) & K_{2}\left(\Lambda_{2}-\Lambda_{1}\right) & K_{2}\left(\Lambda_{3}-\Lambda_{2}\right) & \cdots \\
\vdots & \vdots & \vdots & \vdots & \ddots
\end{array}\right] }
\end{aligned}
$$


Which is

$$
\begin{aligned}
F=I_{\infty} \otimes P+\left[\begin{array}{ccc}
\mathbf{0}_{n} & \mathbf{0}_{n} & \cdots \\
K \Lambda(I-T)
\end{array}\right]+ & {\left[\begin{array}{cccc}
\mathbf{0}_{n} & \mathbf{0}_{n} & \mathbf{0}_{n} & \cdots \\
\mathbf{0}_{n} & \mathbf{0}_{n} & \mathbf{0}_{n} & \cdots \\
\mathbf{0}_{n} & & & \\
\mathbf{0}_{n} & K \Lambda(I-T) \\
\vdots & &
\end{array}\right] } \\
& +\left[\begin{array}{ccccc}
\mathbf{0}_{n} & \mathbf{0}_{n} & \mathbf{0}_{n} & \mathbf{0}_{n} & \cdots \\
\mathbf{0}_{n} & \mathbf{0}_{n} & \mathbf{0}_{n} & \mathbf{0}_{n} & \cdots \\
\mathbf{0}_{n} & \mathbf{0}_{n} & \mathbf{0}_{n} & \mathbf{0}_{n} & \cdots \\
\mathbf{0}_{n} & \mathbf{0}_{n} & & \\
\mathbf{0}_{n} & \mathbf{0}_{n} & K \Lambda(I-T) \\
\vdots & \vdots & &
\end{array}\right] \\
& +\cdots \\
& +T^{\prime} K \Lambda(I-T) \\
& +\left(T^{\prime}\right)^{2} K \Lambda(I-T) T \\
& +\left(T^{\prime}\right)^{3} K \Lambda(I-T) T^{2} \\
& +\cdots
\end{aligned}
$$

which gives

$$
F=I_{\infty} \otimes P+T^{\prime} \sum_{k=0}^{\infty}\left(T^{\prime}\right)^{k} K \Lambda(I-T) T^{k}
$$

or

$$
F=I_{\infty} \otimes P+T^{\prime} \Omega^{*} \text { where } \Omega^{*}=T^{\prime} \Omega^{*} T+K \Lambda(I-T)
$$

\section{A.3 Reduced form coefficients for endogenous variables}

We have

$$
\boldsymbol{z}_{t}=A_{0} \bar{E}_{t}\left[\boldsymbol{z}_{t}\right]+A_{1} \bar{E}_{t}\left[\boldsymbol{z}_{t+1}\right]+B_{0} \bar{E}_{t}\left[\boldsymbol{x}_{t}\right]+C_{0} \boldsymbol{x}_{t}
$$

and propose that

$$
\begin{aligned}
\boldsymbol{z}_{t} & =\Gamma X_{t} \\
X_{t} & =F X_{t-1}+G \boldsymbol{u}_{t}
\end{aligned}
$$

Substituting in the proposed solution gives

$$
\Gamma X_{t}=A_{0} \bar{E}_{t}\left[\Gamma X_{t}\right]+A_{1} \bar{E}_{t}\left[\Gamma\left(F X_{t}+G \boldsymbol{u}_{t+1}\right)\right]+B_{0} \bar{E}_{t}\left[S X_{t}\right]+C_{0} S X_{t}
$$

or

$$
\Gamma X_{t}=A_{0} \Gamma T X_{t}+A_{1} \Gamma F T X_{t}+B_{0} S T X_{t}+C_{0} S X_{t}
$$

from which we can immediately read that $\Gamma$ must satisfy

$$
\Gamma=A_{0} \Gamma T+A_{1} \Gamma F T+B_{0} S T+C_{0} S
$$


If $z_{t}$ is scalar (so that $A_{0}$ and $A_{1}$ are both scalars), this amounts to a requirement that $\left(I-A_{0} T-A_{1} F T\right)$ be invertible:

$$
\Gamma=\left(B_{0} S T+C_{0} S\right)\left(I-A_{0} T-A_{1} F T\right)^{-1}
$$

which in turn requires that $\rho\left\{A_{0} I+A_{1} F\right\}<1$ where $\rho\{\star\}$ is the spectral radius (that is, the largest eigenvalue in absolute value) of the matrix $\star$. If the equilibrium conditions also require terms in $A_{q} \bar{E}_{t}\left[\boldsymbol{z}_{t+q}\right]$ where $q>1$, then equation (A.41) naturally extends to

$$
\Gamma=\left(A_{0} \Gamma+\sum_{q=1}^{\infty} A_{q} \Gamma F^{q}\right) T+B_{0} S T+C_{0} S
$$

\section{A.4 Implementing the solution}

Finding the solution to the model involves (i) defining an upper bound, $k^{*}$, for the number of higherorder expectations to simulate; and (ii) finding the simultaneous fixed point of three systems:

1. The Kalman Filter

2. The Law of Motion for the hierarchy of expectations

3. The endogenous aggregate variables of the economy

This might, in principle, be obtained in a variety of different ways. For example, the simplest implementation is perhaps

repeat

Update the Kalman Filter by one step

Update the Law of Motion by one step

Update the reduced-form coefficients for the aggregate variables by one step until all three converge

However, the size of the full state vector (the hierarchy of expectations regarding the underlying state) can be arbitrarily large in models of heterogeneous information and problems of numerical instability - the accumulation and magnification of round-off errors that must necessarily emerge from floating-point operations on computers - can emerge when iterating a large system over many steps. Large-state Kalman filters are particularly prone to such problems, where issues typically first appear as a failure of symmetry or positive-definiteness in the variance-covariance matrices of the Ricatti equation (Grewel and Andrews, 2008).

To minimise these issues (they can never be removed entirely), it is best to minimise the number of iterations through the Kalman filter. Since the need to obtain a fixed point of the economy is conditional on the Law of Motion for the full state, and the Law of Motion is conditional on the Kalman Filter, a superior algorithm is

repeat

Update the Kalman Filter by one step

Obtain the corresponding fixed point of the Law of Motion

Obtain the corresponding fixed point of the Economy

until the Kalman Filter converges 


\section{B KEY DERIVATIONS WITHIN A NEW KEYNESIAN THEORY OF THE PRICE LEVEL}

\section{B.1 Producing the linearised model}

Equations presented here drop any constant terms for clarity.

The household's Euler equation (combined with market clearing) is given by

$$
y_{t}=E_{t}^{\Omega}\left[y_{t+1}\right]-\sigma\left(i_{t}-E_{t}^{\Omega}\left[p_{t+1}\right]+p_{t}\right)+\sigma\left(x_{t}^{c}-E_{t}^{\Omega}\left[x_{t+1}^{c}\right]\right)
$$

The monetary authority is assumed to have a Taylor-style log-linear representation:

$$
i_{t}=\phi_{y} E_{t}^{\Omega}\left[y_{t+1}\right]+\phi_{\pi}\left(E_{t}^{\Omega}\left[p_{t+1}\right]-p_{t}\right)+x_{t}^{m}
$$

Combining these two equations (and using the household's knowledge of the process for $\boldsymbol{x}_{t}$ ) gives

$$
\begin{aligned}
y_{t} & =\left(1-\sigma \phi_{y}\right) E_{t}\left[y_{t+1}\right]+\sigma\left(1-\phi_{\pi}\right)\left(E_{t}\left[p_{t+1}\right]-p_{t}\right)+\boldsymbol{\mu}_{y}^{\prime} \boldsymbol{x}_{t} \\
\boldsymbol{\mu}_{y}^{\prime} & =\sigma\left(\left[\begin{array}{ll}
1 & -1
\end{array}\right]-\left[\begin{array}{ll}
1 & 0
\end{array}\right] P\right)
\end{aligned}
$$

Define $\delta \equiv 1-\sigma \phi_{y}$. This can then be rewritten as

$$
y_{t}=\sigma\left(1-\phi_{\pi}\right)\left((1-\delta) \sum_{q=0}^{\infty} \delta^{q} E_{t}^{\Omega}\left[p_{t+1+q}\right]-p_{t}\right)+\boldsymbol{\mu}_{y}^{\prime}(I-\delta P)^{-1} \boldsymbol{x}_{t}
$$

A finite level of output therefore requires that the household expects the price level to not grow too quickly. As the model will be shown to fit the requirements of proposition 1, the solution will be of the form $p_{t}=\gamma_{p}^{\prime} X_{t}$ with $X_{t}=F X_{t-1}+G \boldsymbol{u}_{t}$. If I define $\rho\{F\}$ to be the absolute value of the largest eigenvalue of $F$, a finite value of $y_{t}$ will therefore require that $\delta \rho\{F\}<1$.

Firms are subject to incomplete information. The signals observed by firms will be detailed below.

Marginal costs are given by:

$$
m c_{t}(j)=w_{t}+v_{t}^{w}(j)-p_{t}+\eta y_{t}(j)
$$

Household labour supply plus aggregate production (from market clearing):

$$
w_{t}-p_{t}=\left(\frac{1}{\sigma}+\frac{1+\eta}{\psi}\right) y_{t}
$$

Individual product demand:

$$
y_{t}(j)=y_{t}+v_{t}^{y}(j)-\varepsilon\left(p_{t}(j)-p_{t}\right)
$$

Combining the last three gives a fuller expression for marginal costs:

$$
m c_{t}(j)=\underbrace{\underbrace{\left(\eta+\frac{1}{\sigma}+\frac{1+\eta}{\psi}\right) y_{t}}_{\bar{c}_{t}}+\delta_{m c}^{\prime} \boldsymbol{v}_{t}(j)}_{\dddot{m c_{t}}(j)}-\eta \varepsilon\left(p_{t}(j)-p_{t}\right)
$$

where

$$
\delta_{m c}^{\prime}=\left[\begin{array}{lll}
-(1+\eta) & 1 & \eta
\end{array}\right]
$$


The aggregate price level is the average firm's price, which is given by ${ }^{20}$

$$
p_{t}=\bar{E}_{t}\left[p_{t}\right]+\frac{1}{1+\eta \varepsilon} \bar{E}_{t}\left[\overline{m c}_{t}\right]
$$

Combining these two equations then gives (note, too, that $\bar{E}_{t}\left[E_{t}^{\Omega}[\cdot]\right]=\bar{E}_{t}[\cdot]$, since $\mathcal{I}_{t}(i) \subset \Omega_{t} \forall i, t$ ):

$$
p_{t}=\bar{E}_{t}\left[p_{t}\right]+\underbrace{\left(\frac{1}{1+\eta \varepsilon}\right)\left(\eta+\frac{1}{\sigma}+\frac{1+\eta}{\psi}\right)}_{\kappa} \bar{E}_{t}\left[y_{t}\right]
$$

In equilibrium, I can substitute (B.4) into (B.10) and rearrange to obtain

$$
\begin{aligned}
& p_{t}=(1-\xi) \bar{E}_{t}\left[p_{t}\right]+\xi(1-\delta) \sum_{q=0}^{\infty} \delta^{q} \bar{E}_{t}\left[p_{t+q+1}\right]+\boldsymbol{b}_{p}^{\prime} \bar{E}_{t}\left[\boldsymbol{x}_{t}\right] \\
& p_{t}(i)=(1-\xi) E_{t}(i)\left[p_{t}\right]+\xi(1-\delta) \sum_{q=0}^{\infty} \delta^{q} E_{t}(i)\left[p_{t+q+1}\right]+\boldsymbol{b}_{p}^{\prime} E_{t}(i)\left[\boldsymbol{x}_{t}\right]
\end{aligned}
$$

where

$$
\begin{aligned}
\xi & =\left(\frac{1}{1+\eta \varepsilon}\right)\left(\eta+\frac{1}{\sigma}+\frac{1+\eta}{\psi}\right) \sigma\left(1-\phi_{\pi}\right) \\
\boldsymbol{b}_{p}^{\prime} & =\left(\frac{1}{1+\eta \varepsilon}\right)\left(\eta+\frac{1}{\sigma}+\frac{1+\eta}{\psi}\right) \boldsymbol{\mu}_{y}^{\prime}(I-\delta P)^{-1}
\end{aligned}
$$

The equilibrium condition (41a) corresponds to equation (3a) in the definition of an economy with incomplete and heterogeneous information.

\section{B.2 Solving the model}

As the model meets the definition of a linear economy with dispersed information, proposition 1 applies. The matricies of the dispersed-information economy definition (1) are here given by:

\section{For the competitive equilibrium condition (3a)}

$$
\begin{aligned}
& A_{0}=1-\xi \\
& A_{q}=\xi(1-\delta) \delta^{q} \forall q \geq 1 \\
& B_{0}=\boldsymbol{b}_{p}^{\prime} \\
& C_{0}=\mathbf{0}
\end{aligned}
$$

For the law of motion for the underlying state $(3 b)$

$$
P=\rho I_{4}
$$

For firms' signal equations (3e)

$$
\begin{aligned}
M_{0} & =\mathbf{0} \\
M_{1} & =\left[\begin{array}{l}
\boldsymbol{\gamma}_{y}^{\prime} \\
\boldsymbol{\gamma}_{p}^{\prime}
\end{array}\right] \\
N & =\left[\begin{array}{llll}
0 & 0 & 1 & 0 \\
0 & 0 & 0 & 1
\end{array}\right]
\end{aligned}
$$

\footnotetext{
${ }^{20}$ Strictly, this requires that $\int E_{t}(i)\left[\boldsymbol{v}_{t}(i)\right] d i=\mathbf{0}$, but since I have already assumed that idiosyncratic shocks are transitory, this may be obtained without loss of generality through a simple timing adjustment to suppose that $\boldsymbol{v}_{t-1}(i)$ enters firms' signal equation in place of $\boldsymbol{v}_{t}(i)$.
} 


\section{IMPULSE RESPONSES FOR OTHER SHOCKS}

The main text provided charts of impulse response functions following a monetary shock $\left(x_{t}^{m}\right)$ and a common noise shock to firms' signals about the aggregate price level $\left(x_{t}^{n_{p}}\right)$. I here present - without comment - the corresponding charts for a shock to household rates of time preference $\left(x_{t}^{c}\right)$ and a common noise shock to firms' signals about the aggregate level of output. 
The price level and firms' average forecasts

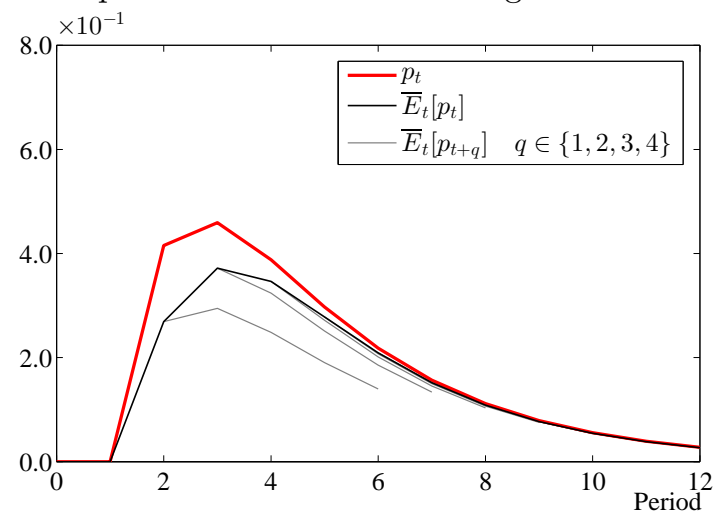

Average forecast errors about the price level

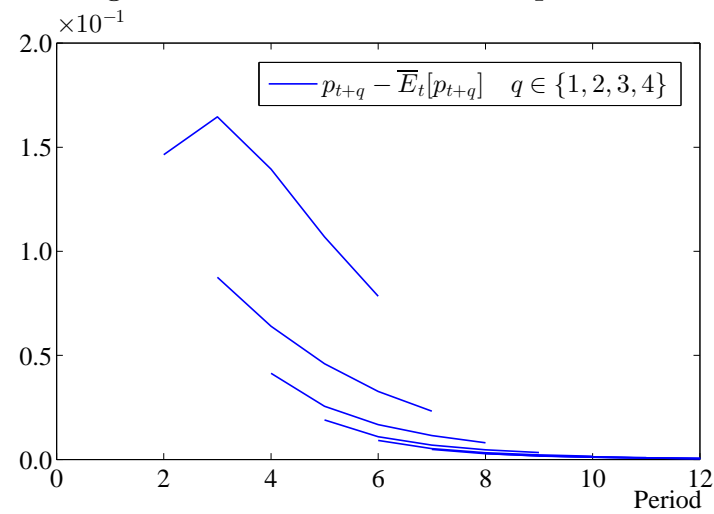

Hierarchy of firms' expectations about $x_{t}^{c}$

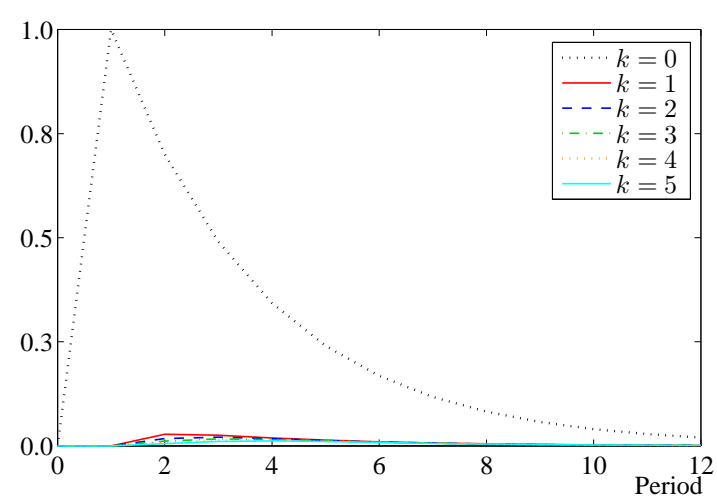

Hierarchy of firms' expectations about $x_{t}^{n_{y}}$

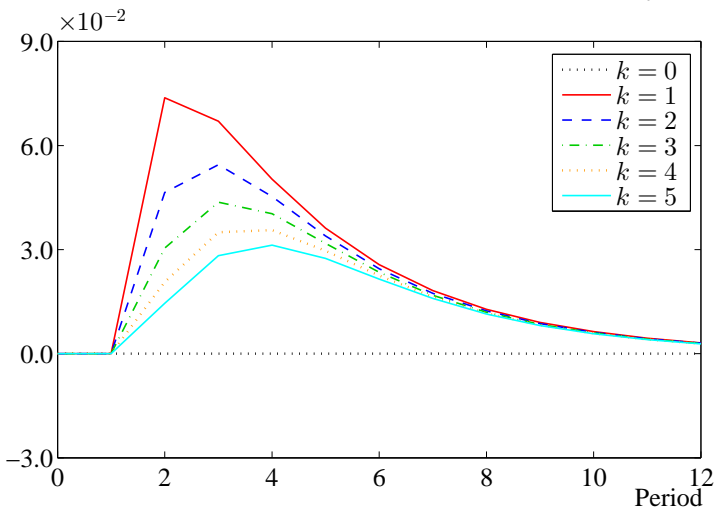

The output level and firms' average forecasts

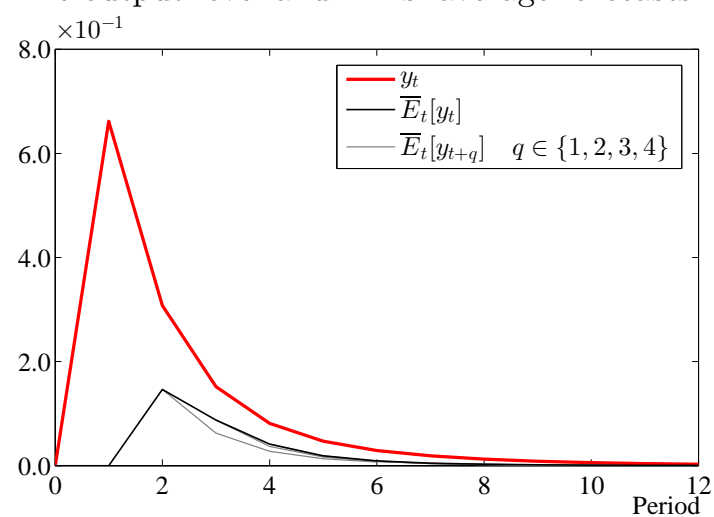

Average forecast errors about the output level

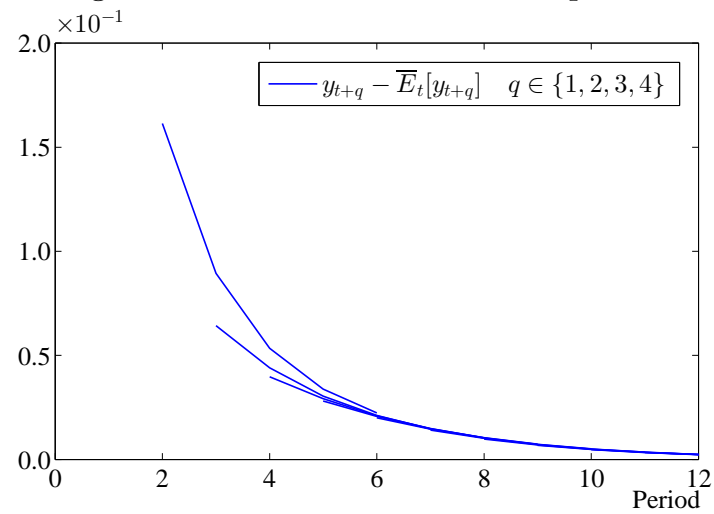

Hierarchy of firms' expectations about $x_{t}^{m}$

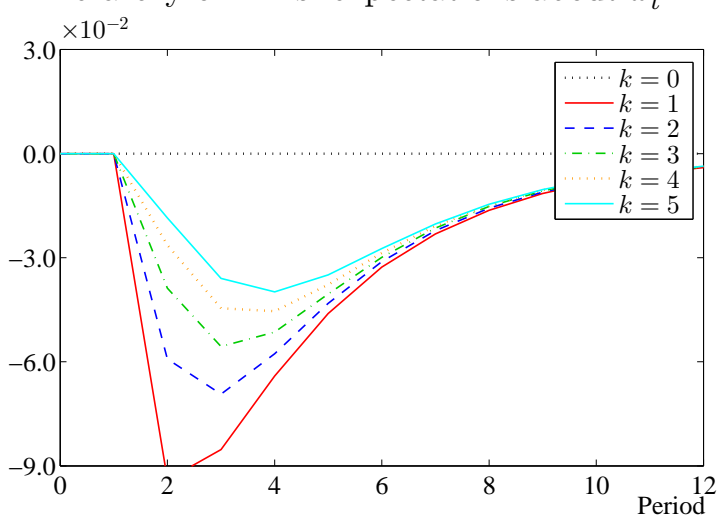

Hierarchy of firms' expectations about $x_{t}^{n_{p}}$

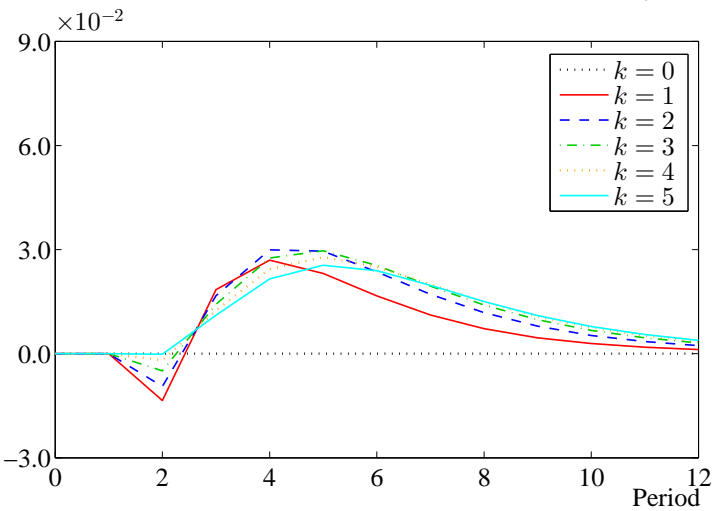

Note: The top two panels show the actual path, the path of firms' average contemporaneous belief and the sequence of firms' average 4-period-ahead forecasts for each of the level of output and the price level. The next two panels show the sequence of firms' average forecast errors for the same. The bottom four panels show the hierarchies of firms' expectations about each of the four aggregate shocks. 
The price level and firms' average forecasts

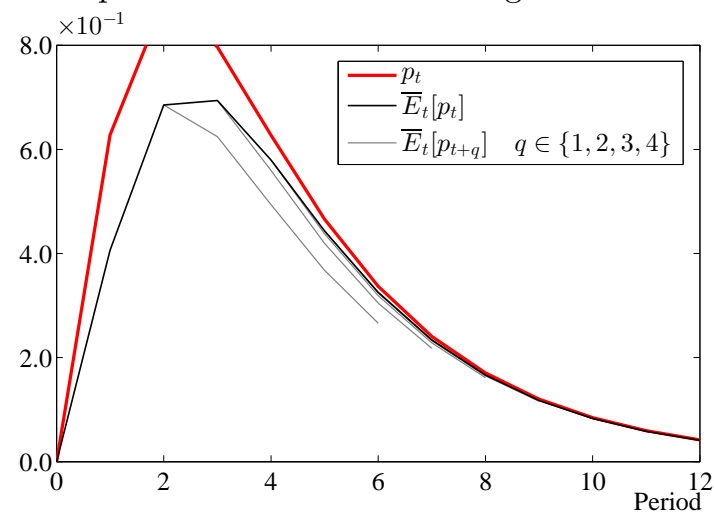

Average forecast errors about the price level

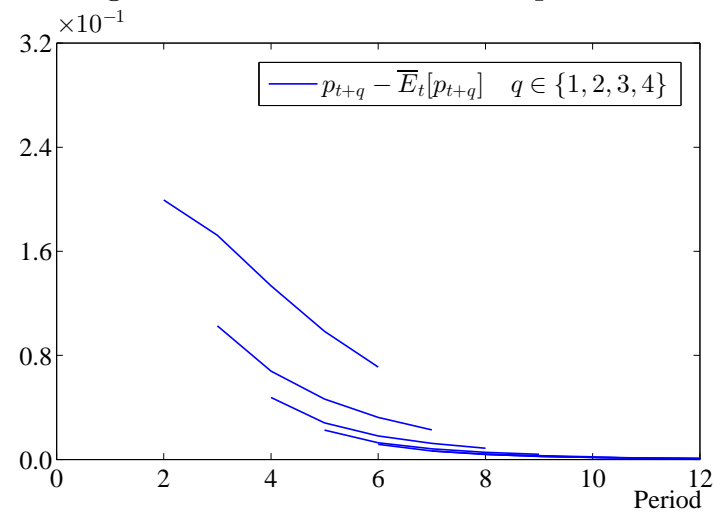

Hierarchy of firms' expectations about $x_{t}^{c}$

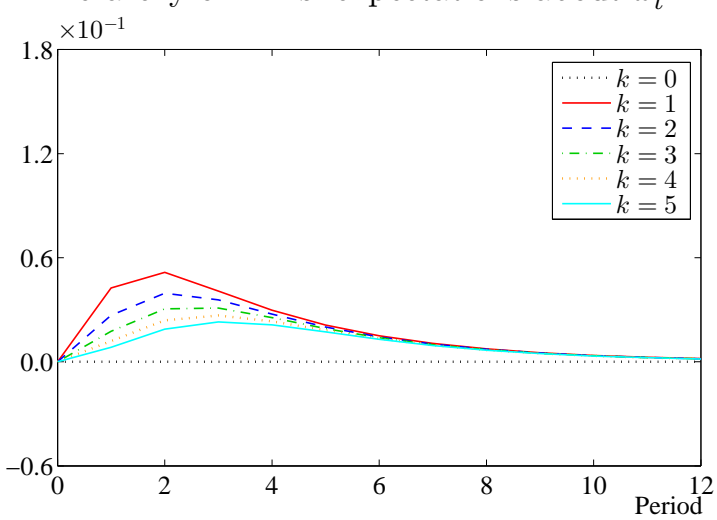

Hierarchy of firms' expectations about $x_{t}^{n_{y}}$

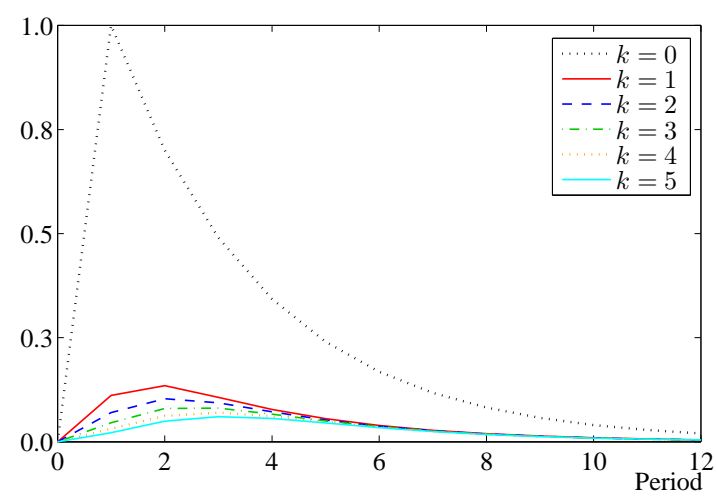

The output level and firms' average forecasts

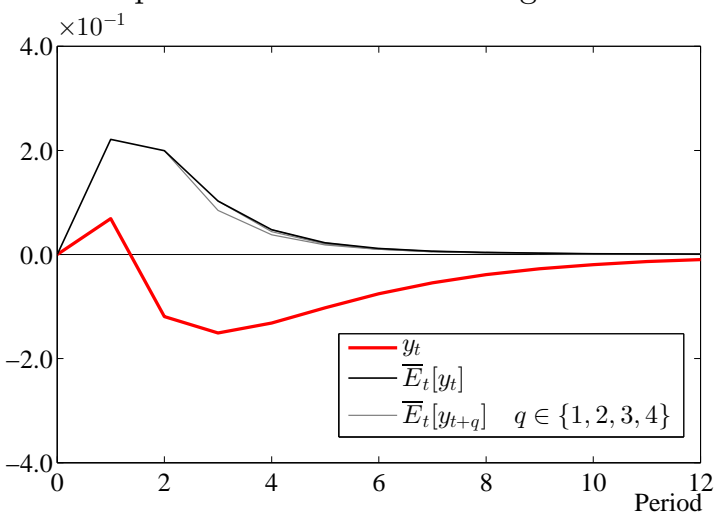

Average forecast errors about the output level

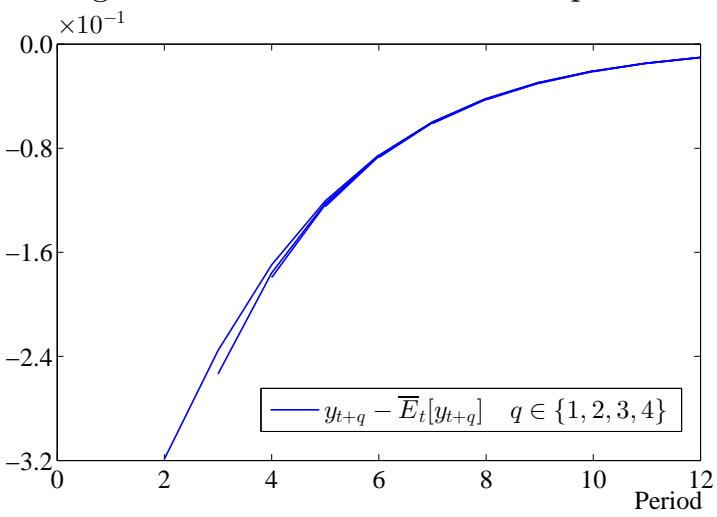

Hierarchy of firms' expectations about $x_{t}^{m}$

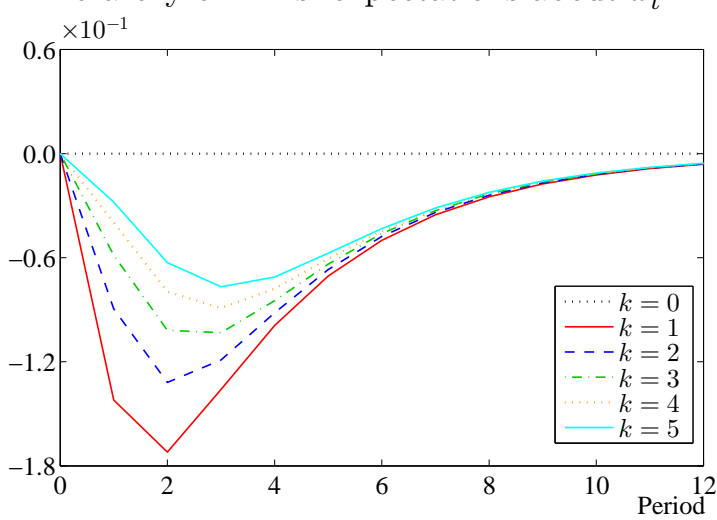

Hierarchy of firms' expectations about $x_{t}^{n_{p}}$

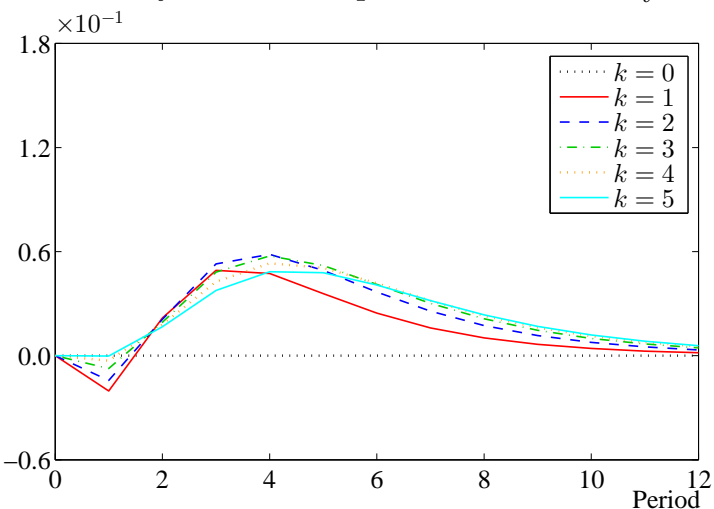

Note: The top two panels show the actual path, the path of firms' average contemporaneous belief and the sequence of firms' average 4-period-ahead forecasts for each of the level of output and the price level. The next two panels show the sequence of firms' average forecast errors for the same. The bottom four panels show the hierarchies of firms' expectations about each of the four aggregate shocks.

Figure 10: Impulse responses following a common noise shock to firms' signals of the output level 


\section{EXTENDING THE MODEL TO INCOMPLETE CENTRAL BANK INFORMATION}

\section{D.1 Producing the linear three-equation version of the model}

The linearisation of the household Euler equation remains unchanged from the baseline model, while that for the monetary authority is altered only to the extent that its expectations are conditioned on an incomplete information set. The expression for the aggregate price level has an extra term, however, to include firms' expectations regarding the current level of aggregate TFP.

$$
\begin{aligned}
y_{t} & =E_{t}^{\Omega}\left[y_{t+1}\right]-\sigma\left(i_{t}-E_{t}^{\Omega}\left[p_{t+1}\right]+p_{t}\right)+\sigma\left(x_{t}^{c}-E_{t}^{\Omega}\left[x_{t+1}^{c}\right]\right) \\
i_{t} & =\phi_{\pi} E_{t}^{C B}\left[p_{t+1}-p_{t}\right]+\phi_{y} E_{t}^{C B}\left[y_{t+1}\right]+x_{t}^{m} \\
p_{t} & =\bar{E}_{t}\left[p_{t}\right]+\kappa \bar{E}_{t}\left[y_{t}\right]-\lambda \bar{E}_{t}\left[a_{t}\right]
\end{aligned}
$$

where $\pi_{t}=p_{t}-p_{t-1}$ and $p_{t}=\int p_{t}(i) d i$. To derive the last equation, first note that marginal costs are given by:

$$
m c_{t}(i)=w_{t}+v_{t}^{w}(i)-p_{t}+\eta y_{t}(i)-(1+\eta)\left(a_{t}+v_{t}^{a}(i)\right)
$$

Household labour supply plus market clearing:

$$
w_{t}-p_{t}=\frac{1}{\sigma} y_{t}+\frac{1}{\psi} h_{t}
$$

Aggregate output (note that the distortion term drops out in a log-linearisation):

$$
y_{t}=a_{t}+\left(\frac{1}{1+\eta}\right) h_{t}
$$

Individual product demand:

$$
y_{t}(j)=y_{t}+v_{t}^{y}(j)-\varepsilon\left(p_{t}(j)-p_{t}\right)
$$

Combining these last four gives a fuller expression for marginal costs:

$$
m c_{t}(i)=\underbrace{\left(\eta+\frac{1}{\sigma}+\frac{1+\eta}{\psi}\right) y_{t}-(1+\eta)\left(1+\frac{1}{\psi}\right) a_{t}}_{\dddot{m c}_{c_{t}}(i)}+\boldsymbol{\delta}_{m c}^{\prime} \boldsymbol{v}_{t}(i)-\eta \varepsilon\left(p_{t}(i)-p_{t}\right)
$$

where

$$
\boldsymbol{\delta}_{m c}^{\prime}=[-(1+\eta) \quad 1 \quad \eta]
$$

Substituting this into firm $i$ 's pricing decision, gathering terms and dropping the terms in $\boldsymbol{v}_{t}(i)$ (on the basis that they are unknowable when the firm sets its period- $t$ price) gives:

$$
p_{t}(i)=E_{t}(i)\left[p_{t}\right]+\left(\frac{1}{1+\eta \varepsilon}\right) E_{t}(i)\left[\overline{m c}_{t}\right]
$$

or

$$
\begin{aligned}
p_{t} & =\bar{E}_{t}\left[p_{t}\right]+\kappa \bar{E}_{t}\left[y_{t}\right]-\lambda \bar{E}_{t}\left[a_{t}\right] \\
\kappa & =\left(\frac{1}{1+\eta \varepsilon}\right)\left(\frac{1}{\sigma}+\eta+\frac{1+\eta}{\psi}\right) \\
\lambda & =\left(\frac{1}{1+\eta \varepsilon}\right)\left(1+\eta+\frac{1+\eta}{\psi}\right)
\end{aligned}
$$




\section{D.2 Solving the model}

I have the following linear model

$$
\begin{aligned}
y_{t} & =E_{t}^{\Omega}\left[y_{t+1}\right]-\sigma\left(i_{t}-E_{t}^{\Omega}\left[p_{t+1}\right]+p_{t}\right)+\sigma\left(x_{t}^{c}-E_{t}^{\Omega}\left[x_{t+1}^{c}\right]\right) \\
i_{t} & =\phi_{\pi} E_{t}^{C B}\left[p_{t+1}-p_{t}\right]+\phi_{y} E_{t}^{C B}\left[y_{t+1}\right]+x_{t}^{m} \\
p_{t} & =\bar{E}_{t}\left[p_{t}\right]+\kappa \bar{E}_{t}\left[y_{t}\right]-\lambda \bar{E}_{t}\left[a_{t}\right]
\end{aligned}
$$

and the proposed solution of the model is

$$
\begin{aligned}
X_{t} & \equiv\left[\begin{array}{c}
\boldsymbol{x}_{t} \\
E_{t}\left[X_{t}\right] \\
E_{t}^{C B}\left[X_{t}\right]
\end{array}\right] \\
X_{t} & =F X_{t-1}+G \boldsymbol{u}_{t}+H \boldsymbol{v}_{t}^{C B} \\
p_{t} & =\gamma_{p}^{\prime} X_{t} \\
y_{t} & =\gamma_{y}^{\prime} X_{t} \\
i_{t} & =\gamma_{i}^{\prime} X_{t}
\end{aligned}
$$

\section{Obtaining the reduced-form coefficients}

To obtain the $\boldsymbol{\gamma}_{*}$ coefficients, substitute the proposed solution into (D.9) to obtain

$$
\begin{aligned}
y_{t} & =\gamma_{y}^{\prime} F X_{t}-\sigma\left(\gamma_{i}^{\prime} X_{t}-\gamma_{p}^{\prime}(F-I) X_{t}\right)+\sigma\left[\begin{array}{llllll}
0 & 0 & 1 & 0 & 0 & 0
\end{array}\right](I-P) S X_{t} \\
i_{t} & =\phi_{\pi} \gamma_{p}^{\prime}(F-I) T^{C B} X_{t}+\phi_{y} \gamma_{y}^{\prime} F T^{C B} X_{t}+\left[\begin{array}{llllll}
0 & 0 & 0 & 1 & 0 & 0
\end{array}\right] S X_{t} \\
p_{t} & =\gamma_{p}^{\prime} T^{P} X_{t}+\kappa \gamma_{y}^{\prime} T^{P} X_{t}-\lambda\left[\begin{array}{llllll}
1 & 0 & 0 & 0 & 0 & 0
\end{array}\right] S T^{P} X_{t}
\end{aligned}
$$

or

$$
\begin{aligned}
\gamma_{y}^{\prime} & =\gamma_{y}^{\prime} F-\sigma\left(\gamma_{i}^{\prime}-\gamma_{p}^{\prime}(F-I)\right)+\sigma\left[\begin{array}{llllll}
0 & 0 & 1 & 0 & 0 & 0
\end{array}\right](I-P) S \\
\gamma_{i}^{\prime} & =\phi_{\pi} \gamma_{p}^{\prime}(F-I) T^{C B}+\phi_{y} \gamma_{y}^{\prime} F T^{C B}+\left[\begin{array}{llllll}
0 & 0 & 0 & 1 & 0 & 0
\end{array}\right] S \\
\gamma_{p}^{\prime} & =\gamma_{p}^{\prime} T^{P}+\kappa \gamma_{y}^{\prime} T^{P}-\lambda\left[\begin{array}{llllll}
1 & 0 & 0 & 0 & 0 & 0
\end{array}\right] S T^{P}
\end{aligned}
$$

Which represent three equations in three unknowns. Substituting the interest rate into the Euler equation gives

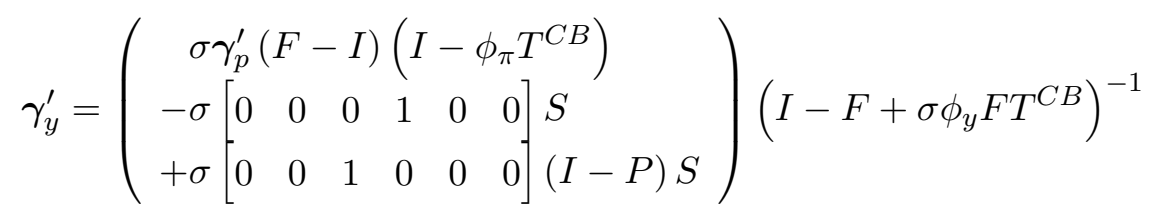

Defining $J \equiv F\left(I-\sigma \phi_{y} T^{C B}\right)$, I can substitute this into the price equation to give

$$
\begin{aligned}
\gamma_{p}^{\prime}\left(I-T^{P}\right) & =\kappa\left(\begin{array}{c}
\sigma \gamma_{p}^{\prime}(F-I)\left(I-\phi_{\pi} T^{C B}\right) \\
-\sigma\left[\begin{array}{llllll}
0 & 0 & 0 & 1 & 0 & 0
\end{array}\right] S \\
+\sigma\left[\begin{array}{llllll}
0 & 0 & 1 & 0 & 0 & 0
\end{array}\right](I-P) S
\end{array}\right)(I-J)^{-1} T^{P} \\
& -\lambda\left[\begin{array}{llllll}
1 & 0 & 0 & 0 & 0 & 0
\end{array}\right] S T^{P}
\end{aligned}
$$


or

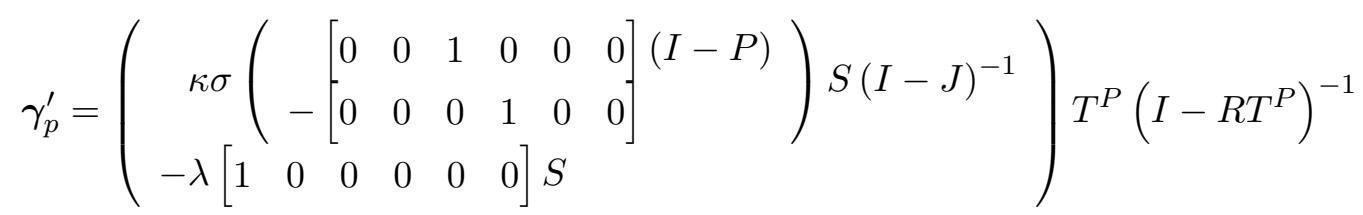

where

$$
R=I-\kappa \sigma(I-F)\left(I-\phi_{\pi} T^{C B}\right)(I-J)^{-1}
$$

Expressions for $\gamma_{y}$ and $\gamma_{i}$ then immediately follow by substituting this back into (D.13) and (D.12b).

\section{Ensuring stability}

Inspecting equation (D.15), it is clear that the solution will be well defined (that is, will lead to a finite expression for the price level) when

$\rho\{F\}<1$ to ensure the stability of $X_{t}$

$\rho\{J\}<1$ to ensure the invertibility of $I-J$

$\rho\{R\}<1$ to ensure the invertibility of $I-R T^{P}$

Analogously to the baseline model, condition (D.16b) relates to stability in expectations of future prices, while condition (D.16c) relates to stability in the hierarchy of expectations.

\section{Firms' signal extraction problem}

Firms' optimal linear estimator remains unchanged from that in the baseline model, with two exceptions:

- The underlying state, $\boldsymbol{x}_{t}$, has been expanded to include the stochastic TFP.

- Firms' signal vectors, $\boldsymbol{s}_{t}(i)$, have been expanded to include firm-specific signals of TFP.

The derivation of the baseline estimator in appendix A.1 abstracts from the exact content of $\boldsymbol{x}_{t}$ and $s_{t}(i)$, and so remains unchanged for firms in this extension, except to note that

$$
\begin{aligned}
M_{0} & =\mathbf{0} \\
M_{1} & =\left[\begin{array}{llllll}
\multicolumn{5}{c}{\gamma_{y}^{\prime}} & \\
{\left[\begin{array}{cccccc}
1 & \gamma_{p}^{\prime} \\
1 & 0 & 0 & 0 & 0 & 0
\end{array}\right] S}
\end{array}\right] \\
N & =\left[\begin{array}{llllll}
0 & 0 & 0 & 0 & 1 & 0 \\
0 & 0 & 0 & 0 & 0 & 1 \\
0 & 0 & 0 & 0 & 0 & 0
\end{array}\right] \\
O & =\left[\begin{array}{lll}
1 & 0 & 0 \\
0 & 1 & 0 \\
0 & 0 & 1
\end{array}\right]
\end{aligned}
$$

I also denote the consequent time-invariant Kalman gain and error variance matrices as $K^{P}$ and $V^{P}$ to emphasise that they are those for price-setting firms. 


\section{The monetary authority's signal extraction problem}

The monetary authority's signal extraction problem is entirely parallel to that of each firm. Given the process for evolution of an unknown state:

$$
X_{t}=F X_{t-1}+G \boldsymbol{u}_{t}
$$

and a signal equation of the general form

$$
\boldsymbol{s}_{t}^{C B}=D X_{t-1}+N^{C B} \boldsymbol{x}_{t}+Z \boldsymbol{v}_{t}^{C B}
$$

the monetary authority's optimal Kalman filter will be the same as that derived in A.1 for individual firms, except to set $M_{0}=\mathbf{0}$ (as for firms) and to replace $M_{1} \Gamma$ with $D, N$ with $N^{C B}$ and $O$ with $Z$.

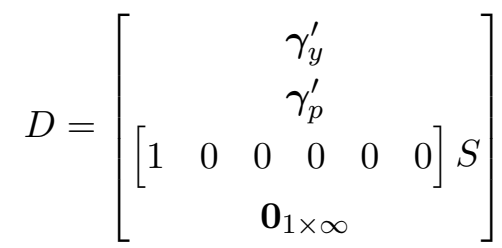

$$
\begin{aligned}
& N^{C B}=\left[\begin{array}{lllll}
0 & 0 & 0 & 1 & 0 \\
0 & 0 & 0 & 0 & 1 \\
0 & 0 & 0 & 0 & 0 \\
0 & 0 & 1 & 0 & 0
\end{array}\right] \\
& Z=\left[\begin{array}{lll}
1 & 0 & 0 \\
0 & 1 & 0 \\
0 & 0 & 1 \\
0 & 0 & 0
\end{array}\right]
\end{aligned}
$$

I denote the consequent time-invariant Kalman gain and error variance matrices as $K^{C B}$ and $V^{C B}$ to distinguish them from the $K^{P}$ and $V^{P}$ for individual firms.

\section{The law of motion for the full hierarchy of expectations}

Recall that the full hierarchy of expectations is given by

$$
X_{t} \equiv\left[\begin{array}{c}
\boldsymbol{x}_{t} \\
\bar{E}_{t}\left[X_{t}\right] \\
E_{t}^{C B}\left[\begin{array}{c}
\boldsymbol{x}_{t} \\
\bar{E}_{t}\left[X_{t}\right]
\end{array}\right]
\end{array}\right]
$$

with $S, T^{P}$ and $T^{C B^{*}}$ defined to extract each component respectively (that is, $S X_{t}=\boldsymbol{x}$, while $T^{P} X_{t}=\bar{E}_{t}\left[X_{t}\right]$ and $\left.T^{C B^{*}} X_{t}=E_{t}^{C B}\left[\begin{array}{c}\boldsymbol{x}_{t} \\ \bar{E}_{t}\left[X_{t}\right]\end{array}\right]\right)$. Note, too, that since the central bank is subject to the law of iterated expectations (LIE), then $E_{t}^{C B}\left[X_{t}\right]=\left[\begin{array}{l}T^{C B^{*}} \\ T^{C B^{*}}\end{array}\right] X_{t}$. As such, I further define $T^{T B} \equiv\left[\begin{array}{l}T^{C B^{*}} \\ T^{C B^{*}}\end{array}\right]$ to select this.

\section{Firms}


Since firms' signal extraction problem remains unchanged, then as shown above in appendix A.2, the evolution of firms' individual expectations will continue to be expressed as

$$
\begin{aligned}
E_{t}(i)\left[X_{t}\right]=F E_{t-1}(i)\left[X_{t-1}\right] & +K^{P} \Lambda^{P}\left(X_{t-1}-E_{t-1}(i)\left[X_{t-1}\right]\right) \\
& +K^{P}\left(\Theta^{P} \boldsymbol{u}_{t}+O \boldsymbol{v}_{t}(i)\right)
\end{aligned}
$$

where $\Lambda^{P}=M_{0} \Gamma F+M_{1} \Gamma+N P S$ and $\Theta^{P}=M_{0} \Gamma G+N Q$. Firms' average expectations will therefore continue to be

$$
\bar{E}_{t}\left[X_{t}\right]=F T^{P} X_{t-1}+K^{P} \Lambda^{P}\left(I-T^{P}\right) X_{t-1}+K^{P} \Theta^{P} \boldsymbol{u}_{t}
$$

\section{The monetary authority}

The surprise in the central bank's signal is given by:

$$
\boldsymbol{s}_{t}^{C B}-E_{t-1}^{C B}\left[\boldsymbol{s}_{t}^{C B}\right]=\Lambda^{C B} X_{t-1 \mid t-1}^{C B: \operatorname{err}}+\Theta^{C B} \boldsymbol{u}_{t}+Z \boldsymbol{v}_{t}^{C B}
$$

where $\Lambda^{C B}=D+N^{C B} P S$ and $\Theta^{C B}=N^{C B} Q$.

$$
\begin{aligned}
E_{t}^{C B}\left[X_{t}\right] & =E_{t-1}^{C B}\left[X_{t}\right]+K^{C B}\left\{\Lambda^{C B}\left(X_{t-1}-E_{t-1}^{C B}\left[X_{t-1}\right]\right)+\Theta^{C B} \boldsymbol{u}_{t}+Z \boldsymbol{v}_{t}^{C B}\right\} \\
& =\left(F T^{C B}+K^{C B} \Lambda^{C B}\left(I-T^{C B}\right)\right) X_{t-1}+K^{C B} \Theta^{C B} \boldsymbol{u}_{t}+K^{C B} Z \boldsymbol{v}_{t}^{C B}
\end{aligned}
$$

\section{The law of motion}

The law of motion is therefore demonstrated, with the matricies $F, G$ and $H$ satisfying

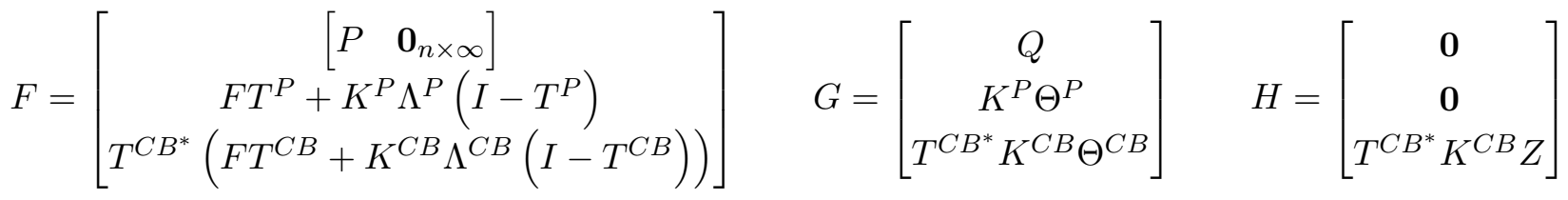

